

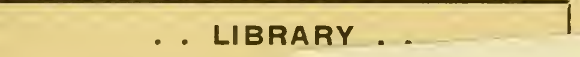

\section{Conne}

\section{Agriculture}

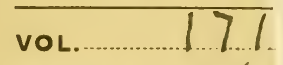

CLASS NO..... 6
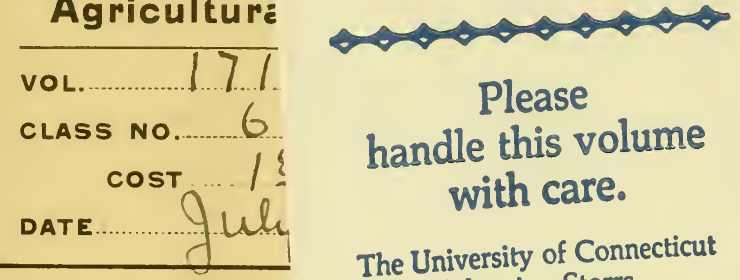

\section{Please} handle this volume with care.

The University of Connecticut Libraries, Storrs

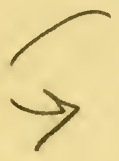

16.01

63

7168

BOOK 616.01 .863 c. 1

BOLDUAN \# APLIED BACTERIOLOGY FOR
NURSES

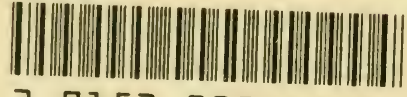

39153000368359 






\title{
APPLIED BACTERIOLOGY FOR NURSES
}

\author{
BY \\ CHARLES F. BOLDUAN, M. D. \\ LECTURER, PREVENTIVE IEDICINE AND HYGIENE, COLLEGE OF \\ PHYSICIANS AND SURGEONS, COLUMBIA UNIVERSITY; CHIEF, SECTIOY \\ of pUblic healti education, U. S. PUblic health SERVICE
}

AND

MARIE GRUND, M. D.

BACTERIOLOGIST, RESEARCH LABORATORY, DEPARTMENT OF HEALTH, CITY OF NEW YORK

THIRD EDITION, THOROUGHLY REVISED

PHILADELPHIA AND LONDON

W. B. SAUNDERS COMPANY 1920 


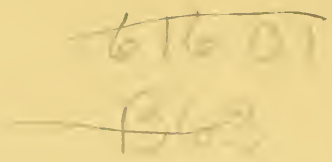

Copyright, I913, by W. B. Saunders Company. Reprinted June, 1914. Revised, reprinted, and recopyrighted

October, I9I6. Reprinted January, I918, and July, I918. Revised, reprinted, and recopyrighted August, 19r?

Copyright, 1919, by W. B. Saunders Company

Reprinted May, 1920

17168

PRINTED IN AMERICA

PRESS OF

W. B. SAUNDERS COMPANY

PHILADELPHIA 


\section{PREFACE TO THE THIRD EDITION}

Wiтн the aim of keeping this book abreast of presentday bacteriologic science, the entire work has been carefully revised and considerable new matter has been added. Thus, the important rôle played in the transmission of disease by vermin has led to the addition of an article on Pediculosis and Disinfestation; the wide-spread employment of the antiseptic treatment of infected wounds, to a note on Dakin's solution and the chloramines; the frequent occurrence of gas gangrene in war wounds, to the inclusion of Bacillus perfringens; the recent pandemic of influenza, to a note on the virus of that disease.

In connection with the chapter on Malaria, it has been deemed advisable to add a description of the life-history of mosquitoes. The chapter on the Pneumococcus now takes up the different types of organisms according to the classification of Cole and Dochez. Under vaccine therapy the use of lipovaccines has been discussed. Trench fever has been added to the list of diseases spread by lice.

In all of these additions, as in the original work, the practical application of the newer knowledge to nursing has constantly been kept in mind.

Washington, D. C.

C. F. B. 



\section{PREFACE}

BACTERIOLOGY dominates so large a part of the art of nursing that a correct understanding of the more important facts and principles of that science is an indispensable part of every nurse's mental equipment. In the following pages emphasis has been laid on the immediate application of the subject to nursing, and only enough general bacteriology has been introduced to give the student a clear conception of the principles underlying her work. A perusal of the various chapters will show that a study of all the ordinary modes of transmission of infection has been presented. Sufficient pathology has been introduced to give the student a fair idea of the nature of the infection described. Many pathogenic bacteria have been omitted, because their discussion would have added little or nothing to the presentation of the principles already laid down. While there is no gainsaying the value of individual laboratory exercises in the study of bacteriology, the writers feel that, so far as instruction to nurses is concerned, simple practical demonstrations by the teacher may very well be substituted for individual laboratory work. Suggestions for such demonstrations have been added at the end of the chapters.

New York City. 



\section{CONTENTS}

\section{GENERAL BACTERIOLOGY}

CHAPTER I

HistoRic . . . . . . . . . . . . . . . . . . . . . . . . . 11

CHAPTER II

Character of Bacteria ................... 14

CHAPTER III

Methods of Studying Bacteria ................ 22

CHAPTER IV

Preparation of Stained Simears............... 25

CHAPTER V

Coltivation of Bacteria ................... 27

CHAPTER VI

Disinfectants and Antiseptics................. 36

Mercuric Chlorid . . . . . . . . . . . . . . . . . . . . 37

Carbolic Acid .......................... 38

Crude Carbolic Acid . . . . . . . . . . . . . . . . . . . . . 38

Quicklime............................. 39

Chlorid of Lime. . . . . . . . . . . . . . . . . . . . . 39

Sulphur Dioxid.......................... 40

Formaldehyd ......................... 40

Iodin. .............................. 40

Peroxid of Hydrogen. . . . . . . . . . . . . . . 40

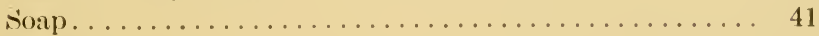

Dakin's Solution ...................... 41

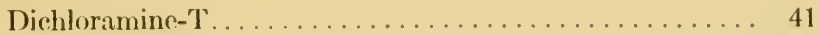

IIalazone............................ 42 


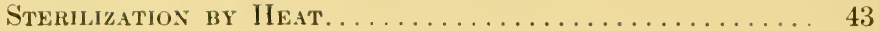

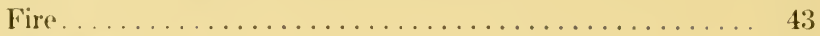

Dry Heat. . . . . . . . . . . . . . . . . . . 48

Moist Heat. ...................... 44

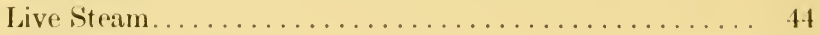

Steam Under Pressurc...................... 46

\section{CHAP'TER VIII}

Relation of Bacterla to Diseasli.............. 45

Inflammation. . . . . . . . .

\section{CHAPTER IX}

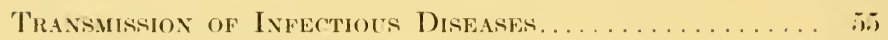

'Terminal Fumigation.....................

Inserts as Carriers of Infeetious Diseasex............ . . . .

\section{CHAPTER N}

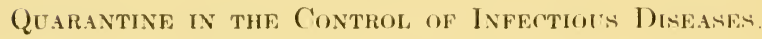

\section{CHAPTER XI}

Iммuniту . . . . . . . . . . . . . . . . . . . . . .

Antitoxins.......................... $6 \pi$

Bacteriolysins........................ 6 .

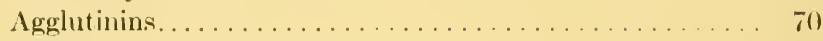

Opsonins........................... 73

Precipitins and Other Antibodies................. 74

Anaphylaxis.........................

Serum and Vaccine Therapy................ 76

Bacterial Vaccines...................... 77

Lipo-vaccines....................... 78

\section{SPECIAL BACTERIOLOGY}

CHAPTER XII

Typhoid Fever............................. 81

CHAPTER XIII

Dysentery and Cholera.................... 86 


\section{CHAPTER XVI}

Tetanus............................. 101

CHAPTER XVII

The Pneumococcus.

\section{CHAPTER XVIII}

Streptococces Infections................... 108

CILAPTER XIX

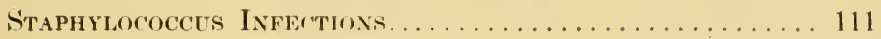

('HAPTER XX

The Meningococcus.

CHAPTER XXI

The Gonocoreus......................... 117

CHAPTER XXII

Syphils.............................. 119

\section{C'HAPTER XXIII}

Exanthemata.......................... 122

Scarlet Fever.......................... 122

Measles and German Measles.................. 123

Small-pox and Cow-pox.................... 124

CHAPTER XXIV

Filterable Viruses...................... 126

\section{CHAPTER XXV}

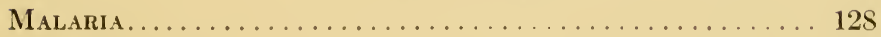

Mosquitoes............................ 130

Yellow Fever.......................... 132

Trypanosomiasis......................... 133 
Fermented Milks......................... 140

\section{CHAPTER XXVIII}

Bacterial food Poisons...................... 143

\section{CHAPTER XXIX}

Bacteriology of WATER.................... 146

Pollution to Be Guarded Against. . . . . . . . . . . . . . 146

Natural Purification of Water................. 147

Water-borne Uiseases. . . . . . . . . . . . . . . . . . 147

Filtration of Water Supplies.................... 148

Domestic Filters.......................... $14 \mathrm{~s}$

Purification by Chlorination. . . . . . . . . . . . . 149

Purification by Distillation. . . . . . . . . . . . . . . 150

Purification by Boiling.................... . 150

Bacteriologic Examination of Water .............. 150

\section{CHAPTER XXX}

Aninal Parasites and Vermin.................. 152

Tapeworms.......................... 152

Trichina. . . . . . . . . . . . . . . . . . . 152

Hookworm . . . . . . . . . . . . . . . . . . . . . . . . 153

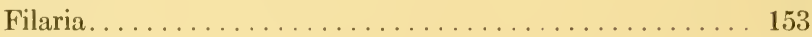

Pediculosis............................. 153

\section{CHAPTER XXXI}

Practice of Disinfection . . . . . . . . . . . . . . . . . 154

Boiling Water........................... 154

Steam................................ 155

Steam Under Pressure. . . . . . . . . . . . . . . . . . . . . . 157

Dry Heat. . . . . . . . . . . . . . . . . . . 160

Chemicals............................... 161

Preparation of Patient for Operation . . . . . . . . . . . . 162

To Prevent Spread of Contagious Diseases. . . . . . . . . 164

Disinfestation . . . . . . . . . . . . . . . . . . . 169 
CHAPTER XXXII

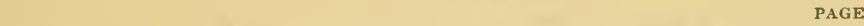
Collection of Material for Bacteriologic Examination. 170 Sputum.......................... 170 Throat Smears......................... 171

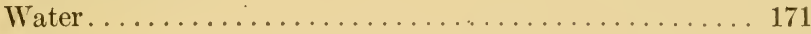

Milk................................ 172

Autopsies............................. 172

Urine.................................. 172

Feces............................ 172

Spinal Fluid............................ 173

\section{CHAPTER XXXIII}

Other Important Pathogenic Micro-organisms. . . . . . . 174

Colon Bacillus....................... 174

Pneumobacillus of Friedländer. . . . . . . . . . . . . . 175

Paratyphoid Bacilli...................... 175

Influenza Bacillus (Pfeiffer's Bacillus) ............ 175

Whooping-cough Bacillus................. 176

Micrococcus of Malta Fever.................... 176

Bacillus Pyocyaneus..................... 177

Glanders Bacillus. . . . . . . . . . . . . . . . . . . 178

Bubonic Plague Bacillus. . . . . . . . . . . . . . . . . . 179

Anthrax Bacillus....................... 180

Malignant Edema Bacillus.................... 181

Bacillus Perfringens...................... 1s1

Leprosy Bacillus . . . . . . . . . . . . . . . . . . . . . . 182

Trench Fever........................... 182

Microsporon Furfur................... 185

Oïdium Albicans...................... 185

Achorion Schönleinii......................... 185

Trichophyton Tonsurans. . . . . . . . . . . . . . . . 185

Poliomyelitis...................................

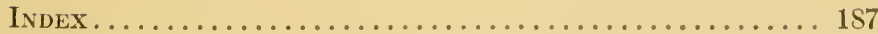





\section{APPLIED BACTERIOLOGY FOR NURSES}

\section{GENERAL BACTERIOLOGY}

\section{CHAPTER I}

\section{HISTORIC}

THE fact that many diseases are caused by tiny living organism called bacteria is so universally accepted nowadays that it is hard to realize our real knowledge of bacteria is less than fifty years old. The discovery of the relation between bacteria and disease has revolutionized medical practice, and has resulted in the saving of countless lives which formerly were lost.

One of the earliest to form a fairly accurate conception of the nature of infectious diseases was Fracastor, an Italian scientist living in the sixteenth century. In 1546 he published an essay in which he likened disease to putrefaction, and spoke of certain kinds of diseases as being spread by "seeds."

A little more than one hundred years later Leeuwenhoek, of Delft, Holland, succeeded in constructing a strong magnifying glass by which he observed tiny, living organisms in tartar scraped from the teeth, in cheese, rain-water, decayed meat, feces, etc. And, 
although it was suggested that these minute organisms were the cause of a large number of diseases, no one succeeded in proving this relationship. Finally, in 1863, Davaine, a famous French physician, demonstrated that anthrax, a disease common in sheep and cattle, was caused by a bacterium. If we seek for the reason why some two hundred years elapsed between the discovery of bacteria by Leeuwenhoek and the recognition of their rôle in the production of disease, we find that this was due to the mechanical imperfections of the microscope and to the difficulties surrounding the isolation and cultivation of these minute organisms. Thanks to the genius of Pasteur and of Koch these difficulties were successfully overcome, and the foundation of modern bacteriology securely laid. Prior to this, however, Lister, who had carefully followed Pasteur's work on fermentation, became convinced that infections following surgical operations were due to the introduction of bacteria. He accordingly devised what is known as "antiseptic surgery," whereby it was sought to kill all the germs which might gain access to the wound at the time of operation and at the subsequent dressings, and at once caused an almost complete disappearance of surgical infections.

Following the splendid work of Pasteur and Koch progress in bacteriology was marvelously rapid. The bacillus of typhoid fever was discovered by Eberth in 1880 ; the bacillus of tuberculosis, by Koch in 1882; the spirillum of cholera, by Koch in 1884; the diphtheria bacillus, by Kilebs and Löffler in 1883; the bacillus of lockjaw, by Kitasato in 1889, and so on.

We have already mentioned that following Leeuwen- 
hoek's discovery of bacteria these organisms were held to be the cause of a great variety of diseases. In fact, for some time people seemed "bacteria mad." We now know that bacteria are associated only with a certain group of diseases which we call infectious diseases. An infectious disease is caused by a living germ, though not necessarily by a bacterium. ${ }^{1}$ For example, typhoid fever, diphtheria, tuberculosis, and pneumonia are caused by bacteria; malaria and syphilis, by tiny germs known as protozoa ${ }^{2}$; while certain diseases of the hair and skin are caused by fungi. ${ }^{3}$ The great importance attaching to infectious diseases as a class arises from the fact that they are communicable. Moreover, if the germ of a particular disease is known, the possibility is given of devising means to prevent the spread of the disease, $i . e$, the transmission of the germ to others. For this reason it is important that nurses should have some knowledge of the nature and characteristics of germs. The study of germs is called bacteriology; and this usually includes not merely bacteria, but also protozoa, yeasts, ${ }^{4}$ and fungi. The term "microbe," so frequently used by the laity, is synonymous with the term "germ," and is usually taken to include the several classes of micro-organisms just mentioned.

${ }^{1}$ BACTERIA are microscopic, unicellular vegetable organisms that multiply by transverse division.

${ }^{2}$ Protozon are microscopic, unicellular animal organisms.

${ }^{3}$ FUNGI are microscopic, multicellular vegetable organisms.

${ }^{4}$ YeAsts are microscopic, unicellular vegetable organisms that multiply by a peculiar process called budding. 


\section{CHAPTER II}

\section{CHARACTER OF BACTERIA}

BACTERIA are extremely minute living organisms. Seen under a powerful microscope they appear as little rods, spheres, or spirals. It is difficult for one unaccustomed to the use of a microscope to conceive of the size of these micro-organisms. They vary in size from $\frac{1}{50,000}$ to $\frac{1}{1000}$ inch, so that a tiny drop of pus often contains many thousand bacteria. Even a minute dust mote floating in the air may earry them. Bacteria are one-celled organisms, $i$. e., each cell is a complete individual. There is no head, no tail, and not even the

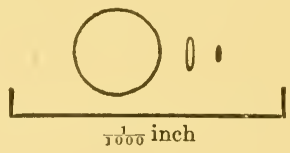

Fig. 1.-Comparative size of human red blood-corpuscle, typhoid bacillus, and influenza bacillus (Jordan).

most powerful microscope reveals any special organs within the cell. The mode of life of bacteria is the simplest that can be conceived. Placed in suitable surroundings, a bacterium after a time divides and forms two bacteria. Each of these grows a little until of the size of the parent, and then, in turn, it also divides, forming two. And so the process goes on, each division giving rise to two bacteria in the place of one. Under proper conditions certain bacteria multiply very rapidly, 
division taking place about every twenty minutes. The number of bacteria produced from a single parent bacterium in twenty-four hours thus becomes enormous. It is perfectly obvious that this rate of growth cannot continue for very long, else the entire world would long ago have become merely one huge mass of bacteria. We shall study the conditions governing the growth and multiplication of bacteria in a subsequent chapter; suffice it here to say that further growth after a time ceases, owing to the accumulation of waste-products, the exhaustion of the food supply, etc.

In form, bacteria are more or less spheric, rod shaped, or spiral shaped. We call the first cocci (singu-

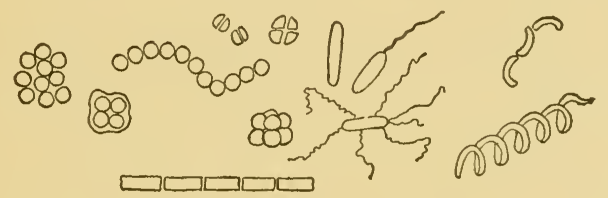

Fig. 2.-Forms of bacteria (Jordan).

lar coccus); the second, bacilli (singular bacillus), and the third, spirilla (singular spirillum). The first group is still further subdivided according to the manner in which the individual organisms tend to group themselves when multiplying. Thus a large class of cocci divide always in a single plane, and so give rise to a string of cocci appearing like a string of beads. Cocci growing in this manner are termed streptococci. In another large class the organisms divide in every plane, so that there is produced a mass having somewhat the appearance of a bunch of grapes. Cocci growing in this manner are termed staphylococci. Other cocci, on multi- 
plying, arrange themselves in groups of two each, and these are termed diplococci, while still others arrange themselves in groups of fours, and these are termed tetrads. In medical bacteriology besides bacilli and spirilla, the streptococci, staphylococci, and diplococci play an important rôle.

In a preceding paragraph it was stated that bacteria multiplied when placed in proper surroundings. On the other hand, tnere is considerable variation in the

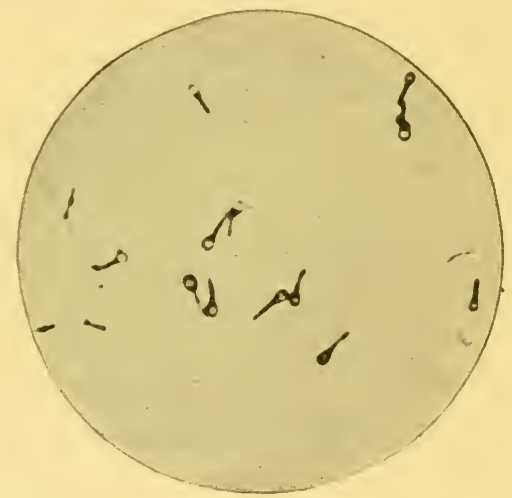

Fig. 3.-Bacillus tetani, showing spores. Pure culture on agar. Fuchsin stain (Kolle and Wassermann).

behavior of different species of bacteria when placed in unfavorable surroundings. Nany quickly perish; others live for some time, and then gradually die off. Still others undergo a peculiar transformation into a highly resistant form known as spores. A spore is a round or oval body, usually highly refractive, and possessing a high degree of resistance against various destructive agents. Spores, as such, do not multiply, and may, therefore, be compared to seeds. A bacterium produces 
only a single spore. Spore formation is limited to the bacilli. The fact that spores are so resistant is practically important, and necessitates a careful study of the principles underlying sterilization. Among the sporeforming bacilli encountered in medicine may be mentioned the bacillus of tetanus (lockjaw), the bacillus of anthrax, and the bacillus of malignant edema.

Some bacteria possess the power to move about. They are, therefore, spoken of as being motile. By em-
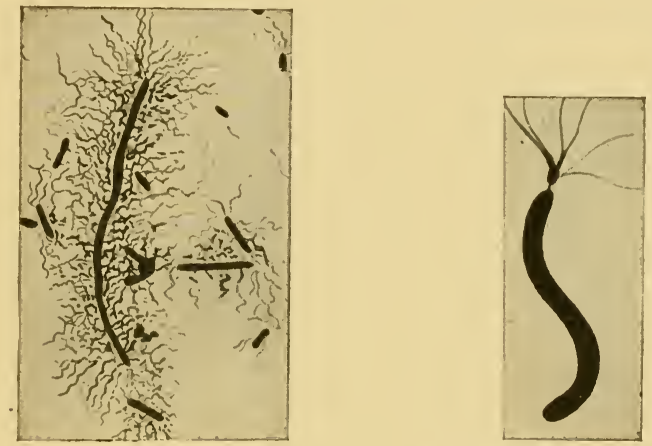

Fig. 4.-Flagella: Proteus vulgaris and large spirillum belonging to the group of sulphur bacteria (Zettnow).

ploying suitable methods the motile bacteria are seen to have little hair-like appendages, called flagella (singular flagellum), which act as swimming arms. Some bacteria have but a single flagellum, others have a little tuft at one or both ends, while still others have flagella on all sides. The typhoid bacillus is a good example of a motile bacterium; it has flagella on all sides.

It is well to remember that not all bacteria produce disease. In fact, those that do (the so-called patho- 
genic bacteria) are only a small proportion of the bacteria thus far known. Many bacteria are very important in preparing food for plants, breaking down complex chemic substances into simpler substances suitable for plant absorption. Still other bacteria are useful in producing fermentations, in disposing of refuse, liquefying sewage, etc. Bacteria are found almost everywherein the air, in water, in the soil, and on everything we touch. Nost of the bacteria of the air, however, are cntirely harmless, although at one time it was believed that they caused the infection of wounds during surgical operations. Lister used to have a spray with dilute carbolic acid playing about the operating room during an operation in order to kill the bacteria which might be in the air. We have since found out that this is unnecessary.

It was stated above that bacteria multiplied enormously when placed under proper conditions. These conditions relate mainly to food supply, to the presence of a suitable temperature, sufficient moisture, absence of much light, presence or absence of oxygen, etc. We shall take up the points in the order named. In supplying living creatures with food, it is always well to have the composition of this as nearly as possible like that of their natural food. In the case of bacteria pathogenic for man and animals it is obvious that the food should have a composition resembling that of the animal body. 'This is accomplished by making use of broths, milk, blood-scrum, and the like. The same principle applies to the temperature at which the bacteria are cultivated. Just as certain tropical plants require a different temperature to grow than do hardy 
northern plants, so do some bacteria require a warmer or a colder environment than others. Bacteria accustomed to grow in the body of warm-blooded animals usually grow best at a temperature near $100^{\circ} \mathrm{F}$. On the other hand, the bacteria normally growing in water, for example, usually grow best at a temperature of about $60^{\circ} \mathrm{F}$. Certain bacteria, growing in manure, grow best at a temperature considerably above $100^{\circ} \mathrm{F}$.

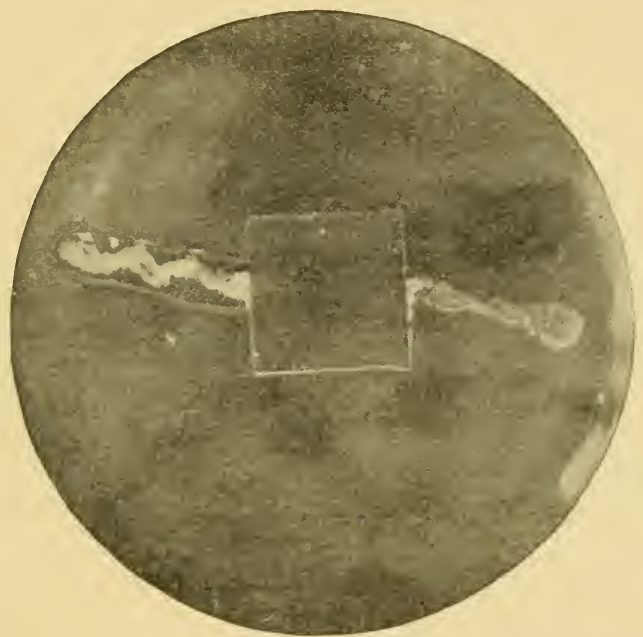

Fig. 5.-Streak culture of the potato bacillus (natural size), showing an aërobic organism which will not grow under a cover-glass (Williams).

All bacteria require a certain amount of moisture for their growth. Noreover, many bacteria die if they are allowed to dry.

The necessity for protecting bacteria which we wish to cultivate against an undue amount of light, particularly against sunlight, is understood when one recalls 
that certain of the light rays exert a destructive action on bacteria. In fact, so resistant a germ as the tubercle bacillus may be killed by several hours' exposure to direct sunlight.

So far as the effect of oxygen on the growth of bacteria is concerned, it is interesting to note that there are three large classes of bacteria, namely, those which require oxygen for their growth, those which will not grow if oxygen is present, and those which will grow
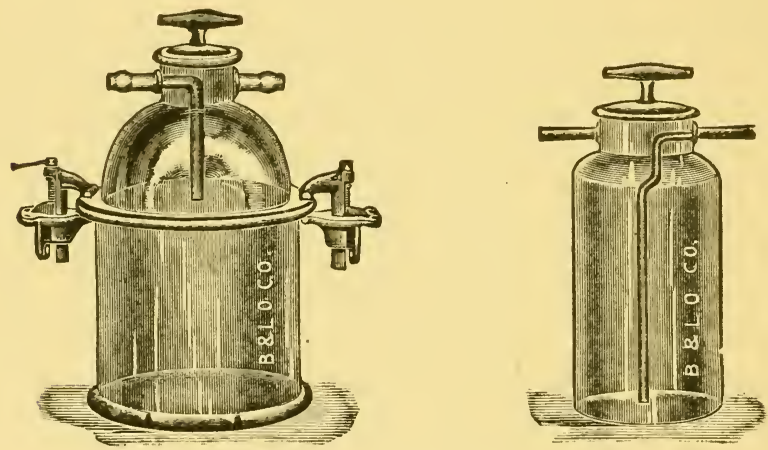

Fig. 6.-Novy's jars for anaërobic cultures.

whether oxygen is present or absent. The bacteria belonging to the first class are called cierobes, those belonging to the second class are ancierobes, and those belonging to the third class are called facultative anaërobes. The bacillus of diphtheria is an aërobe, so is that of tuberculosis; the bacillus of tetanus and that of malignant edema are anaërobes; the colon bacillus and the bacillus of anthrax are facultative anaërobes. Anaërobic cultures are conveniently grown in an atmosphere of hydrogen in a Novy jar, or they may be grown in an 
atmosphere of air from which the oxygen has been abstracted by means of chemicals.

Demonstration.-Moldy pieces of bread. A throat culture on Löfler serum, one or two days old. Teeth scrapings, under a coverglass and magnified, unstained. Hanging-drop preparation, preferably of a motile organism (hay bacillus). Be careful that the objective of the microscope is not pushed through the cover-glass. Spores (an old culture of hay bacilli). 


\section{CHAPTER III}

\section{METHODS OF STUDYING BACTERIA}

While bacteria can be seen with high-power magnifying glasses, it is impossible to study their form without a compound microscope. Such an instrument is shown in Fig. 7.

It consists of a heavy foot or base bearing an upright post, to which the stage and the tube are attached. The object to be examined is placed on the stage, and light is thrown up from the mirror beneath, through the object, and into the series of lenses in the tube. The tube is moved up and down by means of two screws, one called the coarse adjustment, the other called the fine adjustment. Fitting into the upper end of the tube are various eye-pieces or oculars. These are of varying power and are usually numbered from 1 to 5 . Attached to the lower end of the tube is a so-called nose-piece, carrying two or three "objectives," each objective consisting of a series of lenses mounted together. The objectives are usually distinguished by numbers $(3,5$, and 7$)$ or by fractions ( $\frac{2}{3}, \frac{1}{4}$, and $\frac{1}{8}$ inch). When using the higher powers of the microscope it is important to have strong illumination from the mirror. In ordes to bring this about a series of lenses, called the condenser, is placed between the mirror and the stage. But even with this equipment it is difficult to study the finer details of bacterial structure. This can only 
be satisfactorily accomplished by staining the bacteria and examining them by means of very high-power objectives, which dip into a drop of cedar oil placed directly on the specimen to be examined. Such objectives are spoken of as oil-immersion objectives; the one

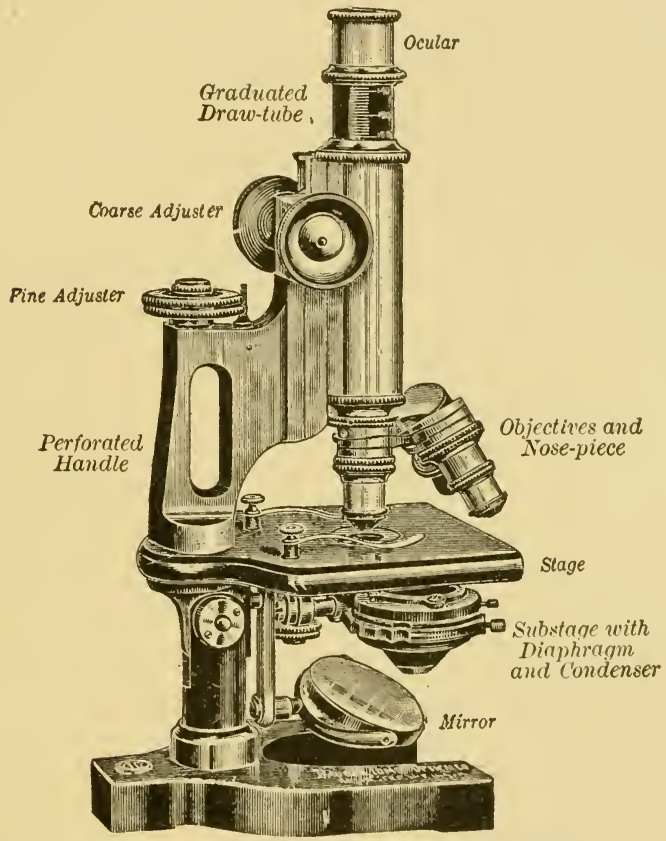

Fig. 7.-Bacteriologic microscope (Ball).

in common use, the $\frac{1}{12}$ inch, when used with a No. 5 eye-piece, magnifies about 1200 times. For the staining of bacteria we usually employ some of the coal-tar dyes, such as methylene-blue, fuchsin, gentian-riolet, ete. The appearance of such stained bacteria is well shown in Plate 1. The use of these stains has a further 
value, in that it often helps to differentiate bacteria from one another. This will be seen when we study Gram's stain and the stain for tubercle bacilli (p. 26).

Demonstration.--Show a reading glass, and a high-power magnifying glass such as is used to count threads in a woven fabric. (Image erect.)

Demonstrate the compound microscope. (Image inverted.) 


\section{CHAPTER IV}

\section{PREPARATION OF STAINED SMEARS}

IN preparing bacteria for microscopic examination a tiny bit of the material (pus, sputum, exudate, culture, etc.) is thinly spread on a glass slide and allowed to dry. Then the slide is passed several times through the flame in order to "fix" the preparation. By this is meant the drying, killing, and coagulating of the material, so that it will remain fixed to the slide and not wash off in the staining fluid. For the ordinary examination the preparation is next flooded with the staining fluid-e.g., watery solution of methylene-blue-and allowed to stain for several minutes. The stain is poured off, the slide washed in water, dried with blotting-paper and in air, and is then ready to be examined. The simple stains in common use are watery solutions of methyleneblue, of gentian-violet, or of fuchsin. Some bacteria, however, do not take these simple stains readily, and it is necessary to add something to the staining fluid to cause the stain to "bite in." The substance thus added is called a mordant. Carbolic acid is an excellent mordant, a solution of carbolic acid and fuchsin being extensively used to stain tubercle bacilli.

It was said above that stains were also used in identifying bacteria. Most bacteria, for example, when stained and then treated with acids quickly lose their color. Some, however, withstand the action of acids, retain- 
ing their color even after prolonged contact. These are spoken of as "acid-fast" bacteria. This test is extensively used in identifying tubercle bacilli, for these belong to the acid-fast group. (See Plate 1.)

Another staining method largely used in identifying bacteria is one devised by Gram. This is carried out as follows: The bacteria, spread and fixed on the slide in the usual way, are stained with a solution of gentianviolet with the aid of a little heat. At the end of several minutes the stain is poured off, and, without washing, the slide treated with 'a solution of iodin. Following this, the preparation is washed with absolute alcohol and then with water. When treated in this way certain bacteria are found to retain the original violet stain, while others lose it during the alcohol treatment. This is a very valuable reaction, and is extensively used in identifying the germs of meningitis, gonorrhea, etc. Bacteria which retain the violet stain when treated according to Gram's method are called "Gram-positive," while those which lose their stain are called "Gram-negative."

In passing we may say that, in addition to these ordinary staining methods, special procedures have been devised for the demonstration of flagella in motile bacteria and for staining spores, capsules, etc.

The teacher is to demonstrate simple staining, explaining the various steps, tubercle staining (Ziehl's method), and Gram's stain.

For this exercise let the students examine as many stained specimens as possible, to fix in their minds the appearance and relative size of bacteria. 
CHAPTER V

\section{CULTIVATION OF BACTERIA}

IN order to properly study bacteria it is absolutely essential that they be grown by themselves, $i$. $e$., not

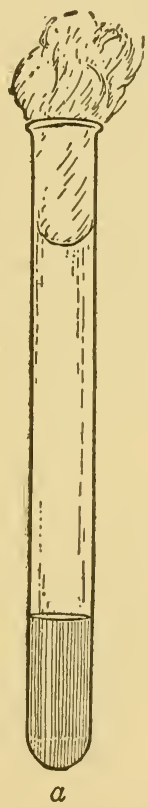

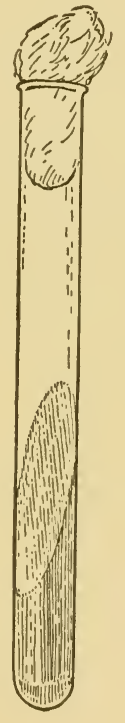

$b$

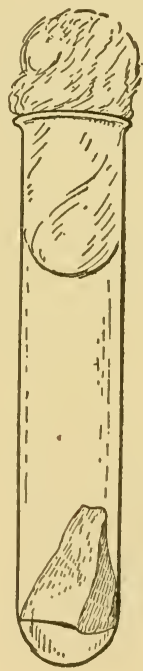

c

Fig. 8.-Media in tubes: $a$, Broth; $b$, agar slant; $c$, potato (Hiss and Zinsser).

mixed with a lot of other bacteria. In other words, it is necessary to obtain a pure culture. We shall assume 
that we have such a culture; let us now consider the methods by which we continue to grow the same. Our first step is to plant the bacteria either in a fluid culture-medium, such as beef-broth, milk, etc., or on the

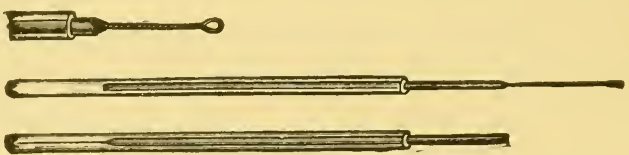

Fig. 9.-Platinum wires for bacteriologic use.

surface of a solid medium, such as gelatin, agar, solidified blood-serum, potato, etc. It is obvious that these culture-media must be absolutely free from other germs, $i$. e., they must be perfectly sterile. In planting the

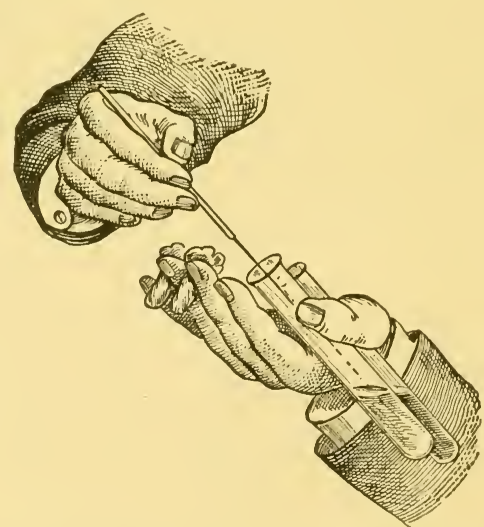

Fig. 10.-Method of holding tubes during inoculation (McFarland).

culture, we have at hand the tube containing our original pure culture and a tube of the sterile medium, e. g., sterile broth, closed at the top with a cotton plug. All we need to clo is to transfer a little loopful of culture by 
means of the platinum wire loop to the tube of sterile broth. In order to avoid carrying along other germs, however, we first hold the wire loop in the flame until it glows, thus destroying any germs that may have

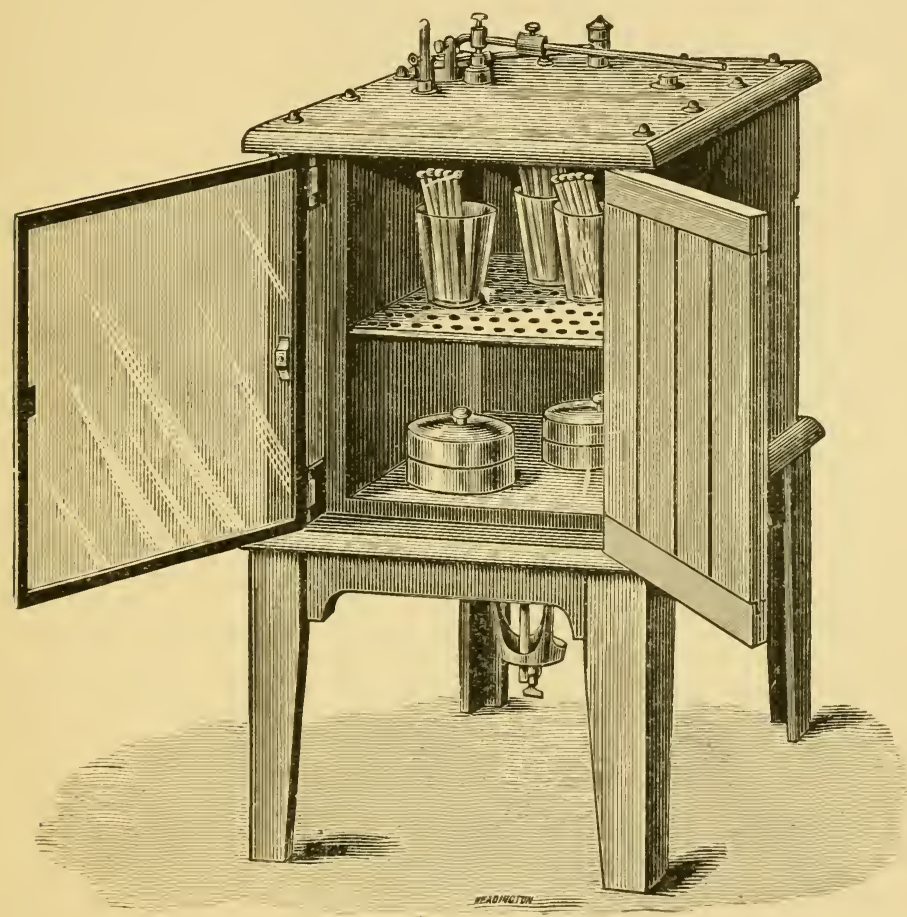

Fig. 11.-Incubator (Eyre).

lodged on the wire. The loop cools in a moment, the culture is transferred, the tubes are again closed with the cotton plugs, and the wire is at once passed through the flame before being laid down. Thus all danger of spreading the germs about is avoided. 
The freshly planted culture is now placed in the incubator. This is a kind of oven whose walls are filled

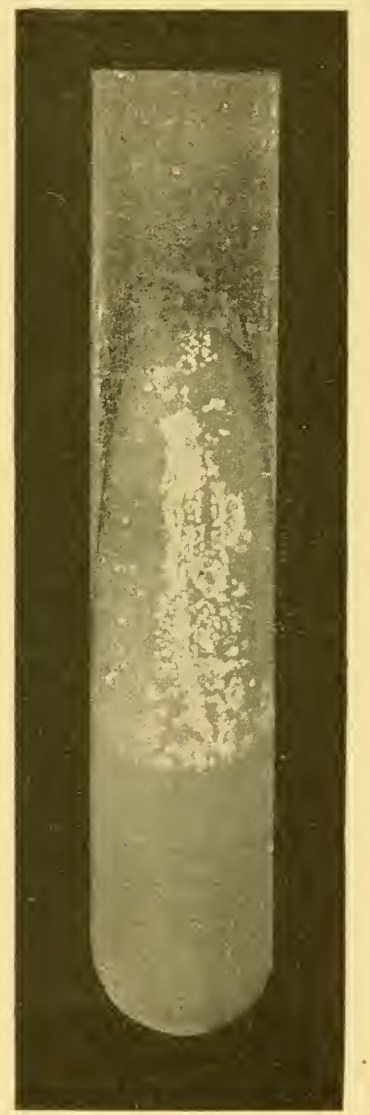

Fig. 12.-Streptococcus pyogenes, culture on agar. Slightly enlarged (Williams).

with water, and whose interior is kept at a uniform temperature by means of a lamp or gas flame controlled by 
a suitable heat regulator. For the ordinary pathogenic bacteria the incubator is set to maintain a constant temperature of about $99^{\circ} \mathrm{F}$.

In studying the bacteria of water, a temperature of $60^{\circ} \mathrm{F}$. is usually employed. The general type of incubator is shown in Fig. 11, page 29.

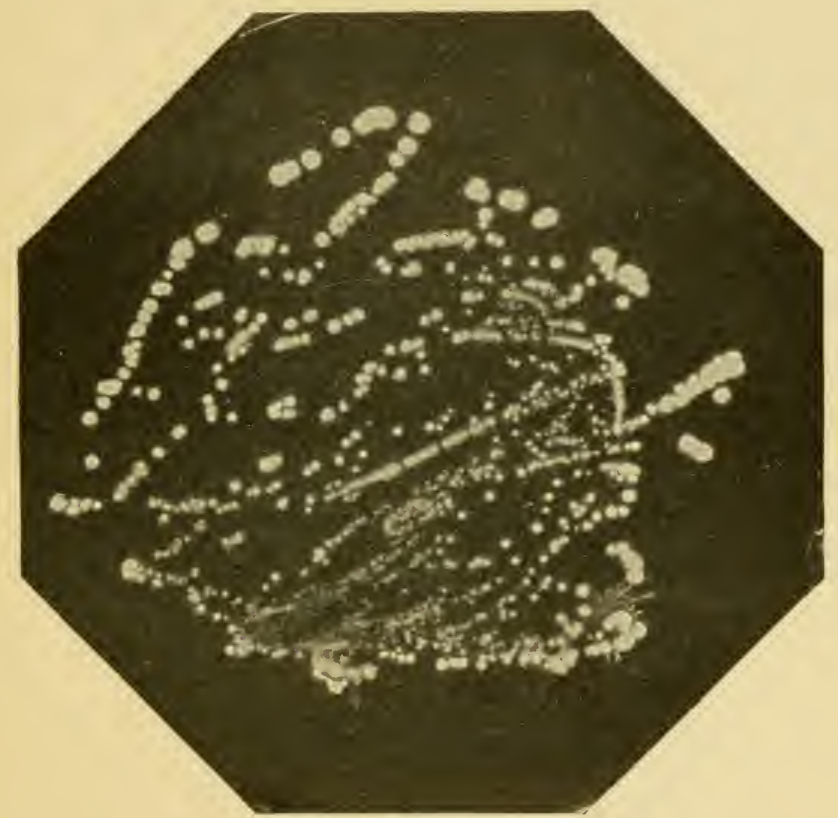

Fig. 13.-Streak plate. (From Hiss and Zinsser, "A Text-Book of Bacteriology," D. Appleton \& Co., publishers.)

After remaining in the incubator for twelve to twenty hours it will be noticed that the appearance of the beefbroth has changed. Originally perfectly clear, it now is more or less uniformly cloudy, or it may have a cloudy sediment or be covered with a scum. If the cul- 
ture was planted on sterile agar (a kind of gelatin) it will now be found to be covered with a peculiar, more or less slimy mass, or with a number of small, rounded spots, This cloudiness in the fluid culture, or this slimy mass on the solid cultures, is the new growth, and is made up of. millions of tiny bacteria. Just as in planting seed in the ground, a plant arises from each seed; so, in planting bacteria on the surface of a solid medium, wherever a single bacterium was deposited a whole group of similar bacteria develop. These groups become visible to the naked eye, forming usually more or less rounded

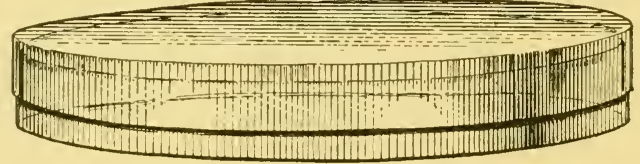

Fig. 14.-Petri dish for making plate cultures (McFarland).

masses, varying in size from that of a pin's head to disks $\frac{1}{2}$ inch in diameter. Such masses of similar bacteria, the offspring of a single individual, are spoken of as "colonies." The number of colonies developing is thus an index of the number of living germs in the material planted. If the bacteria originally planted were very numerous, the colonies developing are so closely crowded that they form one continuous film, in which it is impossible to distinguish separate colonies. It is apparent that we can discover the number of living germs in a specimen of fluid by planting a known quantity of the fluid on a solid medium, growing the culture, and then noting the number of colonies which develop. This is facilitated by using shallow flat glass 
dishes, called "Petri dishes" or "plates." This "plating" method is extensively used to determine the number of living bacteria in milk and in water.

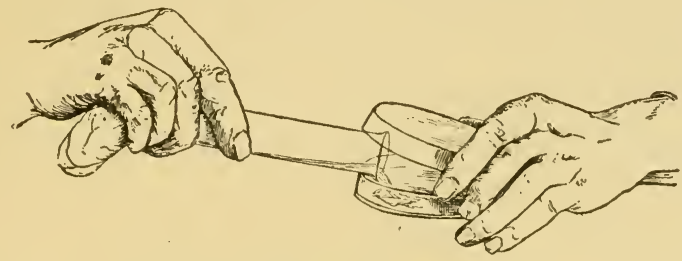

Fig. 15.-Pouring plates (Eyre).

Plate cultures are also employed in isolating bacteria in pure cultures. Without entering into the details of

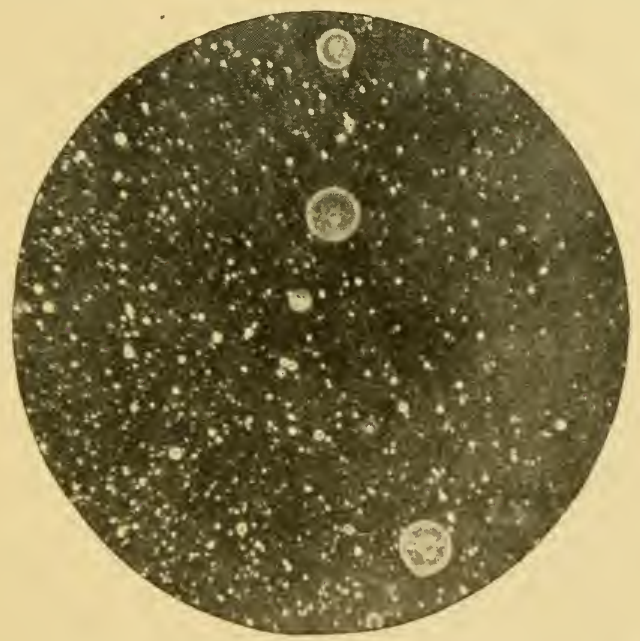

Fig. 16.-Appearance of colonies on gelatin in Petri dish (Williams).

the method, we may say that in general it consists in the preparation of a number of plate cultures from the material to be examined, selecting the plate on which 
the colonies are not too closely crowded, and then, by means of a sterile straight platinum wire, carefully transferring some of the bacteria from a single colony to a tube of sterile medium. This process is spoken of as "fishing" a plate. It is obvious that, even though the original material contained many different kinds of bacteria, the cultures obtained by "fishing" will each contain but a single kind in pure culture.

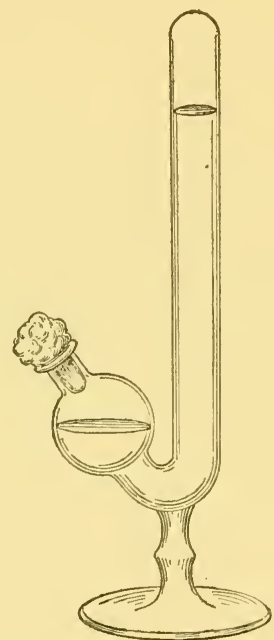

Fig. 17.-Smith's fermentation-tube (McFarland).

The cultivation of bacteria on different media constitutes an important means of studying and identifying the various species. For example, certain bacteria when grown in gelatin cause the gelatin to become fluid, while others do not. Certain bacteria cause milk to turn sour and coagulate, some cause it to beeome putrid, while others apparently leave it unchanged. 
In media-containing sugars some bacteria ferment the sugars with the production of acid, others with the production of gas and acid, while still others do not ferment the sugar at all. In studying the production of acid we can add a little litmus to the medium and note whether the blue color changes to red. The formation of gas is best observed by growing the culture in a fermentation-tube.

Demonstration.-The teacher should inoculate various media, both liquid and solid, using organisms growing both at room temperature and body heat (e.g., hay bacillus), and organisms growing only at body heat (e.g., pneumococcus). Some of the latter variety should be inoculated in duplicate, and the duplicate kept at room temperature, to show that there will be no growth under these conditions. Agar-plate cultures should be made from milk (diluted) and from tap-water.

Streak-plate cultures may be made from the throat or from teeth scrapings. 


\section{CHAPTER VI}

\section{RELATION OF BACTERIA TO DESTRUCTIVE INFLUENCES}

\section{DISINFECTANTS AND ANTISEPTICS}

In a previous chapter it was pointed out that bacteria required a certain degree of heat in order to thrive. For most pathogenic bacteria this is about $100^{\circ} \mathrm{F}$. Higher temperatures, on the other hand, exert an injurious action on bacteria, so that even a short exposure to the temperature of boiling water quickly kills most pathogenic bacteria. Destruction of bacteria can also be effected by prolonged exposure to temperatures considerably less than the boiling-point of water. This is spoken of as "pasteurization," after Pasteur, who first applied this method of killing bacteria. The effect of low temperatures on bacteria varies considerably with different. species. Bacteria accustomed to grow at body temperature usually cease to grow or grow very slowly at ordinary room temperatures. There is practically no growth at all at $40^{\circ} \mathrm{F}$. At freezing temperature many bacteria die off, but even the low temperature of liquid air does not certainly kill all forms.

Bacteria also vary in their resistance to drying, the vegetative forms usualiy drying quickly, while certain spore forms appear to resist drying indefinitely. As has already been pointed out, direct sunlight exerts a 
destructive action on bacteria. The combination of heat, drying, and sunlight is extremely efficacious in killing bacteria.

The study of chemicals which exert a destructive influence on bacteria (disinfectants) is of great practical importance. Depending on the intensity of their action, we usually speak of these substances as being either "germicides" (germ killers) or "antiseptics" (preventing germ growth). Every germicide in diluted form is an antiseptic. The conditions under which the disinfectant acts is of the greatest practical importance. Thus, carbolic acid acts better in 5 per cent. solution than in higher concentrations, and the efficiency is increased by the addition of salt, but diminished by the presence of alcohol. The rate of penetration into bacterial cells decreases as the concentration increases above a certain limit. The temperature at which the process is carried on also has a marked influence on the rate of disinfection. The presence of albuminous substances largely interferes with the action of certain disinfectants, notably with mercury bichlorid. The following are some of the more commonly used disinfectants:

Mercuric chlorid, also called corrosive sublimate, bichlorid of mercury, or, for short, "bichlorid," while strongly germicidal, has the disadvantage of being extremely poisonous, of forming insoluble and inert compounds with albuminous substances, and of acting on metals. Despite these drawbacks, however, this is one of the most commonly used disinfectants at the present day. It is employed largely in the form of ready made tablets, containing usually sufficient "bichlorid" to 
make a solution 1:1000 when one tablet is dissolved in a pint of water. Most of the tablets contain either citric or tartaric acid or ammonium chlorid to prevent the formation of insoluble compounds with albuminous matter. Many of the tablets also contain some harmless blue, pink, or yellow coloring-matter to aid in identifying the solution. For ordinary use solutions of 1:1000 will suffice, when brought into contact with bacteria, to kill the vegetative forms within fifteen minutes. Stronger solutions, however, must be employed when much organic matter is present. Mercuric chlorid should not be employed to disinfect metal instruments, as it quickly ruins them by its action.

Carbolic acid, or phenol, is a white crystalline substance readily liquefied by heat. It can be kept liquid by the addition of 5 per cent. water or glycerin, making what is sold in the drug stores as "pure carbolic acid." For disinfecting purposes it is ordinarily used in the form of a 5 per cent. solution in water, and, while it is less powerful than mercuric chlorid, it has the advantage of being only slightly affected by albuminous material, and of not acting on metals. Its efficiency is increased by the addition of common salt up to saturation: $1: 400$ kills the less resistant bacteria, and 1:100 kills the remainder. A 5 per cent. solution kills the less resistant spores within a few hours, and the more resistant in from a day to four weeks.

Crude carbolic acid consists mainly of cresols and very little phenol. By saponification of mixtures of cresols and neutral tar oils a product is obtained which makes an emulsion with water. Creolin is a type of numerous preparations of this character. They are all 
poisonous and sensitive to albuminoids. Moreover, these emulsions have the disadvantage of being opaque. Lysol is mainly a solution of the cresols in fat or linseed oil saponified with addition of alkali. It gives a clear solution with water, having marked germicidal powers and considerable solvency for grease. It is extensively used in the form of a 1 per cent. solution in gynecologic and obstetric practice. Tricresol, a refined mixture of the three cresols, is soluble in water to the extent of 2.5 per cent. It is about three times the strength of carbolic acid.

Quicklime, used in the form of freshly slaked lime suspended in water, is a powerful disinfectant. A 1 per cent. watery solution of the freshly slaked lime kills bacteria which are not in the spore form within a few hours. A 3 per cent. solution kills typhoid bacilli in one hour, while a 20 per cent. solution, added to equal parts of feces or other filth and thoroughly mixed, will completely sterilize them within one hour.

Chlorid of lime, so called (really chlorinated lime), depends for its efficacy on the chlorin it contains, and, as this is readily lost on exposure to the air, it is important that chlorid of lime be kept in tight containers. A solution in water containing 0.5 to 1 per cent. of chlorid of lime will kill most bacteria in one to five minutes. A 5 per cent. solution usually destroys spores within one hour. Chlorid of lime is particularly useful in the disinfection of stools. Together with washing-soda it is also extensively used as a hand disinfectant by surgeons.

In recent years chlorinated lime is user extensively in disinfecting municipal water-supplies. When so used 
about 15 pounds are added to $1,000,000$ gallons of water. This is equivalent to approximately 0.5 part free chlorin per 1,000,000 parts of water. (See also page 149.)

Sulphur dioxid gas, produced by burning sulphur in air, was formerly extensively used as a disinfectant for sick rooms, but has now been largely discarded in favor of formaldehyd. Ordinarily 4 pounds of sulphur are burned for each 1000 cubic feet of air space, and the room is kept sealed for at least eight hours. In order to be efficacious the air in the room in which the sulphur is burned should be moist. Sulphur fumigation is still largely used to kill rats and vermin in combating the spread of plague.

Formaldehyd is a gaseous compound having an extremely irritating odor. It is most conveniently used in the form of a watery solution containing about 40 per cent. of the gas, and known commercially as "formalin." A.2 per cent. watery solution of formalin destroys the vegetative forms of bacteria within five minutes. In the form of the gas formaldehyd is extensively used in the disinfection of sick rooms. At least 4 ounces of formaldehyd should be allowed for each 1000 cubic feet of air space. The details of such disinfection are discussed on p. 167.

Iodin, in the form of tincture of iodin, is extensively used as a disinfectant of the skin for surgical operations.

Peroxid of hydrogen $\left(\mathrm{H}_{2} \mathrm{O}_{2}\right)$ is an energetic disinfectant. A 20 per cent. solution (a good commercial hydrogen peroxid) will quickly destroy the pus-producing cocci and spore-free bacteria. It combines with organic matter, becoming inert. It is prompt in its action and not poisonous, but apt to deteriorate if not 
properly kept. It is extensively used to wash out abscess-cavities and purulent sinuses, and also as a gargle and mouth-wash.

Soap.-Castile and ordinary white bath soap possess moderate disinfecting power, and in conjunction with hot water and a scrub brush have a wide and varied usefulness. Soaps alone, however, cannot be depended upon when thorough disinfection is required.

Dakin's Solution.-As the result of a study of the treatment of infected wounds, Carrel and Dakin devised an antiseptic treatment with a neutral solution of hypochlorite of soda. When properly prepared the solution contains 0.475 per cent. of the hypochlorite, with small quantities of neutral salts. It is isotonic to blood-serum. More recently a simple apparatus has been devised whereby Dakin's solution can readily be prepared from pure, liquid chlorine.

Dichloramine-T.-Dakin has also devised two chemical compounds, called chloramine- $\mathrm{T}$ and dichloramine- $\mathrm{T}$ respectively. These exert a marked disinfecting action even in the presence of blood-serum, and they have accordingly come into considerable use in the dressing of infected wounds. Ordinarily these substances are used in the form of solutions in oil, especially in chlorinated eucalyptus oil. Such solutions can then be mixed with chlorinated paraffin oil, if it shouid be found desirable to dilute the solution. Since light decomposes the chloramine solutions, the use of amber or, better still, black bottles is advisable. Under favorable conditions a solution properly prepared will keep for several weeks.

In ordinary wounds the application of these antiseptic solutions is made once in twenty-four hours. For 
gangrenous or for very foul wounds a more frequent application should be made, as the active chlorine, on which the action of the chloramines depends, is more rapidly consumed by such wounds.

Halazone is the name given by Dakin to a compound allied to the preceding and designed especially for the emergency disinfection of drinking-water. Dakin's experiments indicate that a concentration of $1: 300,000$ will sterilize an ordinarily heavily contaminated water in about thirty minutes. Halazone has been prepared in the form of tablets made with sodium carbonate or with dry borax.

Demonstration.-The teacier should inoculate a loopful from a twenty-four-hour broth culture of typhoid (or colon) bacilli into the following tubes: and make subcultures from each of these tubes at
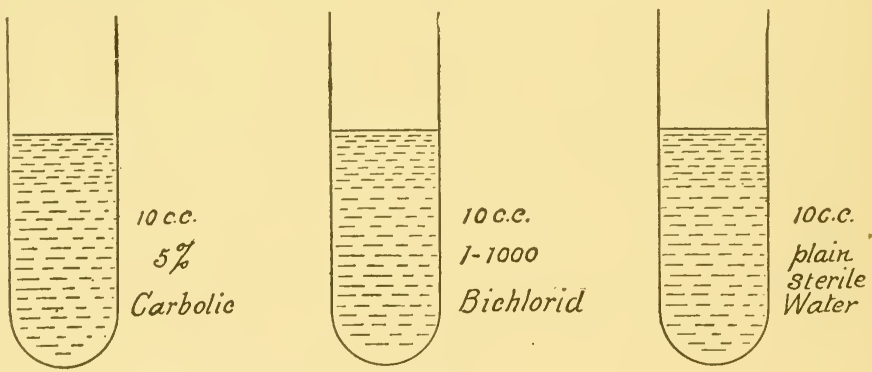

Fig. 18.

the end of one minute or five minutes by inoculating a loopful from these tubes into plain sterile broth.

Instead of making broth subcultures, agar poured plate cultures can be made. 


\section{CHAPTER VII}

\section{STERILIZATION BY HEAT}

In making use of heat to destroy bacteria the method employed depends largely on the character of the material to be sterilized. Heat may be used in the form of fire, $i$. e., the naked flame, or as dry heat, or as boiling water, or live steam, or live steam under pressure.

(1) Fire.-Many infected articles which it is desired to be rid of can be burned in the fire, thus absolutely destroying the infectious bacteria. Infected mattresses, rugs, books, papers, and magazines, toys, pus-soaked dressings, paper sputum cups and paper handkerchiefs, and other similar articles are often best disposed of in this way. In an emergency it is sometimes very convenient to sterilize a knife or other surgical instrument by passing it through the flame, or by dipping it into alcohol and then lighting the alcohol.

(2) Dry IIeat.- In many instances the use of fire is out of the question. In such cases we may often employ dry heat to advantage. In bacteriologic laboratories special ovens are constructed for sterilizing glassware, etc., by means of dry heat. In the home the oven of the kitchen stove will usually answer equally well. The temperature of the oven should range about $300^{\circ} \mathrm{F}$., and the articles should remain exposed for about an hour. 
(3) Moist Heat.-It has been found that the presence of moisture markedly increases the destructive effect of heat. The simplest method of combining these two factors is to boil the articles to be sterilized in water. Surgical instruments are usually sterilized in this way,

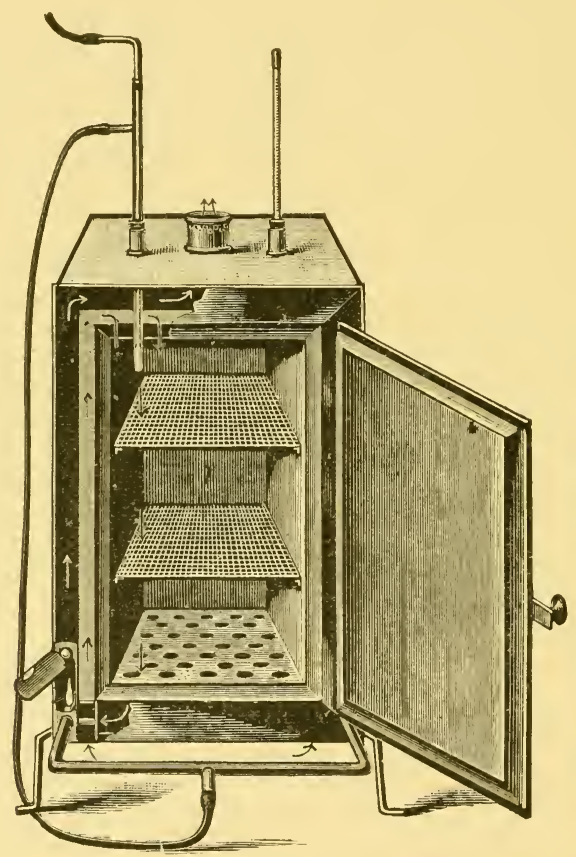

Fig. 19.-Hot-air sterilizer (McFarland).

and so are catheters, douche-nozzles, hypodermic needles, etc.

(4) Live Steam.-Another method of using moist heat is by means of live steam in a steam sterilizer. The accompanying figure shows the construction of the 
Arnold steam sterilizer. This consists of a very shallow boiling pan, a steam chamber, which is surrounded by the removable hood, and a large pan, which catches the drip water. The large pan is connected with the small pan by a number of small openings, thus constantly keeping a supply of water in the boiling pan. The advantage of this design is the rapidity with which steam

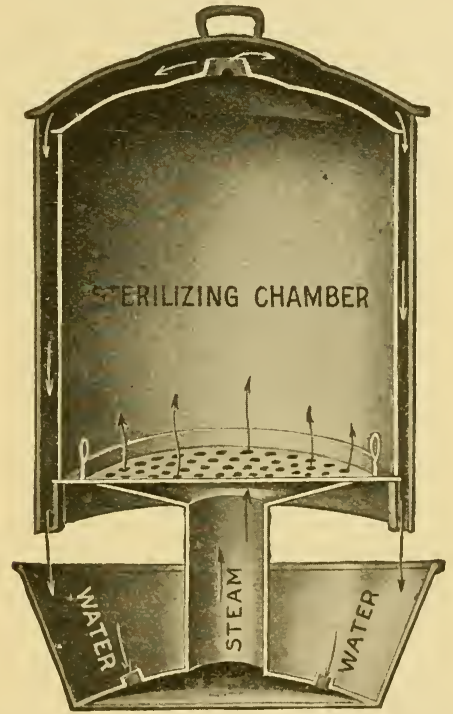

Fig. 20.-Arnold steam sterilizer (Fowler).

is developed and the little attention the apparatus requires when in operation. The temperature within the steam chamber is approximately that of boiling water, $212^{\circ} \mathrm{F}$. This form of sterilizer is extensively used to sterilize the various nutrient media used for growing bacteria. In order to be certain that sterilization has been complete it is customary to sterilize these 
in the Arnold sterilizer for an hour on each of three consecutive days. This makes certain the destruction of

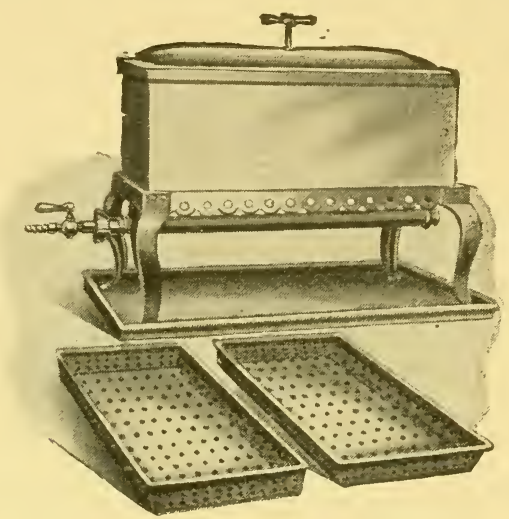

Fig. 21.--Instrument sterilizer.

all spores. Surgical dressings may also be sterilized in this form of sterilizer.

(5) The destructive action of steam can be enormously increased by employing it under pressure. For this a special form of apparatus is required. It is impossible to heat water, in an open vessel or in an Arnold sterilizer, to more than $212^{\circ} \mathrm{F}$. As soon, however, as we heat the water in a tightly closed vessel, which will not allow the steam to escape, we can raise the temperature beyond this. The higher the pressure of the steam, the higher the temperature. It is mainly because of this fact that the use of steam under pressure is so much more effective in sterilization than the use of live steam not under pressure. Another reason is the 
greater penetration secured by having the steam under pressure.

The accompanying figure shows a common type of steam sterilizer.

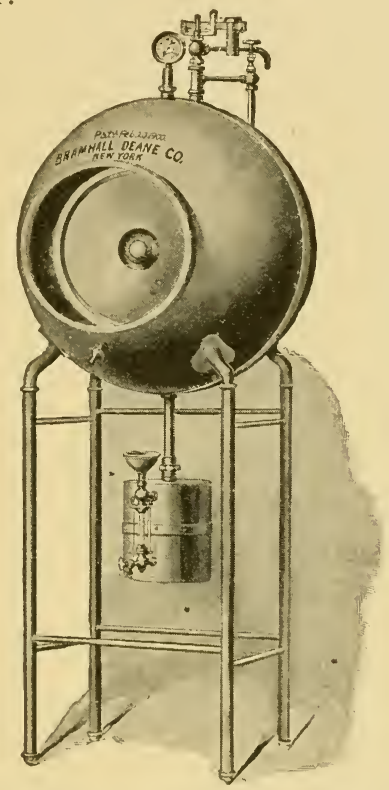

Fig. 22.-A pressure steam sterilizer. The steam jacket entirely surrounds the chamber, to which the steam is admitted through a valve. Pressure may be continued on the jacket while the dressings are removed. The safety-valve is set to relieve at 15 pounds.

The teacher should demonstrate the use of heat for sterilization by inoculating six broth tubes with a well sporulated culture of hay bacilli, and heating two in an Arnold sterilizer for five minutes, two others in a pressure steam sterilizer for five minutes (pressure of 15 pounds), leaving two unheated. After this, all six tubes are placed in an incubator over night. 


\section{CHAPTER VIII}

\section{THE RELATION OF BACTERIA TO DISEASE. INFLAM- MATION}

WE have already called attention to the fact that only a small proportion of the known bacteria are producers of disease, $i$. e., are pathogenic. In order to prove positively that a disease is due to. a certain bacterium it is absolutely necessary that this bacterium be always found in the disease. Furthermore, it must be possible to reproduce the same disease by the injection of pure cultures of the bacterium, and from the diseased tissues thus produced it must be possible to again isolate the germ.

The manner in which the various bacteria produce disease, their entrance into the body, the part of the body commonly attacked, all these differ considerably with the different micro-organisms. Some, like the bacillus of diphtheria and the bacillus of tetanus (lockjaw), secrete very powerful poisons, and, while these bacteria do not themselves penetrate deep into the body tissues, their poison is absorbed and gives rise to severe symptoms. In the case of other bacteria, for example, the tubercle bacillus, the germs penetrate deep into the body tissues and there multiply. In their growth they give off poisons which cause the gradual destruction of the tissues in which they lodge. In this way the tubercle bacillus causes large parts of the lung to be destroyed or bones to be eaten away, etc. 
Most germs, for some obscure reason, affect by preference certain parts of the body. The typhoid bacillus usually lodges in the wall of the small intestine; the meningococcus prefers the lining of the brain and spinal cord; the gonococcus is very prone to attack the mucous membrane lining the genital organs, and also the conjunctival membrane (outer lining of the eye). The pneumococcus affects chiefly the respiratory organs; the diphtheria bacillus, the throat and nasal passages.

The extent and kind of disease produced by the same bacterium also varies greatly. This, of course, depends largely on the size of the dose introduced, but also on the degree of resistance of the patient. We shall speak of this in a moment.

The more important pathogenic bacteria are the bacillus of tuberculosis, the typhoid bacillus, diphtheria bacillus, dysentery bacillus, spirillum of cholera, the pneumococcus, the streptococcus, the staphylococcus pyogenes, the meningococcus, the gonococcus, the bacillus of tetanus, of anthrax, of glanders, of bubonic plague, and of malignant edema. The germs of malaria, syphilis, and sleeping-sickness are tiny organisms called protozoa. ${ }^{1}$ The germs of ringworm and of barbers' itch are fungi. ${ }^{1}$ The germs of smallpox, chickenpox, scarlet fever, ${ }^{2}$ measles, yellow fever, and hydrophobia have not yet been discovered, though there is no doubt whatever of the germ nature of these diseases. Several alleged "cancer germs" have been described, but not only has their relation to cancer not yet been proved, but there is still considerable doubt whether cancer is a germ

${ }^{1}$ See Definitions, page 13.

${ }^{2}$ See page 122 . 
disease. Some authorities claim that pellagra is a germ disease, but the weight of evidence appears against this belief. On the other hand, acute articular rheumatism is generally regarded as a germ disease, most bacteriologists believing that the specific germ has not yet been identified.

\section{INFLAMMATION}

Inflammation is described as "a local reaction caused by agents which have produced tissue injury." Among the causes of inflammation we find blows, poisonous substances like snake venom, acids, or other irritant chemical compounds, excessive heat or cold, and, finally, perhaps the most important of all, bacteria. The degree of injury produced depends on a number of factors. In the inflammation due to bacteria it depends on the number of bacteria introduced, the virulence of the organisms, the length of time they remain, and on the resistance of the infected tissues.

The first response on the part of the body consists in a dilatation of the blood-ressels of the affected region and a quickening of the blood flow. This quickening, however, is soon followed by a slowing of the blood-current, and the passage through the wall of the blood-vessels of blood-serum and white blood-corpuscles (leukocytes). Sometimes the amount of blood-serum is small, but the number of white blood-cells large; at other times the reverse may be true. If the inflammation is severe, red blood-cells also pass through the wall of the bloodvessels.

Let us see what takes place when some staphylococci invade the deeper parts of the skin and give rise to a boil. As soon as these germs have entered they act as an irritant. 
to the various cells around them, just as a tiny particle of dust irritates the eye. All about the body cells are the capillaries, flowing through which are the various bloodcells suspended in a watery fluid called the blood-plasma. The irritation produced by the staphylococci is at once felt by the blood-stream, and for a short time it flows faster and the blood-ressels dilate, as though in this way to wash the irritant away. Undoubtedly there are many times when this suffices, especially when the irritating agent acts for only a short time and is very mild. If this is not the case the blood-current slows, and now an interesting process begins. The white blood-corpuseles (leukocytes) make their way through the wall of the blood-ressel and hunt out the offending bacteria. They act exactly as though they were police officers going after a law breaker. Accompanying the leukocytes is a flow of serum into the tissues, and this, as we shall see, contains substances which aid the leukocytes in their fight. If one watches this process under a microscope one can see the white blood-cells (leukocytes) actually engulf the invading bacteria, sometimes taking up ten or a dozen bacteria. ${ }^{1}$ But the fight is not yet over. It is all a question now whether there are enough leukocytes to combat the bacteria, and whether the leukocytes can destroy the bacteria which they have engulfed. As a rule, some of the leukocytes, instead of destroying the bacteria which they have "swallowed," are themselves destroyed by the bacteria.

Meantime, while some of the leukocytes are busy fighting the bacteria, other cells are busy massing themselves

${ }^{1}$ In connection with this the student should study Fig. 37, which shows a leukocyte filled with bacteria. 
solidly around the scene of conflict, forming a dense ring or wall which shuts off the fighters from the rest of the body. Inside the ring many of the combatants are killed, so that, in addition to living bacteria and living leukocytes, there is now an accummulation of cellular and bacterial débris. When the inflammation has proceeded in this way we have an abscess. The pus in an abscess is composed of leukocytes, broken-down tissue cells, bacteria, fibrin, serum, and débris.

However, the inflammation may take a somewhat different course-an abscess does not always result. The course depends mainly on the nature and virulence of the invading bacterium, the part of the body invaded, and the resistance of the patient. Thus it may happen that the invading organisms are so virulent or so numerous that before the leukocytes and other cells have completed their wall about the scene of conflict the invading bacteria have extended into the tissues far beyond. Again and again the leukocytes and other body cells gather and attempt to localize the conflict, the inflammation meantime involving a large area of tissue. This kind of inflammation is spoken of as a cellulitis or a purvilent infiltration; it is often due to the streptococcus.

In typhoid fever we meet with another type of inflammation, namely, an ulceration. In this disease we have a localization of typhoid bacilli in certain lymph-follicles known as "Peyer's patches," situated in the wall of the small intestine. Instead of forming circumscribed abscesses, the inflammation here produces ulcers opening on the inner surface of the gut. In other words, an ulcer is an abscess whose outer wall is missing.

When bacteria invade the pleura a variety of inflam- 
matory reactions may occur. Thus we may have a "dry pleurisy." In this form of inflammation the passage of the defending leukocytes is accompanied by the exudation of large amounts of fibrin, as though nature deliberately intended to glue the two opposing pleural surfaces together. Or we may have a "pleurisy with effusion," in which the number of defending leukocytes which pass out of the blood-vessels is relatively small, while the quantity of blood-serum which passes out is enormous. One cannot help thinking that this is intended to dilute the irritant which has caused the inflammation. Finally, we meet with cases in which both the number of leukocytes and the amount of serum are large, forming really a thick pus. This form of pleurisy constitutes an "empyema."

In some instances, as in the case of the staphylococcus boil described above, the bacterium itself invades the tissues and constitutes the irritant which gives rise to the inflammation. In other cases the inflammation is produced mainly by poisons given off by the bacteria. The latter is well seen in diphtheria, where the bacilli remain on the tonsil and the poison (diphtheria toxin) causes inflammatory changes in various parts of the body.

In case the inflammation is slight, both the serum and the leukocytes which have passed out of the blood-ressels may re-enter the circulation. When the cells are more numerous they may first undergo a kind of digestion and then be absorbed by certain scavenger cells of the body.

When pus is formed it usually works its way to the surface and is discharged either through external openings or into cavities of the body. 
Injured tissue cells may recover if the inflammation is not severe, or they may soften, break down, and be removed.

When the body has actually been destroyed as the result of an inflammation, we find that there is almost always the formation of connective tissue to take the place of that destroyed. This constitutes what is subsequently known as a scar. 


\section{CHAPTER IX}

\section{THE TRANSMISSION OF INFECTIOUS DISEASES}

UNTIL recently no theory has been more generally accepted, both by the medical profession and the public at large, than that infectious diseases are commonly transmitted by clothing, baggage, money, rags, and innumerable other articles, which are supposed to convey pathogenic organisms in their active state from one person to another. These alleged agents are known as "fomites." Since the discoveries of Pasteur and Koch, and particularly during the past ten or fifteen years, practical sanitarians have been slowly but surely accumulating conclusive evidence of the fallacy of the fomites theory. Not so long ago malaria was attributed to the presence of "miasma," or poisonous vapors emanating from swamps; now we know that this disease is transmitted from man to man through the bite of a mosquito. Up to within a few years, yellow fever was held to be transmitted by "fomites," and the medical history of the South is rich in statistics which presume to offer conclusive proof that the clothing of those who had been exposed to yellow fever was responsible, at various times, for outbreaks of this disease. Yet we now know that yellow fever is transmitted only through the bite of a particular species of mosquito. Satisfactory evidence has been given us that plague, which was believed to be caused by almost anything in tie nature of "fomites," 
is conveyed to man by the rat, through the medium of fleas which infest these animals. A few years ago it would have been difficult to find a text-book which did not in positive terms state that typhus fever is transmitted by clothing, baggage, and other articles. Yet careful investigations, particularly the recent work of Goldberger and Anderson in Mexico, proves that the disease is transmitted by the body louse and not by fomites. With regard to two common diseases of childhood, namely, measles and scarlet fever, public health authorities are coming more and more to believe- that desquamation of the skin is a negligible factor, and that these diseases are conveyed from person to person by the infected discharge of the mucous membrane involved.

It is only within comparatively recent years that we have appreciated the importance and danger of mild, ambulant, or irregular cases of infectious diseases, and the frequency with which they occur. They are undoubtedly one of the most common and dangerous factors in the transmission of infection because they often pass unrecognized. More recently we have learned of "carriers," or persons who, while themselves well, harbor the specific micro-organism, and may transmit it to others. These undoubtedly play an important rôle in the spread of infectious diseases.

All these observations have served to discredit the fomites theory, and, while there is no doubt that in some rare instances clothing, rags, books and toys, etc., may act as a medium of infection, we should devote our attention principally to the usual or common means of infection. The knowledge we now possess on this subject proves that infectious diseases are transmitted by 
persons rather than by things-by contact with others, by certain discharges of those who are infected, and by insects and vermin.

\section{TERMinAL FUMigation}

The question which at once arises is as to the need of terminal room fumigation in infectious diseases. If such diseases are not carried by fomites, why go to all the trouble of room fumigation? As a matter of fact, a number of progressive health departments have discontinued most of the terminal fumigations formerly done after contagious diseases. Among these may be mentioned the health departments of Providence, New York City, Boston, and Milwaukee. In New York a very interesting experiment was conducted in 1914 and 1915, fumigation being discontinued in some of the boroughs and continued in the others. No increase in the prevalence of the contagious disease followed the discontinuance of terminal fumigation. It should be understood, however, that in discontinuing fumigation, increased stress is laid on other and more efficient methods of disinfection, namely, thorough cleaning, fresh air and sunlight, and particularly renovation (i.e., repainting and repapering) when necessary. Noreover, the reader must bear in mind that fumigation is still necessary in such diseases as typhus (to kill vermin), yellow fever (to kill mosquitoes), and plague (to kill rats).

\section{INSECTS AS CARRIERS OF INFECTIOUS DISEASES}

Before leaving this subject, it will be well to devote a little attention to the rôle played by insects and vermin in the transmission of infectious diseases. This rôle may 
be non-specific (merely mechanical) or specific. Thus, when typhoid bacilli are carried by flies from some infected feces to a pitcher of milk, the transmission is merely a mechanical transfer of the bacilli on the fly's legs and proboscis. It does not matter what species of fly is concerned; in fact, it nead not be a fly at all, but some other insect. The transmission of plague from infected rats to man is probably of this kind, and, as far as our present knowledge goes, so is the transmission of typhus fever and trench fever by lice.

Quite different are the circumstances governing the specific transmission. Common examples of these are malaria, yellow fever, and sleeping sickness. When malaria is carried from one person to another by the mosquito it is found that this is always a mosquito of the species Anopheles. The ordinary Culex mosquito is unable to effect the transmission. In malaria, as we have already seen, the tiny parasite sucked up in the patient's blood by the biting mosquito undergoes certain characteristic changes, and it is only after these changes have been completed that the mosquito is able to infect another person. But for some unknown reason these changes occur only in the stomach of Anopheles and not in other species of mosquitos. In yellow fever and sleeping-sickness conditions are entirely analogous, in the former a species of mosquito known as Aëdes is required, and in the latter a species of biting fly know as "tsetse fly" effects the transmission.

The following is a partial list of insects which carry disease:

Yellow fever mosquito (Aëdes calopus), formerly called Stegomyia calopus. 
Malaria mosquito (Anopheles maculipennis).

House fly (Musca domestica) may carry organisms of typhoid fever, cholera, and other diseases.

Tsetse fly (Glossina palpalis) transmits sleeping-sickness. Tick (Dermacentor andersoni) transmits Rocky Mountain spotted fever.

Tick (Margaropus anmulatus) transmits Texas fever.

Stable fly (Stomoxys calcitrans) may transmit infantile paralysis (poliomyelitis).

Flea (Xenopsylla cheopis), a carrier of bubonic plague.

Body louse (Pediculus vestimenti) transmits typhus fever and trench fever.

Bedbug (Cimex lectularius) transmits relapsing fever.

So far as the nurse is concerned, the above facts call for careful attention to flies, mosquitoes, fleas, bedbugs, lice, and other vermin about every case of infectious disease. 


\section{CHAPTER X}

\section{QUARANTINE IN THE CONTROL OF INFECTIOUS DISEASES}

QUARANTINE, or isolation, as a method of controlling the spread of infectious diseases dates from the efforts made by Venice in 1403 to check the spread of the dreaded "Black Death." All passengers arriving on ships at the port of Venice were isolated in a special hospital situated on a small island adjoining the city. Here they were kept for forty days before being allowed to enter the city. This, then, is the origin of the term "quarantine," quadrayinta meaning forty. With increasing knowledge of the transmission of infectious diseases there has come a change in our methods of dealing with the spread of these diseases, and this has markedly affected the duration of the period of isolation enforced by health authorities.

To a large extent the minimum period of enforced isolation has been arrived at as the result of bacteriologic investigations and animal experimentation. In addition to this we are guided by disappearance of fever, freedom from crusts or scabs, and the absence of catarrhal or suppurative processes.

The period of isolation required in different diseases varies considerably in different cities. In describing conditions as they prevail in New York City at the present time, therefore, we aim merely to give the student a general idea of the considerations which guide health officials in their action. 
A patient ill with diphtheria in New York City must be kept isolated for at least two weeks, and even then the patient may not be discharged until after two consecutive negative cultures have been obtained from both nose and throat.

In contrast to this logical termination of isolation in diphtheria by means of cultures, the period of isolation in scarlet fever is very nearly arbitrary. In New York City isolation is maintained until at least thirty days from the appearance of the rash. Desquamation is no longer held to be of any special significance in the conveyance of infection. Suppurative processes, on the other hand, are more seriously regarded and often serve to confine the patient for several weeks beyond the period named. It is possible that the recent observations of Mallory (page 122) will furnish a more definite basis for fixing the duration of isolation necessary in this disease.

In measles the patient may be released from isolation and allowed to return to school five days after the appearance of the rash. Formerly the period of isolation was much longer, but experiments on nonkeys by Anderson and Goldberger showed that five days was sufficient. To be sure, this applies only to patients who are free from serious catarrhal or pneumonic complications.

In typhoid fever there is no fixed time limit to the period of isolation. Stool examinations for typhoid bacilli should be made after the patient's temperature has been normal for at least ten days. In the case of food handlers (cooks, waiters, dairymen, etc.) return to work is prohibited so long as the stools contain typhoid bacilli. Accordingly, at least two consecutive stool examinations made a week apart should fail to show typhoid bacilli 
before such an individual may be allowed to return to his work.

In smallpox the patient is invariably removed to the isolation hospital of the Department of Health. Isolation is maintained until all scabs have disappeared, including the deep-seated "seeds" beneath the epidermis of the soles of the feet.

In epidemic cerebrospinal meningitis isolation is maintained for fourteen days, for it has been found that meningococci in the nasopharynx of convalescents are very rare after the twelfth or fourteenth day. Whenerer facilities permit healthy contact carriers should be sought out and isolated.

In acute anterior poliomyelitis (infantile paralysis) the minimum period of quarantine is six weeks, a period fixed largely as the result of experimental work on animals.

In yellow ferer it is now well established that the patient's blood remains infective about three days. Moreover, after having been bitten by an infected mosquito it requires about five days for symptoms to develop. (See also page 133.) Isolation, therefore, is relatively short and amounts, moreover, only to screening the-patient from mosquitoes.

In typhus fever recent work would indicate that isolation need not be maintained for much besond the return of the fever to normal. Inasmuch as the disease is spread by lice, care should be taken to destroy all lice by thorough washing of the patient and disinfection of his clothing and other belongings.

In cholera the termination of isolation rests solely on the result of the bacteriologic examination of the stools. A minimum requirement is two consecutive negative stools taken at intervals of five days after convalescence is complete. 
In whooping-cough a more definite routine is now being developed, for the disease is believed to be transmitted mainly in the early days. The whooping-cough bacilli are scarcely found after the second week, so that isolation may be relaxed two weeks after the onset of the spasmodic cough. Nevertheless, when taken out, the child should be kept strictly away from other children until the spasmodic cough has entirely disappeared.

In German measles isolation is usually fixed at one week, in mumps (parotitis) until all swelling is gone, and in chickenpox (varicella) until all the scabs are off. 


\section{CHAPTER XI}

\section{IMMUNITY}

IT is well known that certain infectious diseases occur naturally only among some of the lower animals, and do not affect man; while, conversely; others appear to attack only man. Among the latter may be mentioned typhoid fever, syphilis, gonorrhea. In speaking of the resistance evidently possessed by certain individuals or certain species, we make use of the term natural immunity. Thus, chickens and frogs possess a natural immunity against tetanus (lock-jaw); dogs, a natural immunity against anthrax; goats, a natural immunity against tuberculosis, and man, a natural immunity against certain diseases of cattle. This natural immunity, however, is not absolute. Chickens, for example, can be infected with tetanus if the body is chilled, and frogs can be made susceptible to tetanus by keeping them unduly warm.

Another form of immunity is that observed in individuals who have had one attack of a particular infection; thereafter they are practically safe from a second attack. These individuals are said to possess an acquired immunity. This form of immunity is well illustrated in scarlet fever, measles, small-pox, yellow fever. Often this immunity lasts throughout the lifetime of the individual, though there are exceptions. 
In - studying this acquired immunity, Pasteur, a French scientist who lived 1822 to 1895 , conceived the idea of artificially producing an attack of a given infection in order to protect the individual against another attack. He realized that it was necessary, however, to so control matters that the original attack should run a very mild course and not endanger the life of the individual. After considerable experimental labor, Pasteur found that this could be accomplished by artificially weakening the bacteria with which the original attack of the disease was produced. Subsequently Salmon and Smith, in this country, showed that it was not necessary to produce even a mild attack of the disease by the injection of living bacteria, but that the injection of dead bacteria would produce an immunity against that particular infection.

Acquired immunity, whether caused by a previous natural attack of the disease, or artificially by the inoculation of bacteria, is always strictly specfic, that is, the protection extends only to the particular disease which has previously occurred or whose germs have previously been injected. An attack of scarlet fever protects only against scarlet fever, but not against measles. Inoculating an individual with typhoid bacilli protects him only against typhoid fever, but not against dysentery, plague, cholera, etc. This acquired immunity is often transmitted from mother to offspring, transmission being effected mainly, according to Famulener, through the colostrum. This shows the importance of placing baby to the mother's breast soon after birth.

Before examining into the nature of this very specific form of immunity, it will be well to call attention to 
certain important means by which the body defends itself against bacterial invasion in general. Many of these are so commonplace that their significance is often overlooked:

(1) The protection afforded to the body by the unbroken skin is undoubtedly one of the most important means of defence. It is well to remember this, and especially to bear in mind that we say "unbroken" skin. In the sterilization of the skin prior to a surgical operation a great deal of harm is sometimes done by too vigorous scrubbing or the application of too concentrated disinfectants.

(2) A similar protection, though less powerful, is afforded by intact and healthy mucous membranes. Any condition injuriously affecting these renders the body more liable to bacterial invasion. This is well illustrated by the frequency with which an attack of measles (which affects the mucous membranes to a marked degree) is the starting-point of other and more serious infections.

(3) The acid gastric juice undoubtedly destroys large numbers of bacteria which are swallowed. Disorders of digestion may, therefore, constitute the deciding factor in determining a bacterial invasion, especially of the intestinal tract.

(4) It has been found that fresh blood-serum is able to kill a considerable number of bacteria, and this, therefore, constitutes another mode of defence against bacterial invasion.

(5) The white blooci-cells, or leukocytes, as they are called, appear to be designed especially to destroy in- 
vading bacteria. These cells take hold of, or rather engulf, the bacteria and digest them. ${ }^{1}$

(6) Still another mode of defence is seen in what takes place in abscesses. When these are examined, it is found that the body has built a wall around the infected area, thus shutting off the bacteria and their poisonous products from the rest of the body.

Returning now to the mechanism of the specific acquired immunity discussed above, we find that, in response to the invasion by pathogenic bacteria, the body manufactures certain specific substances designed to destroy the invaders or to neutralize their poisonous products.

These antagonistic substances are spolien of as antibodies. The important artibodies thus far known are as follows:

(1) Antitoxins.

(2) Bacteriolysins, hemolysins (cytolysins).

(3) Agglutinins.

(4) Opsonins.

(5) Precipitins.

(6) Antiferments.

Antitoxins.-When an animal is injected with gradually increasing doses of toxin-e. g., with diphtheria toxin-it will be found that after a time the animal withstands doses of the poison which would suffice to kill hundreds of animals not so treated. This was done in 1890 by von Behring, who found that the blood of the treated animals contained something which neutralized

${ }^{1}$ Certain substances, such as alcohol, also exposure to cold, make the leukocytes sluggish, so that drunkeness on the part of an individual or exposure to cold often lead to bacterial invasion. 
the diphtheria poison and rendered it harmless. It was natural to see whether this blood-serum could be used to treat other animals which had previously been injected with diphtheria poison, and on doing this von Behring found that the serum thus used was able to save the animals from death. The action of the substance in the serum which counteracted the effect of the poison was found to be exactly like that of an alkali on an acid, $i$. e., it neutralized the poison. It was, therefore, called an antitoxin, meaning against toxin. The antitoxic serum from an animal treated with toxin does not differ in appearance from that of a normal untreated animal. And even when tested chemically, but little difference can be discovered between the two. In order, therefore, to recognize the presence of this antitoxin in the serum, and especially in order to measure its amount, we must test it in animals, and see how small a quantity of antitoxic serum will save an animal after injection with a certain amount of diphtheria toxin. When guinea-pigs are used for the test, it may be found that $\frac{1}{1000} \mathrm{~cm}$. of the antitoxic serum will often be sufficient to save the animal from death, even after it has been injected with ten fatal doses of the diphtheria toxin! Sometimes, in fact, as little as $\frac{1}{5000} \mathrm{~cm}$. suffices. The strength of the antitoxic serum is, therefore, expressed in units. In the examples just cited the serum would be said to have a strength of 100 or of 500 units respectively.

Bacteriolysins.-Just as when an animal injected with gradually increasing doses of toxin produces an antitoxin in its blood, so also, when injected with bacteria, it produces substances which kill and dissolve 
the injected micro-organisms. We have already said that fresh blood-serum is able to kill a considerable number of bacteria; when injected with gradually increasing amounts of bacteria, however, this destructive power increases enormously, but only for the particular kind of bacterium used for injection. Thus, if an animal is injected with typhoid bacilli the serum will, after a time, kill enormous numbers of typhoid bacilli, even in very small doses; tested against cholera bacilli, or any other bacteria, its destructive effect is merely that of normal serum from an untreated animal. When the action of the serum on the bacteria is studied under the microscope it is seen that the bacteria are actually dissolved. Hence, such a serum is spoken of as a "bacteriolysin," which means bacteria dissolving. Since the bacteria are killed by this action, we alsc speak of the serum as being "bactericidal," which means bacteria killing.

It has been found that this action of the serum may be developed against other cells than bacteria. When red blood-cells are used the serum acquires dissolving properties for these; and here, again, the action is strictly specific, so that when blood-cells from a chicken are injected into an animal the serum of the injected animal acquires increased solvent powers only for chicken blood-cells, but not for blood-cells of other animals. Instead of using the word bacteriolysin, we speak of such a serum as a hemolysin, meaning blood dissolving.

The term "cytolysin" is used to embrace all these dissolving sera, "cyto" signifying cell; hence, cell dissolving.

Investigation showed that the mode of action of these 
dissolving scra was somewhat complex and required the joint action of two different constituents. One of these constituents decomposes very easily, so that a serum which has stood several days may be found to have almost entirely lost its solvent power. Curiously, however, the addition of a little fresh serum, even from a normal animal, immediately restores its power. This very unstable constituent, which is present in all serum, even in serum from normal animals, is spoken of as complement, because it completes or complements the action of the other constituent. The stable constituent is called the amboreptor or the immune body.

IThen the animal is repeatedly injected with gradually increasing doses of bacteria (or other cells), it responds by manufacturing large quantities of this amboceptor or immune body, directed specifically against the injected bacteria. This substance lays hold of the invading bacteria, and, with the aid of the complement, effects their destruction. The complement alone would be unable to destroy the bacteria; the amboceptor is needed to prepare the bacteria in some way as yet unknown.

Agglutinins.- When the serum of an animal which has been repeatedly injected with gradually increasing doses of bacteria is brought into contact with some of these bacteria, careful observation under a microscope reveals a very interesting series of changes. Thus, if typhoid bacilli are mixed with a specific antityphoid scrum (obtained, say, from a rabbit previously injected with typhoid bacilli), one notices first that the motility of the bacilli becomes markedly diminished. This is followed by the gradual collection of the bacilli into clumps. At the end of an hour or two, in place of countless bac- 
teria moving quickly through the field, one sees merely several groups of absolutely immobile bacilli. If the reaction is feeble, the clumps are small, and one finds comparatively many isolated and perhaps also moving bacteria. This phenomenon is spoken of as agglutination, and the substance in the serum which brings it about as agglutinin. The clumping thus brought about does not kill the bacteria; moreover, it makes no difference whether the serum is freshly drawn or has been kept for some time, it will agglutinate equally well, and does not require the addition of fresh serum as do the bacteriolysins.

Like the antitoxins and the bacteriolysin, the agglutinins are strictly specific, $i$. $e$., a serum from an animal injected previously. with typhoid bacilli will agglutinate only typhoid bacilli; one from an animal injected with cholera bacilli will agglutinate only cholera bacilli, etc.

Since the agglutinins do not kill the bacteria, it may be asked what their function is. Up to the present time we do not know. Through the studies of Gruber and of Widal, however, the agglutinins have come to play a prominent part in the diagnosis of bacterial infections, and, in what is called the Widal reaction, afford an important aid in diagnosing typhoid fever. The Widal test in typhoid fever may be performed with blood-serum from the patient or, still simpler, with a drop of blood collected on a glass slide and allowed to dry. If the latter method is employed, the drop is soaked off with sufficient distilled water to make approximately a dilution containing 1 part of blood in 20 of the mixture. Next, a loopful of this mixture is mixed with a loopful 
of a broth culture of typhoid bacilli, and this mixture of diluted blood and typhoid culture then examined by

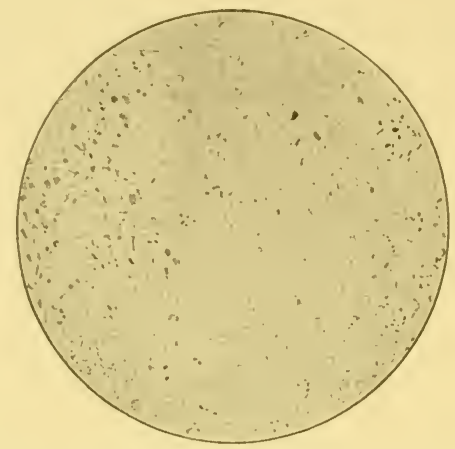

Fig. 23.-Typhoid bacilli unagglutinated (Jordan).

means of the hanging-drop method under the microscope. If complete agglutination takes place within

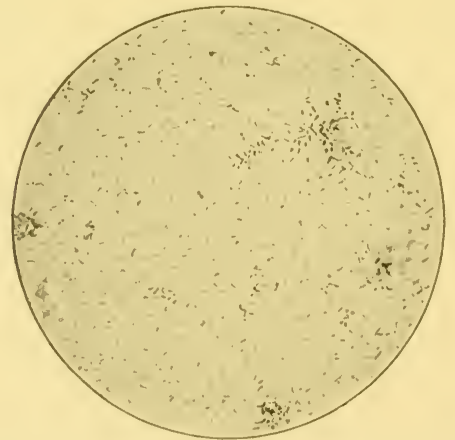

Fig. 24.-Typhoid bacilli partially agglutinated (Jordan).

twenty to thirty minutes, one speaks of having obtained a positive Widal reaction. This means that the patient 
is suffering from typhoid fever or has recently had the disease, for the serum continues to show the reaction for some time after convalescence.

Agglutination reactions may also be employed in a reverse manner for identifying bactcria. In that case, one employs an agglutinating serum made against a certain bacterium and tests the bacterium one is studying. If it agglutinates with this serum, one argues that it is identical with, or at least very closely related to, the bacterium used for making the serum.

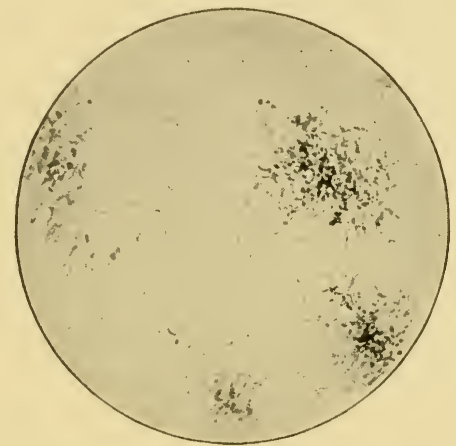

Fig. 25.-Typhoid bacilli, showing typic clumping by typhoid serum (Jordan).

Opsonins.-We have already said that the white blood-corpuscles-i.e., the leukocytes-take up bacteria and destroy them. Sir Almroth Wright, a distinguished English physician, discovered that certain substances present in blood-serum had the power of increasing the appetite, as it were, of the leukocytes, and, furthermore, that the amount of these substances could be increased by properly administered injections of the appropriate bacteria. These substances he called 
opsonins. They are specific, just as are the antitoxins, the bacteriolysins, and the agglutinins; that is to say, when the body is injected with typhoid bacilli; only the opsonic power for typhoid bacilli is affected; when staphylococcus pyogenes is employed, only the opsonic power for this germ is affected; when pneumococci are injected, only the opsonic power for pneunococci is affected. Wright devised a slecial technic for measuring the amount of opsonin present in a serum, and expressed this in what he calls the opsonic inclex. This is merely the opsonic power of the patient's serum, as compared with the opsonic power of several known normal sera, using the same leukocytes and the same bacteria in the one test. Although Wright believes that this opsonic index is essential in the bacterial vaccine treatment of infections, most other observers have failed to find the index of any real help).

Precipitins and Other Antibodies.- IVe have seen above that the injection into the animal body of bacteria or other cells is followed by the production of a number of different antibodies. If, instear of injecting bacteria, we inject solutions of albuminous material, for example, inject a rabbit with chicken egg-albumin (white of $\mathrm{egg}$ ), we shall find that the rabbit's serum arcquires the power to produce a precipitate when mixed with chicken egg-albumin. This action is highly specific, so that if the serum is tested against albumin from any other animal-e.g., from a duck-no precipitate will be produced. If a rabbit is injected with human blood (which, of course, is really an albuminous solution) the rabbit serum will produce a precipitate when mixed with human blood, but not when mixed with any other blood. 
The antibodies concerned in this reaction are called precipitins. The precipitin test is now made use of in criminal cases where it is necessary to determine whether certain blood-stains are from human blood or otherwise. This reaction may also be used to determine whether sausage contains any horse meat. In addition to the foregoing, still other antibodies are known. When ferments are injected into an animal, the latter responds by producing antiferments. When certain antibodies are injected, anti-antibodies are produced. The entire subject is extremely complex, and further discussion in such a work as this is out of place.

Anaphylaxis. - When albuminous substances are taken into the body through the mouth, that is, into the stomach and intestines, they are acted on by certain ferments, digested, and serve as body nourishment. When, however, they are introduced through other channels-e. g., by means of hypodermic, intramuscular, or intravenous injection-they cause the production of antibodies as was described above. Some of these antibodies appear to have digesting properties; at least they split up the injected material, evidently so that the body may get rid of it. Recent studies have shown that this non-intestinal splitting up of albuminous substances may give rise to serious symptoms, and that the rashes sometimes following the injection of diphtheria antitoxin are due to this cause. It has been found that such rashes are more likely to follow second injections. In experimenting with guinea-pigs it is possible to so arrange matters that the second injection will prove fatal. This phenomenon is spoken of as anaphylaxis. 


\section{SERUM AND VACCINE THERAPY}

The principles underlying the production of diphtheria antitoxin have already been described. Injected into a patient suffering from diphtheria, the antitoxin at once lays hold of the toxin which the diphtheria bacilli are producing and quickly restores the patient to health. The great convenience in the use of diphtheria antitoxin lies in the fact that we can get a horse to produce it for us, and then by bleeding the animal, collecting the serum, and injecting this serum into man, can confer immunity against diphtheria on the person so injected. We speak of this kind of immunity as passive immunity, because the man's body has taken no active part in the production of the protective substance, the antitoxin. It is, of course, plain that the antitoxin can merely ward off from the cells of the body the toxin which is threatening them; the toxin which has already begun to act on the cells cannot be neutralized by the antitoxin. In every case of diphtheria, therefore, it is most important to give the full dose of antitoxin as early as possible, and to give a small dose also to all who have been or expect to be in direct contact with the patient.

In the case of tetanus antitoxin the clinical results have not been as striking as with diphtheria antitoxin. Its use in the form of preventive injections has undoubtedly saved many lives. Moreover, if injected intraspinally, tetanus antitoxin is very useful in the treatment of tetanus. In the past, when the serum was administered intravenously, the therapeutic results were very poor. One reason why the serum often fails in the treatment of developed cases of tetanus is because the diagnosis 
cannot possibly be made until after the toxin has had abundant time to combine with the body cells. In the treatment of epidemic cerebrospinal meningitis spinal injections of specific antimeningococcus serum have reduced the mortality to about one-half that of cases not so treated.

So far as the bacteriolysins are concerned the clinical results have not been very satisfactory. Investigation has disclosed many difficulties which must still be overcome. In speaking of these sera it is better to use the term "antibacterial," because, after all, when we immunize an animal against a certain bacterium we do not produce merely a bacteriolysin, but a serum which contains also agglutinins, precipitins, opsonins, and, perhaps, still other antibodies.

Because of the non-success attending the use of the antibacterial sera, attention has been turned to treatment of bacterial infections by means of active immunization. Thus, when we inject a horse with diphtheria toxin in order to produce antitoxin we actively immunize; when we inject the antitoxin into a child in order to protect the child against diphtheria we passively immunize. (See page 99.)

Bacterial Vaccines.-Active immunization consists usually in injecting the patient with dead bacteria, thus causing the production on his part of the various antibodies already described, and thus bringing about a condition of immunity. The bacteria are usually grown on agar, in the ordinary way, and, after being washed off into a test-tube containing a little salt solution, are heated for about half an hour to $60^{\circ} \mathrm{C}$. in order to kill all the bacteria. Sterility is insured by suitable tests. The suspen- 
sion is then diluted so that each cubic centimeter will contain exactly a certain number of million bacteria, after which it is ready for injection. Such a suspension is spoken of as a "bacterial vaccine." The doses of the different vaccines vary. In the case of staphylococcus vaccine the ordinary dose is from $250,000,000$ to 500,000 ,000. Gonococci are usually given in much smaller doses, namely, from $15,000,000$ to $50,000,000$. The dose of typhoid raccine is from $500,000,000$ to $1,000,000,000$. The vaccines are usually given in several doses, injections being made from five days to a week apart.

Lipo-vaccines.-A lipo-vaccine is one in which the bacteria are suspended not in saline solution, but in an oil. By this means absorption is made slower, there is less reaction, and massive doses can be given at one injection. Such a lipo-raccine was first devised by French scientists for triple vaccire (typhoid, paratyphoid a, and paratyphoid b) and has since been adapted by the L. S. Army medical authorities to a wide variety of vaccines.

At the present time treatment either by specific sera or by bacterial or other vaccines is employed in-

Diphtheria.-Antitoxic serum therapeutically. Serum or toxin injections for immunization.

Tetanus.-Antitoxic serum, both therapeutically and for immunization.

Epidemic Cerebrospinal Meningitis.-Specific serum therapeutically. Vaccines have been used for immunization.

Typhoid Fever.-Vaccines for immunization. Neither serum nor vaccines of use therapeutically.

Cholera. -Specific serum has been used therapeutically; results indifferent. Vaccines used for immunization. 
Plague.- - Taccines have been tried for immunization.

Tuberculosis.- Neither therapeutically nor for immunization have either serum or vaccine vielded satisfactory results.

Pneumonia.-Serum therapeutically has apparently been of value in certain types of cases. Vaccines have not vielded satisfactory results.

Streptococcus Infections.-Therapeutic results either with serum or vaccines have been unsatisfactory.

Gonococcus Infections.- Vaccines, therapeutically, useful in certain types of infection. (See page 118.)

Boils and Other Staphylococcus Infections.-Vaccines, therapeutically, have been of value in certain cases.

Whooping-cough.- Vaccines are now being tried therapeutically. Results somewhat encouraging.

Rabies.-Pasteur's method of treatment by vaccines is undoubtedly of great value. The vaccine consists of an emulsion in salt solution of spinal cord from a rabbit dead of artificially inoculated rabies. The cord is dried for varying periods and the injections are made daily, beginning with a cord dried fourteen days and changing to a stronger cord (dried less), so that finally the injected material consists of a cord dried only three days.

Influenza.-Neither serum nor vaccines have given satis. factory results either therapeutically or for immunization. 



\section{SPECIAL BACTERIOLOGY}

\section{CHAPTER XII}

\section{TYPHOID FEVER}

The typhoid bacillus was discovered in 1880 by Eberth. It is a motile bacillus about $\frac{1}{10,000}$ inch long and $\frac{1}{40,0 \times 0}$ inch thick. It decolorizes when stained according to Gram's method, and does not produce spores. Typhoid bacilli grow readily on the ordinary laboratory media, even at room temperature. They do not ferment lactose (milk-sugar), so that when grown in litmus milk or on lactose litmus agar they do not change the color of the medium.

Typhoid fever is due essentially to the invasion of the body by typhoid bacilli which lodge in certain parts of the wall of the small intestine, causing ulceration of that organ and very severe constitutional symptoms.

A curious feature of the disease is the development, about the sixth or seventh day of the fever, of small rosecolored spots on the patient's trunk, usually on the abdomen and on the lower part of the back.

In typhoid fever the bacilli are found chiefly in certain parts of the wall of the small intestine and in the intestinal contents. In early stages of the disease they are also found in the blood, and they are also present in the rose spots already mentioned. In the wall of the intestine 
they cause ulceration, and this frequently involves the blood-ressels, giving rise to severe hemorrhages. Sometimes the ulceration passes entirely through the intestinal wall, and this is called a perforation. With the escape of fecal matter into the peritoneal cavity comes the development of peritonitis. In many cases the typhoid bacilli are found not only in the feces but also in the urine. This is important to remember in guarding against infection of others.

In the country, where privies and cesspools are common, it often happens that typhoid stools insufficiently disinfected find their way into a well, spring, or stream, and so lead to the infection of others. In summer, when flies abound, it sometimes happens that flies carry infected material from such a privy directly into the kitchen, and deposit typhoid bacilli on the food standing about. If a pitcher of milk thus becomes infected, the bacilli at once thrive and multiply so that in a very short time the milk contains enormous numbers of typhoid bacilli. Some infections have been traced to the washing of dairy utensils - cans, etc.-in typhoidinfected water. Other cases have been caused by unrecognized mild cases, especially when the latter had something to do with the handling of food. In the city a large number of cases are undoubtedly due to quite direct infection from a previous case. It is now well established that oysters taken from beds polluted with sewage may carry typhoid infection. This is more apt to happen with oysters which have been "fattened" in sewage-polluted water. It is advisable, therefore, to eat no oysters which have been "fattened"; the lean, gray oyster is always to be preferred. When a patient re- 
covers from typhoid fever the bacilli usually disappear from the feces, but in about 5 per cent. of the cases the patients continue to harbor bacilli in their typhoid feces although they themselves are perfectly well. Such persons are spoken of as "bacillus carriers," and constitute a very difficult feature of the typhoid problem. The author has traced a number of epidemics of typhoid fever to dairymen who were such bacillus carriers.

From what has been said it follows that great care must be taken to properly disinfect the discharges, both urine and feces, of all persons having typhoid fever. Moreover, this should include all those cases of fever in which the presence of a typhoid infection is possible, even though the diagnosis is not ret positively established. Many a case of obscure fever, rumning a mild course, and therefore dismissed as of no consequence, has subsequently been found to have been typhoid fever, and resulted in the infection of other's because no typhoid precautions were taken. Chloric of lime is one of the most efficient disinfectants for the stools, but, like all disinfectants, it should be used freely, and in such a way that the disinfectant will really remain in contact with the feces for a sufficient time. If the masses of feces are hard, a constipated stool, it is important to break them up with a stick and mix them thoroughly with the disinfectant. Ordinarily it is well to keep the disinfectant in contact with the stool in the vessel for about an hour before emptying the vessel. In the city the stool can then be poured into the closet; in the country, where there is merely a shallow earth closet, it is advisable to bury the stools. The underclothing, night clothes, handkerchiefs, towels, 
etc., of the patient, as well as the bed-linen, must be carefully disinfected before it is given out to be laundered. Disinfection of these articles is accomplished by soaking them for some hours in earbolic aeid solution of from 2 to 5 per cent. Bichlorid of mereury solution, 1:5000, can also be similarly used. Very useful in deodorizing and disinfecting stools is the solution of chlorids put up by many druggists. For the purposes of at once disinfecting the hands after handling the patient, the nurse should have standing near the bed a basin containing either 5 per cent. carbolic acid solution, or 1:1000 bichlorid of mercury, or some other convenient hand disinfectant of similar strength. In this more than in any other infectious disease it is important to keep flies out of the sick room.

When typhoid bacilli are examined under the microscope in a drop of sterile bouillon they will be found to be uniformly scattered throughout the drop and in active motion. When to such a drop a little blood from a typhoia patient is added the bacilli at once begin to gather together in clumps and cease their movements. Blood from a normal person has no such effect. This reaction is very valuable for diagnosis, and is known as the "Widal test" for typhoid fever. It has been found that blood from a typhoid patient can be diluted from twenty to forty times or more, and still produce this peculiar clumping effect; in some eases, in fact, diluting the blood several thousand times still permits the reaction to take place. The collection of the blood for the test is a very simple matter, as a couple of drops of blood dried on a glass slicle suffice. It is important, however, to let the blood dry spontaneously, and not attempt to hasten the drying by heat. 
Thanks largely to the work of Wright, much has been done to prevent infection with typhoid bacilli by protecting the individual through antityphoid vaccination. For this purpose a bacterial raccine is used, the typhoid bacilli being very carefully killed by heat. The vaccination should consist of three injections a week apart. The first one contains 500,000,000 bacilli, and the second and third each 1,000,000,000. When lipo-vaccines are used a massive dose is giren in a single injection, not repeated.

The results of such protective antityphoid vaccinations have been excellent; very few cases of typhoid fever develop among those so vaccinated, and the cases that do occur usually run a milder course.

Treatment of developed cases of typhoid fever by means of these raccines or by specific sera has proved to be without value.

Inasmuch as experience has shown that now and then infections resembling typhoid fever are due to paratyphoid bacilli, protective inoculation is sometimes practised with a so-called "triple vaccine" consisting of typhoid bacilli, paratyphoid bacilli type $\mathrm{A}$, and paratyphoid bacilli type $B$. As a rule the reactions from triple vaccine are more severe than from the ordinary typhoid vaccine. 


\section{CIIAPTER XIII \\ DYSENTERY - CHOLERA}

\section{DYSENTERY}

The dysentery bacillus was discovered by Shiga in Japan, and by Flexner in the Philippines. It is a Ciram-negative, non-motile bacillus, somewhat smaller than the typhoid bacillus. Two main varieties are encountered, those which ferment mannite (a kind of sugar) and those which do not.

Acute dysentery, in this climate, is usually due to the dysentery bacillus or some closely related variety. In tropical countries a form of chronic dysentery is due to organisms called amebre, and it is, therefore, customary to speak of "bacillary dysentery" and "amebic dysentery." The usual summer diarrheas, however, are not due to dysentery bacilli.

Like typhoid fever, bacillary dysentery is due to the swallowing of bacilli.which have come from the fecal discharges of another person. Sometimes these bacilli are carried quite directly, sometimes indirectly, on food and drink. Occasionally the germs are carried by fies.

Bacillary dysentery affects especially the mucous membrane of the large intestine. In mild eases only the superficial portion is involved, but in severe cases deep ulceration may occur. The stools are at first fecal, but soon become nothing but mucus and serum. The mucus 
resembles calf's foot jelly in appearance; it is frequently bloody. When the disease is at its height there are from twenty to fifty stools in the twenty-four hours. At this time dysentery bacilli are very abundant in the stools and the superficial layers of the affected mucous membrane. With the return of the fecal stools the bacilli disappear.

The path of infection in dysentery is the same as it is in typhoid fever, $i$. e., by means of infected water, milk, or other food contaminated from the stools of dysentery patients. The means of guarding against infection are, therefore, the same as in typhoid fever. All the stools should be carefully disinfected, one of the best disinfectants for this purpose being chlorid of lime. Careful attention should be paid to soiled cloth-

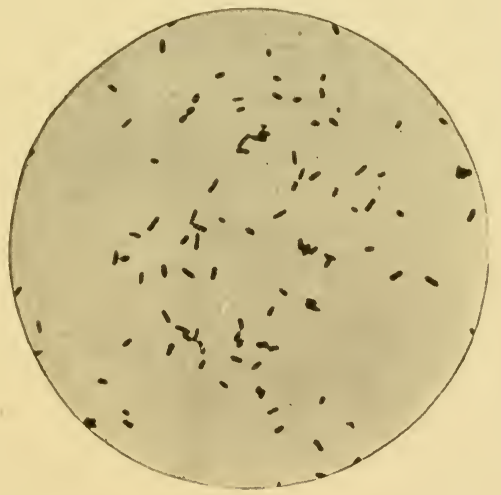

Fig. 26.-Bacillus of dysentery from agar culture. Fuchsin stain (Kolle and Wassermann).

ing and bedding, and, when rectal irrigations have been employed, the irrigation-tube should be disinfected by boiling. 


\section{CHOLERA}

The spirillum of cholera was discovered by Koch in 1SS4, and from its form is often called the "comma bacillus." It grows well on ordinary culture-media, even at room temperature, and when grown on gelatin causes liquefaction of the medium. The cholera spirillum can multiply in water. It is motile, does not produce

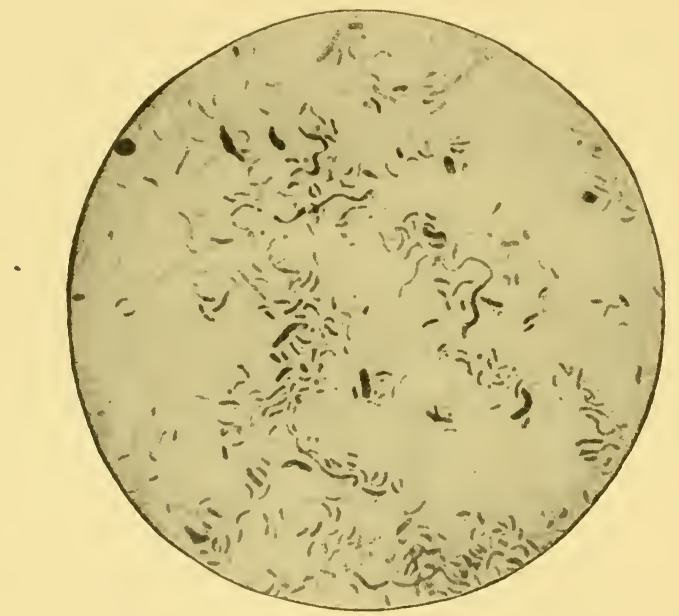

Fig. 27.-Spirillum of Asiatic cholera, from a bouillon culture three weeks old, showing long spirals; $\times 1000$ (Fränkel and Pfeiffer).

spores, and is decolorized when stained according to Gram's method.

Cholera is constantly present in India and other parts of Asia, hence the name "Asiatic cholera." From time to time enormous epidemics of the disease invade Europe, causing thousands of deaths. 
The disease is produced only by swallowing the germs of cholera, and since the germs invariably come only from the intestinal contents of man, it follows that sewage pollution of water, the contamination of milk and food through handling by cholera patients, and food infection through flies constitute the common avenues of infection.

Unlike the typhoid bacillus, the cholera spirillum does not penetrate deep into the wall of the intestine, but produces an intense poison while multiplying in the intestinal contents and in the superficial layers of the intestinal mucous membrane. The absorption of the poison produces the clinical symptoms of the disease. These begin with diarrhea and colicky pain in the abdomen. In a short time the diarrhea becomes intense and profuse and is accompanied by vomiting. Nany of the patients die at this period in a state of collapse. The stools are at first yellowish, but soon become grayish white, and are then termed "rice-water stools." These discharges often contain the cholera spirilla in practically. pure culture. When recovery takes place the stools gradually resume their normal color and the cholera spirilla disappear.

The disease is spread chicfly by contaminated water used for drinking, cooking, and washing. Tegetables washed in infected water, particularly lettuce, cress, and the like, may convey the disease. Wash-women and others who are brought into very close contact with the linen of cholera patients or their stools are prone to contract the disease. Like in typhoid fever, it has recently been found that some healthy persons may carry cholera germs in their stools. These are spoken 
of as "bacilli carriers," and have already been spoken of in connection with typhoid fever.

So far as the prevention of further infection is concerned, the same precautions must be taken as have already been described under Typhoid Fever and under Dysentery. 


\section{CHAPTER XIV}

\section{TUBERCULOSIS}

The bacillus of tuberculosis, also called the tubercle bacillus, was discovered by Koch in 1882 . It is the cause not only of "consumption" (tuberculosis of the lungs), but also of all other forms of tuberculosis, such as tuberculosis of bone (Pott's disease, hip-disease, white swelling, cold abscess), tuberculosis of the intestines, of the peritoneum, of the kidney, of the meninges, of glands (scrofula), etc. The tubercle bacillus is a slender rod, $\frac{1}{10,000}$ inch long and $\frac{1}{75,000}$ inch thick. It is strictly aërobic, grows only on special media, and then but slowly, is not motile, and does not produce spores. It stains with difficulty, but, once stained, resists decolorization with acids. It is, therefore, spoken of as an "acid-fast" bacillus. (See Plate I.)

Tuberculosis is an extremely common discase in man, and causes about one-eighth of all deaths. The disease is also very prevalent among cows, and hence tubercle bacilli are often found in cows' milk. The tubercle bacilli from this source differ somewhat from those found in human pulmonary tuberculosis, and until recently there was considerable controversy regarding the rôle of bovine tuberculosis in the spread of tuberculosis in man. It is now established that while pulmonary tuberculosis is practically always caused by bacilli of human origin, certain other tuberculous in- 
fections, especially in children, are due to milk from infected cows, and that the danger should be guarded against.

In man the most common form of tuberculous infection is that of the lung. In this situation the bacilli set up destructive inflammatory changes, and as a result of these a considerable quantity of sputum is usually coughed up. This sputum is loaded with tubercle bacilli, and is, therefore, highly infectious. During the act of coughing and sneezing tiny particles of infected sputum are scattered into the air and may be inhaled by other persons in the vicinity. Or these infected particles may lodge on the furniture, hangings, floor, etc., in the form of dust, and so again constitute a grave menace to others. In tuberculosis of the intestine (tuberculous enteritis) tubercle bacilli are found in large quantities in the feces, and this source of infection must be guarded against. For that matter, even in ordinary pulmonary tuberculosis tubercle bacilli are usually found in the feces, owing to the fact that the patients swallow some of their sputum.

There is hardly an organ which may not be attacked by the tubercle bacillus. Tuberculosis of the spine, or Pott's disease, is the common cause of hunch-back; tuberculosis of the meninges (tuberculous meningitis) is familiar to us as hydrocephalus or water-on-the-brain, met with in infancy; tuberculosis of the hip-joint is usually called, for short, "hip disease." Other common forms of tuberculous infection are tuberculous peritonitis, tuberculous pleurisy, tuberculosis of the kidney, tuberculosis of the bladder, tuberculosis of the larynx, tuberculosis of the skin, tuberculosis of the eye, tuberculosis of bone, gland tuberculosis, etc. 
As already said, however, tuberculosis of the lung is by far the most frequent form of infection. In seeking to prevent the infection of others, therefore, it is important that the consumptive be carefully instructed to always spit into a vessel containing some disinfectant, or into a paper sputum cup which can be burned each day. In coughing, the scattering about of droplets of sputum should be prevented by holding a paper handkerchief in front of the mouth. The consumptive's room should contain no unnecessary furniture, bric-a-brac, hangings, or other objects likely to catch dust. Remembering that drying and sunlight are potent in the destruction of bacteria, it follows that the maximum of air and sunshine should be provided. Dry sweeping should not be permitted, dust should always be wiped up with a rag dampened with crude oil. From what has been said concerning the bacteriology of tuberculosis, other precautions will suggest themselves.

When tubercle bacilli are grown for a time in glycerin beef-broth, they gradually cause the broth to become loaded with poisons. When such a broth culture is evaporated and filtered, so as to be entirely free from tubercle bacilli, we have what is known as tuberculin. A curious thing about this tuberculin is that when minute quantities are injected into an individual infected with tuberculosis, a characteristic reaction takes place, marked by fever, prostration, some pains, increased cough, etc. In a normal, uninfected individual no such reaction is produced. This tuberculin reaction is thus of diagnostic value. It can also be applied by searifying the skin with a needle and rubbing a drop of tuberculin into the scarifications. A positive reaction 
is denoted by distinct inflammatory changes at the site of the inoculation. This method of making the test is often spoken of as the von Pirquet test. If a dilute solution of tuberculin is dropped into the eyes, it may give rise to a reaction in the form of a marked congestion of the conjunctiva. This is spoken of as the conjunctival or Calmette reaction. Rubbed into the skin in the form of an ointment, tubereulin may also give rise to a reaction. This is Moro's test.

Tuberculin is also used in the treatment of tubereulosis. For this purpose very minute quantities are injected and the amounts gradually increased. 


\section{CHAPTER XV}

\section{DIPHTHERIA}

THE diphtheria bacillus was discovered by Klebs, and first isolated in pure culture by Löffler. It is, therefore, usually spoken of as the Klebs-Löffler bacillus. It is rather long and thin, frequently somewhat clubbed at the ends, and possesses peculiar staining properties. It is a non-motile, Gram-positive, strictly aërobic

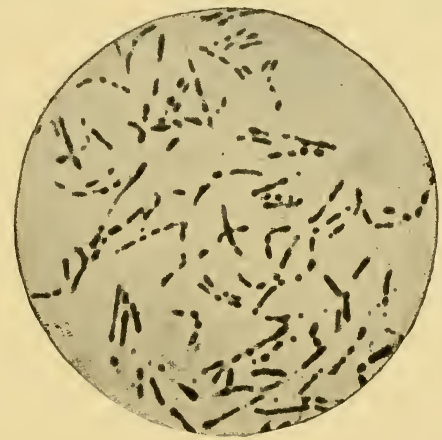

Fig. 25.-Bacillus of diphtheria, fifteen-hour serum culture. Löffler's methylene-blue; × 2000 (Denny, Journal of Medical Research).

organism, and produces a powerful poison, diphtheria toxin, when grown in broth cultures.

The regions most frequently invaded by the diphtheria bacillus are the tonsils and palate, the nasal passages, and the larynx. The characteristic feature of the inflammation produced by this bacillus is the forma- 
tion of a peculiar dirty gray membrane on the surface of the part. This membrane consists of fibrin, pus cells, and granular débris, and contains numerous diphtheria bacilli. Somewhat similar membranes, however, are produced by other bacteria, especially by streptococci, and, while an experienced clinician can often tell by the appearance of the membrane whether the infection is due to the diphtheria bacillus or not, most physicians prefer to have the diagnosis established by bacteriologic examination. This should be done by spreading some of the membrane on a slide, fixing, and staining with Löffler's alkaline methylene-blue, and then examining under the microscope. In addition, where the facilities are at hand, by means of a sterile swab rubbed first over the membrane, and then over the surface of a tube of sterile Löffler's serum, a culture is made, incubated for from twelve to eighteen hours, and the growth examined under the microscope. In cases of true diphtheria such a culture will usually show enormous numbers of diphtheria bacilli. Both methods should be employed in order to insure a correct diagnosis, for certain germs, for example, those of Vincent's angina, will not grow on the culture-medium.

Knowing the location of the diphtheria bacilli, it is not difficult to devise measures to prevent the infection of others. All the mouth and nasal discharges must be carefully disinfected, carbolic acid being very useful for this purpose. Disinfection should, of course, extend to spoons, glasses, and other things coming in contact with the mouth. When examining the throat it is well to interpose a pane of glass between the patient and examiner, in order to safeguard the latter when the patient 
coughs. Quarantine is usually kept up until bacteriologic examination shows the absence of diphtheria bacilli.

In 1893 Behring, a German scientist, found that animals could be accustomed to injections of diphtheria poison, and that after a time the blood of these animals had acquired the power to cure other animals injected with many times a fatal dose of diphtheria poison.

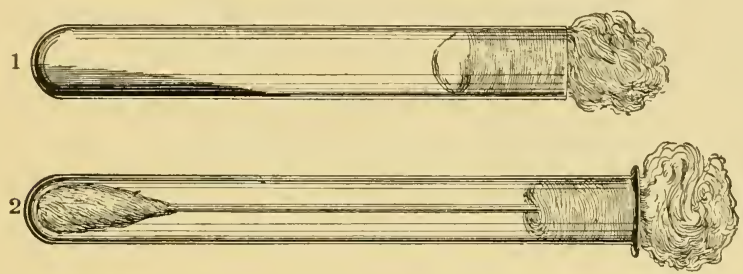

Fig. 29.-1, A tube of blood-serum; 2, a sterilized cotton swab in test-tube. Rub the swab gently but freely against the visible exudate, and without laying it down, after withdrawing the cotton plug from the culture-tube, insert it into the latter, and rub that portion which has touched the exudate gently but thoroughly over the surface of the blood-serum without breaking its surface. Now replace the swab in its own tube, plug both tubes, and place them in the box provided by the health officials. This is to be sent to the bacteriologic expert. In laryngeal diphtheria the swab is to be passed far back and rubbed freely against the mucous membrane of the pharynx and tonsils (Anders).

We have already said that the diphtheria bacillus when grown in broth produces a strong poison. In fact, the diphtheria bacilli produce all their evil effects through this poison. The bacilli remain on the surface, i.e., they do not enter the blood, nor do they invade the deeper tissues. In this respect they differ from streptococei, which, as already stated, may also give rise to a membranous inflammation of the throat. The streptococci penetrate the 
tissues, enter the blood-stream, and often lead to inflammation in other parts of the body, arthritis, endocarditis, pyemia, etc.

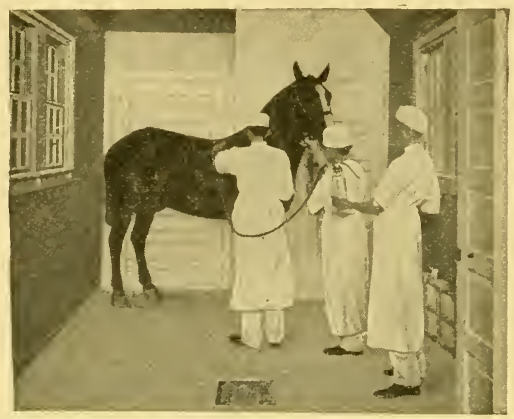

Fig. 30.-Injecting horse with toxin. (Courtesy of H. K. Mulford Company, Phila.)

The poison produced by diphtheria bacilli is spoken of as diphtheria toxin. The something in the blood

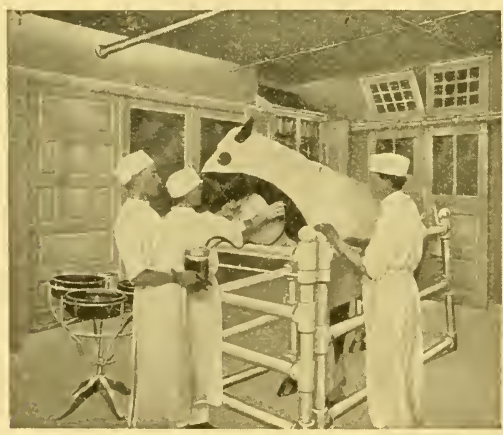

Fig. 31.-Bleeding horse in operating-room. Every precaution is taken to insure asepsis. (Courtesy of H. K. Mulford Company, Phila.)

of the treated animals which was able to overcome or neutralize the effects of the diphtheria toxin is, there- 
fore, called diphtheria antitoxin. At the present time this diphtheria antitoxin is made by injecting horses with gradually increasing doses of diphtheria toxin over a period of several months, until at last the horse will stand, at one injection, as much diphtheria toxin as would ordinarily suffice to kill several hundred horses. Then the animal is bled, as much as ten quarts of blood being sometimes collected at one bleeding. When this blood is allowed to stand in a sterile vessel, in a cool place, it clots, and a clear, light-yellow fluid separates. This fluid is the blood-serum, and constitutes the diphtheria antitoxic serum used in the treatment of the disease. It is necessary to carefully test this antitoxic serum for purity and also for its strength. The latter is indicated by finding out against how many fatal doses of toxin a certain quantity of the serum will protect an animal. This is expressed by saying the serum contains so many units per cubic centimeter. ${ }^{1}$ The ordinary sera now on the market contain from 500 to 1500 . units per cubic centineter.

In the treatment of diphtheria the antitoxic scrum should be given early and in full doses (from 30000 to 10,000 units, depending on the severity of the discase). Ordinarily the serum is given by means of hypodermic injections, but in severe cases, especially when secn late, it is well to make the injections directly into a vein. When there are several children in the family affected, injections may also be given to the well children, in order to prevent their contracting the disease. Such

${ }^{1}$ As a matter of fact, one unit is that amount of antitoxin which will just protect a guinea-pig against 100 fatal doses of diphtheria toxin. 
injections are spoken of as "immunizing injections"; the dose for this purpose is usually 1000 units.

Schick Reaction.-A few years ago Schick, of Vienna, devised a simple skin reaction by which to determine whether or not an individual was susceptible to diphtheria infection; $i$. $e$., to determine whether the individual had or had not diphtheria antitoxin in the blood. It has been demonstrated that over 90 per cent. of newborn infants have antitoxin in their blood. At one year of age only about 60 per cent. remain immune, while between five and fifteen years of age about 50 per cent. are immune. After this the proportion of immune individuals rises so that between twenty and forty years over 75 per cent. are immune to diphtheria.

The test consists in the injection into the skin of a small amount of diphtheria toxin. Within twenty-four to fortyeight hours a marked area of redness and induration develops in those who are susceptible; in those not susceptible there is practically no reaction. The Schick test is being used extensively to determine the need of actively immunizing children exposed to diphtheria infection.

When we immunize a person against diphtheria by means of diphtheria antitexin the immunity conferred lasts only a few weeks. This is because the antitoxin injected is horse antitoxin and so is really a foreign substance in the human body. For this reason the plan has recently been adopted of making a person immune against diphtheria by injecting him with diphtheria bacilli and diphtheria toxin, thus causing the body to produce its own antitoxin. This plan, spoken of as active immunization, has been extensively tried by Park and Zingher, and appears to yield excellent results. 


\section{CHAPTER XVI}

\section{TETANUS}

Tetanus is caused by a bacillus which was first obtained in pure culture by Kitasato in 1889, five years after Nicolaier had succeeded in producing tetanus in laboratory animals by inoculating them with garden earth. In spite of the relatively frequent occurrence of the bacillus of tetanus in street dust, garden earth, manure, etc., tetanus is a rather rare disease. This is due to the fact that certain conditions must be present before the germ can do its deadly work. Thus, inoculation with a pure culture rarely produces the disease, but if other bacteria and dirt are introduced into the wound at the same time the bacillus can elaborate its toxin. An open wound is not nearly so favorable for its development as a small deep puncture or laceration; the type of wound which most frequently leads to tetanus is that made by a Fourth-of-July toy pistol. The bacillus of tetanus does not grow in the presence of oxygen, $i . e$., it is an anaërobe, and is usually cultivated in the laboratory in an atmosphere of hydrogen gas, or in air from which oxygen has been abstracted. If this condition is fulfilled, it grows quite well on the ordinary culture-media, producing gas and a very disagreeable odor.

Grown under favorable conditiors, the bacillus is a slender rod, of medium length, which is not decolorized by Gram's stain, i.e., it is "Gram-positive." It is able to travel across the microscopic field, owing to the pres- 
ence of flagella, which are arranged around its entire body. It shows greater resistance than most other bacteria to drying, to heat, and to chemic disinfectants, because it has the power to produce spores under adverse conditions. The spore is located at one end of the bacillus, and, being larger in diameter than the bacillus itself, gives to the latter somewhat the appearance of a nail. Heating to $105^{\circ} \mathrm{C}$. for ten minutes is sufficient to

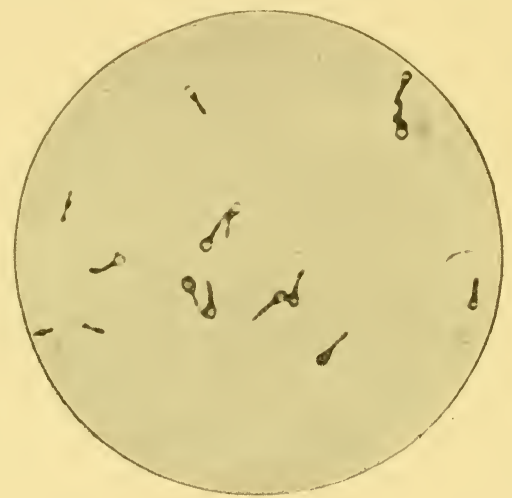

Fig. 32.-Bacillus of tetanus, showing spores. Pure culture on agar. Fuchsin stain (Kolle and Wassermann).

kill tetanus spores, yet they have remained alive on splinters of wood and have caused the discase after eleven years.

When tetanus bacilli are introduced into a wound they remain there and do not invade the body as do, for example, the streptococci. It is important to bear this in mind. If the conditions are favorable they continue to live and multiply. They give rise to but little local disturbance; in fact, local symptoms are frequently absent. But the bacilli produce a powerful toxin which is the cause of the general symptoms. The toxin can be sepa- 
rated from cultures by filtration through a Berkefeld filter, and causes typical tetanus when introduced into animals. Its action is weakened by exposure to light and entirely destroyed by heating to $55^{\circ} \mathrm{C}$. and over. Like diphtheria toxin, tetanus toxin, when injected in small and gradually increasing doses into horses, produces in the serum of these animals an antitoxin. In fact, the toxin-antitoxin reactions, which have become so important in diphtheria, were first studied in connection with the bacillus of tetanus. The serum of immunized horses protects laboratory animals against experimental tetanus, and it was thought that the same might be used in the treatment of tetanus in man. But, unfortunately, tetanus symptoms develop late, anywhere from four to fourteen days after inoculation, while, to be of service, the antitoxin must be given before the toxin has spread through the system. To obtain the best results the antitoxin should be injected intraspinally. Nicoll, of New York, has used the antitoxin in this way and has saved a considerable proportion of cases. If for any reason spinal injections cannot be given, the antitoxin should be injected intravenously. In such a case 10,000 units (U. S. standardization) should be given and repeated every eight to twelve hours.

(Tetanus antitoxin is prepared like diphtheria antitoxin, but its standardization is not uniform, each country having its own standard unit.)

Inasmuch as tetanus bacilli are not uncommonly pres- . ent in garden earth all patients whose wounds have been contaminated with earth, as on the battlefield, should receive an immunizing dose (1500 L. S. units) of tetanus antitoxin. 


\section{CHAP'TER XVII}

\section{THE PNEUMOCOCCUS}

The pneumococcus, also called the diplococcus lanceolatus, was discovered by Fränkel. As its name implies, the organism occurs usually in lance-shaped twos. It is not decolorized when stained according to

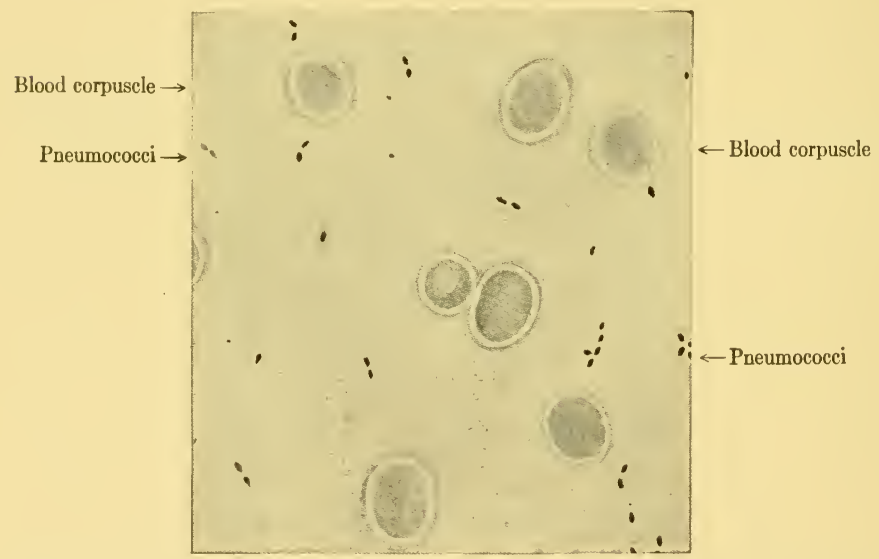

Fig. 33.-Capsulated pneumococci in blood from the heart of a rabbit; carbol-fuchsin, partly decolorized; $\times 1000$ (McFarland).

Gram's method, and when occurring in sputum or blood is usually surrounded by a thick gelatinous capsule. The pneumococcus is non-motile and does not produce spores. It grows on ordinary media, but prefers those to which a little blood or blood-serum has been added. 
The pneumococcus is closely allied to the streptococcus, from which it is sometimes hard to distinguish.

Four varieties of pneumococci are recognized, as follows:

Type I, found in about 30 to 50 per cent. of all cases of pneumonia, and has a mortality of about 25 per cent.

Type II, found in from 15 to 40 per cent. of the cases of pnuemonia, and has a mortality of about 60 per cent.

Type III, also called the Pneumococcus mucosus, causes from 5 to 15 per cent. of the cases of pneumonia, and has a mortality of about 60 per cent.

Type IV is often found in normal throats. It causes about 20 per cent. of the cases of pneumonia and has a low mortality rate, from 5 to 10 per cent.

Serum treatment appears to give the best results in pneumonia due to Type I.

When collecting specimens of sputum for laboratory tests to determine the type of pneumococcus present, care should be taken that the specimen is fresh, collected in a sterile bottle without disinfectant, and sent at once to the laboratory.

The pneumococcus is responsible for most of the cases of lobar pneumonia and for more than half of the other forms of 1 neumonia. Other infections in which the pneumococcus is frequently the causative agent are pleurisy, otitis media, with its complicating mastoiditis, meningitis, endocarditis (inflammation of the valves of the heart), rhinitis (inflammation of the nasal passages), tonsillitis, arthritis (inflammation of joints), conjunctivitis, and keratitis (inflammation of the outer covering of the eyeball).

Usually when the pneumococcus invades the lungs an 
extensive inflammation of the lungs results. If the inflammation involves an entire lobe or more it is spoken of as a lobar pneumonia; when it is scattered throughout the lung it is called a bronchopneumonia.

In pneumonia there is a marked pouring-out into the air spaces of leukocytes, serum, and fibrin. Mixed with this are degenerated epithelial cells from the air spaces, red blood-cells, pneumococci, and cell débris. The affected lobe becomes almost solid and may be compared to a sponge which has been saturated with pus. There is much absorption of poison from all this material, hence the high fever, delirium, rapid pulse, etc. If the patient recovers the lung gradually resumes its normal condition, the exudate being absorbed and carried off by the scavenger cells of the body (white blood-cells). Some of it, to be sure, is expelled by coughing.

In pneumonia the pneumococci are found in enormous numbers in the sputum; in otitis media, in the pus discharged from the ear; in rhinitis it is in the nasal secretion; in tonsillitis, in the exudate covering the tonsils; in conjunctivitis and keratitis, in the mucopurulent secretion of the eye.

We see, therefore, that a great many different sources of infection must be guarded against. So far as the care of pneumonia patients is concerned, all the sputum should be carefully disinfected, and care should be taken that, in coughing, particles of sputum are not sprayed into the air. In crowded rooms the inhalation of such moist spray particles by others is undoubtedly a common source of infection. Patients suffering from pneumonia aré often too ill to prevent their soiling their lips, face, and hands with sputum, and the nurse should, 
therefore, be on her guard to prevent further infection from this source. The enumeration of the main sources of infection as given above should suffice to guide the nurse in guarding others against pneumococcus infection. It is encouraging to know that the pneumococcus is very sensitive to germicidal agents. Exposed to direct sunlight pneumonic sputum loses its infectivity after a few hours. The fine spray expelled in coughing that remains suspended in the air soon dries so completely that no pneumococci survive after two hours. 


\section{CHAPTER XVIII}

\section{STREPTOCOCCUS INFECTIONS}

The Streptococcus pyogenes ${ }^{1}$ was observed by Koch and, independently, also by Ogston in 1882, but was first isolated by Fehleisen in 1883 . The согсi are spheric or

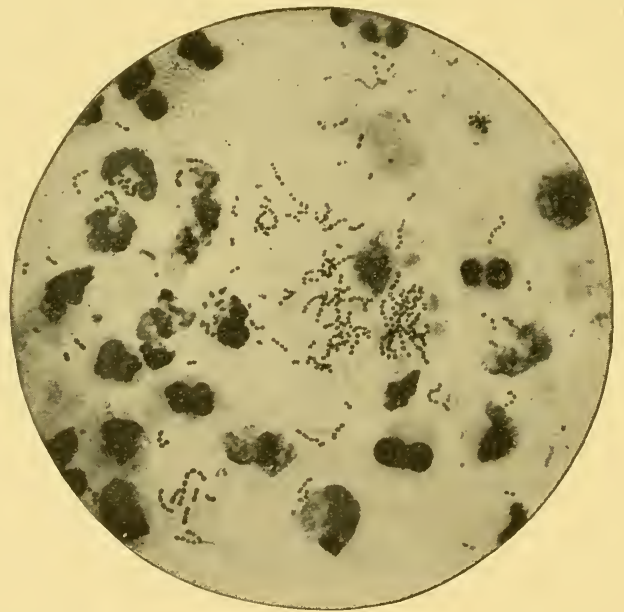

Fig. 34.-Streptococeus pyogenes, from the pus taken from an abscess; $\times 1000$ (Fränkel and Pfeiffer).

oval, and occur in chains of eight, ten, twenty, or more individuals, though often merely in pairs. They stain readily with the ordinary stains, and retain the color 
when treated according to Gram's method. They grow readily on various media, but prefer media containing blood or blood-serum. Many varieties of streptococci have a peculiar dissolving effect on blood, so that, when grown on solid media containing blood, each colony is seen to be surrounded by a clear zone. We speak of such varieties as "hemolyzing" (blooddissolving) streptococci.

Streptococcus pyogenes is the cause of a great variety of infections in man. Among these may be mentioned erysipelas, cellulitis, sepsis, puerperal infection, acute peritonitis, tonsillitis, bronchopneumonia, otitis media, and its complicating mastoiditis, meningitis, enteritis, endocarditis, synovitis, and arthritis. It must not be understood, however, that these infections are always due to streptococcus pyogenes, for we have already learned that other bacteria may be the cause. A number of observers hold that scarlet fever is a streptococcus infection, but the general opinion is that this organism is merely a secondary invader, probably through the tonsils.

The Streptococeus pyogenes, fortunately, is not difficult to kill. Thus, an exposure to a temperature of $130^{\circ} \mathrm{F}$. for from ten to twenty minutes ordinarily suffices. Bichlorid of mereury, 1:5000, carbolic acid, 1 per cent., lysol, $\frac{1}{2}$ per cent., kill the germ in a few minutes.

It should be unnecessary to enumerate all the precautions which a nurse should take in preventing the spread of streptococcus infection to others. They will differ, of course, with the kind of infection one is dealing with. It is well to remember, however, that 
transmission is probably always direct, and that infection through the air is very unlikely. For this reason, it is unreasonable to insist on isolating cases of crysipelas while keeping cases of puerperal sepsis in the ward. In fact, so long as the skin remains unbroken in the former condition, there is not much likelihood of transmission to others. The most virulent streptococci are those coming immediately from septic infections. Owing to the extreme susceptibility of women directly after childbirth to infection by way of the inner raw surface of the uterus, it is imperative that no nurse who has just before been in contact with streptococcus infections, or even with pus of any kind, be allowed to care for obstetric cases.

An antistreptococcus serum, obtained by injecting horses repeatedly with various cultures of Streptococcus pyogenes, has been used in the treatment of streptococeus infections. The results, as reported by different observers, are variable, but in certain cases appear to be good. The dlose of the scrum is large, from 50 to 100 c.c. or more intravenously, is usually recommended. Moser, of Vienna, uses the serum extensively in the treatment of severe cases of scarlet fever, and claims good results: The treatment of streptococcus infections by means of bacterial vaccines has yielded rather favorable results in the hands of some observers. 


\section{CHAPTER XIX}

\section{STAPHYLOCOCCUS INFECTIONS}

THE staphylococcus was first observed by Pasteur in 18S0, and first carefully studied in pure culture by Rosenbach in 1881. As seen in colonies, the organism appears orange, white, or lemon yellow, and is, therefore, divided into varieties termed respectively Staphylococcus aureus, Staphylococcus albus, and Staphylococcus citreus. The individual organisms are small spheric bodies, which usually group themselves in irregular masses. They stain well with the ordinary stains, and do not decolorize when treated according to Gram's method. They grow well even at room temperature, and do not demand any special media. When grown on gelatin they cause liquefaction of the medium.

The staphylococcus is much more resistant than other non-spore-bearing bacteria. Cultures may sometines be heated for an hour to $140^{\circ} \mathrm{F}$. without killing all the organisms. Dried pus contains living staphylococci for weeks and even months, and they can be found alive in the dust of air almost everywhere. To kill the organism in jus with bichlorid of mereury, 1:100(), requires an exposure of several hours.

The most common bacterial excitants of acute abscesses in man are the Staphylocoreus and the Streptococcus progenes, though, of course, other bacteria may also produce abseeses. The Staphyloroceus albus 
appears to be an almost constant inhabitant of the skin, and to be the common cause of "stitch abscess." In contrast to most other pathogenic bacteria, the staphylococcus appears to be able to infect through the unbroken skin. The organism has also been found in various pustular affections of the skin and mucous membranes, in acute abscess in the lymph-glands, in empyema, endocarditis, septicemia, and pyemia. Boils and carbuncles are very frequently due to this organism.

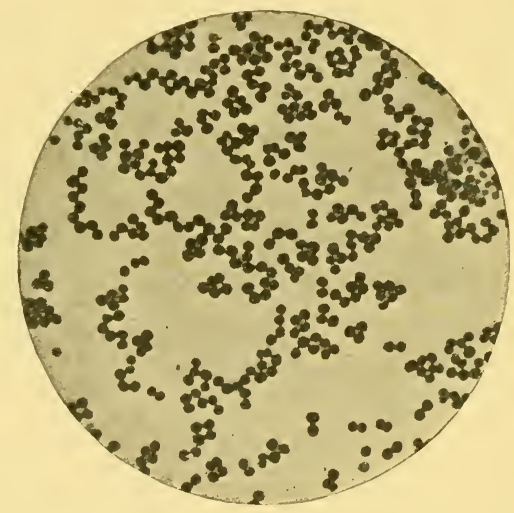

Fig. 35.-Staphylococcus pyogenes aureus (Günther).

So far as a source of infection of others is concerned, we really need not worry much about the occurrence of the staphylococcus in the dust in air. Lister, it will be remembered, kept a spray of carbolic acid solution playing about the operating-room during surgical operations in order to kill the germs which might be present in the air. Experience, however, soon showed that this was unnecessary. The presence of the staphylococcus on the skin is of more importance, but this, too, 
presents no great obstacle in controlling infection. The main point to bear in mind, in guarding against the spread of these infections, is the high resistance of the organism, especially in pus, and this indicates careful attention on the nurse's part, chiefly to the sterilization of instruments, hypodermic needles, and the like.

In recent years considerable success has attended the treatment of abscesses, boils, and other localized staphylococcus infections by means of bacterial vaccines. The doses ordinarily employed are from $300,000,000$ to $500,000,000$ dead staphylococci suspended in salt solution. The injections are given at intervals of about five or six days. 


\section{CHAPTER XX}

\section{THE MENINGOCOCCUS}

The meningococcus, also called the Diplococcus intracellularis meningitidis, was discovered by Weichselbaum in 1887. It is a somewhat flattened organism, occurring mostly in twos (diplococcus), and occasionally in small chains of fours. When stained according to Gram's method it decolorizes; that is, it is Gram-negative. It does not grow well except on media to which blood-serum or ascitic fluid has been added. The organism is not very resistant, and dies readily on drying or on exposure to direct sunlight.

The meningococcus is the cause of epidemic cerebrospinal meningitis. Other forms of meningitis are caused by the tubercle bacillus, by the pneumococcus and streptococcus, and occasionally also by other bacteria. In epidemic cerebrospinal meningitis the meningococcus is found in the purulent exudate covering the meninges and in the cerebrospinal fluid drawn by means of lumbar puncture. In fact, it is only by means of lumbar puncture that the variety of meningitis present can be determined.

It has also been found that the meningococcus is present in the nasal secretions of patients suffering from epidemic cerebrospinal meningitis, and in the nasal secretions of about 10 per cent. of the persons in intimate contact with such patients. The exact mode of 
infection is not known, but is probably through infected nasal secretions. This, of course, indicates the measures which should be taken in order to prevent the spread of the disease to others.

Epidemic cerebrospinal meningitis has been treated with specific antimeningococcus serum, obtained by injecting horses with cultures of the meningococcus.

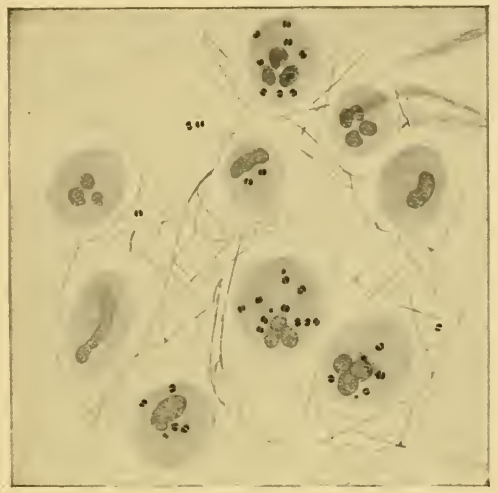

Fig. 36.-Meningococcus in pus cells: Pus cells containing diplococci from the meninges. A few diplococci are in the exudate outside of the pus cells. Between the pus cells there are delicate fibrillæ of fibrin. The illustration is an accurate representation of a group of cells in the field of the microscope (Councilman).

The serum is injected, by means of lumbar puncture, into the spinal canal, and the results thus obtained have been very encouraging, the death-rate being but one-half that of cascs not so treated. As in all treatment with a specific sera, it is useless to employ antimeningococcus serum in cases of meningitis produced by germs other than the meningococcus. It is important, therefore, before employing the serum to make sure that the 
case is really one of meningococcus meningitis. This, as already stated, is done by means of lumbar puncture. The fluid thus obtained is centrifuged, the sediment spread on a slide, dried, fixed, and then stained according to Gram's method. In case of meningococcus meningitis Gram-negative diplococci will be found mostly in the interior of pus cells. (See Fig. 36, page 115.) If the organisms are Gram-positive the case is not one of meningococcus meningitis. 


\section{CHAPTER XXI}

\section{THE GONOCOCCUS}

THE micrococcus of gonorrhea was discovered by Neisser in 1879. It is a small coccus, occurring in pairs (diplococcus). The two organisms which form the pair are flattened on their adjacent sides, which gives to the organism somewhat the appearance of a coffee bean. When stained by Gram's methoa the gonococcus is

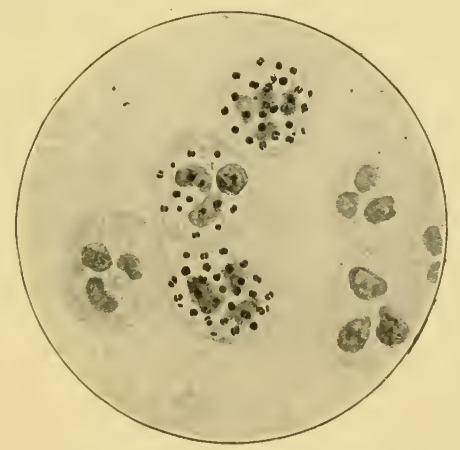

Fig. 37.-Gonococci in urethral pus (McFarland).

decolorized, $i$. e., it is "Gram-negative." It can only with difficulty be grown on artificial media, but thrives fairly well on glucose agar to which either blood or ascitic fluid has been added. Quick drying destroys it, and it cannot resist a temperature of $45^{\circ} \mathrm{C}$. more than a few minutes. But in thick smears, on linen, etc., it has been found alive after a lapse of seven weeks. 
The gonococcus is the cause of various severe purulent inflammations, among which the most important are gonorrheal urethritis and vaginitis and gonorrheal ophthalmia, as well as chronic joint affections and chronic endocarditis. In adults ophthalmia is usually due to an indirect infection, through soiled towels, etc., but in newborn babies it is caused by direct inoculation with gonococei found in the vaginal discharge of the mother. As a prophylactic measure the use of a 2 per cent. solution of silver nitrate in the eyes of every newborn baby has become a routine practice in obstetrics, with the result that the number of cases of blindness due to gonorrheal ophthalmia neonatorum has materially diminished.

In smears of fresh pus many of the gonococci will be found within the pus cells, and this peculiarity, together with their behavior toward Gram's stain, are aids in the diagnosis. (The meningococcus in pus from meningitis gives a similar picture, but it is smaller than the gonococcus, and does not, as a rule, occur under the same conditions.)

The gonococcus may remain dormant in the vagina and urethra for years, and at any time set up a fresh acute process. A vaccine, prepared by suspending the killed gonococcus in an indifferent fluid (physiologic salt solution), has apparently given good results in some joint lesions. The dose varies from $20,000,000$ to 1,000 ,000,000 , repeated at intervals of three to seven days. Attempts have been made to produce a curative serum by inoculating horses with increasing doses of vaccine, but so far the results of its use have not been specially satisfactory. 


\section{CHAPTER XXII}

\section{SYPHILIS}

IT was not until 1904 that the causative micro-organism of syphilis was discovered, and not until 1911 was it successfully cultivated on artificial media. The organism belongs to the class known as Treponema, and in shape resembles a cork-screw. The organism stains with difficulty. For rapid exaninations the socalled "ultramicrosccpe," or microscope with darkfield illumination, is usually employed. The picture thus produced is shown in Fig. 38 .

Acquired syphilis begins with a characteristic sore known as a chancre or hard chancre. If the disease has been acquired through sexual intercourse the sore appears on the genitals. The stage of chancre is also spoken of as the primary stage. It lasts about six to eight weeks, and is followed by the secondary stage. The symptoms of the secondary stage include a rash, sore throat, pains in the joints, falling out of the hair, etc. The duration of this stage is variable, and no hardand-fast line can be drawn between it and the tertiary stage. During the latter the disease shows a tendency to produce certain skin eruptions, gummatous growths in the viscera, and degenerations.

The ulcerations, especially the primary sore (chancre), and the so-called "mucous patches" in the mouth and 
throat, are exceedingly infectious. Examined with the dark-field microscope, scrapings from these ulcerations are seen to swarm with the Treponema pallidum. A syphilitic having mucous patches may infect a drinking-cup or a spoon and cause infection of others. The infection then makes its appearance on the lip or tongue of the victim. Infection may also be carried through kissing.

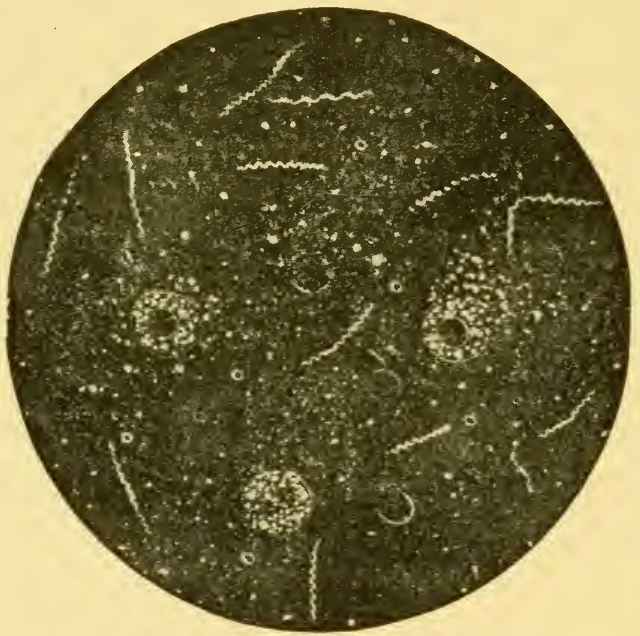

Fig. 38.-Treponema pallidum appearing as bright refractive body on a dark field, as shown by India ink or ultramicroscope (Park and Williams).

When syphilis is transmitted from parent to offspring, the disease often shows itself in the baby by what are called "snuffles." The secretion from the nose of such babies is highly infectious. A syphilitic baby should not be given to a healthy wet-nurse to suckle. If the mother cannot nurse it, the baby should be brought up on the bottle. 
A great aid in the diagnosis of syphilitic infections is that devised by Wassermann, of Berlin. This. test can be performed either on the blood or the cerebrospinal fluid of patients. While a positive result indicates a syphilitic infection, a negative result does not indicate the absence of such infection. 


\section{CHAPTER XXIII}

\section{EXANTHEMATA ${ }^{1}$}

UNDER this head are included measles, German measles, scarlet fever, small-pox, chicken-pox, and typhus fever. They are alike, in that no specific organism has yet been demonstrated and definitely proved to be the cause of the infection. The causative agent is spoken of as a "virus," and typic clinical symptoms can be produced in healthy animals or humans by inoculation with skin or blood from patients ill with one of the exanthematous diseases.

Scarlet Fever.-In 1904 Nallory described tiny glistening corpuscles in tissue cells which he regarded as the protozoan causes of scarlet fever. Other observers were unable to demonstrate them in living tissues, but found them also in measles' blisters and in some antitoxin rashes. They are now generally regarded as degenerated leukocytes.

More recently (March, 1916) Mallory reports isolating from the tissues of children dying early in the course of the disease, especially from the tonsils, fauces, root of the tongue, trachea and lungs, a strongly Gram-positive bacillus growing between the epithelial cells. In form it varies from coccus-like to large bacillary organisms. He believes that this is the cause of scarlet fever, and has accordingly

${ }^{1}$ Exanthemata, the plural of exanthem $=\mathrm{a}$ breaking out, an eruption. 
named it provisionally Bacillus scarlatince. It produces a poison which causes necrosis and denudation of the covering epithelium and leads to an exudation of serum and leukocytes.

The results reported have not yet been confirmed; if they are, this represents a most important discovery.

The streptococci which cause the severe sore throats in scarlet fever are by most bacteriologists considered as a constant but secondary infection, and not as the cause of the general symptoms and of the rash of scarlatina.

Measles and German Measles.-Bodies similar to Mallory's scarlet fever bodies have been described, and an influenza-like bacillus has been held responsible for the coryza which accompanies measles, but nothing definite has been proved about the bacteriology of these two diseases.

The virus of measles, whatever its nature, exists in the blood of the patient during the fever. This has been demonstrated by several investigators, who have succeeded in producing the disease in monkeys by inoculating these animals with the blood of measles patients. After the fever abated the blood was no longer infectious. In monkeys the disease runs a milder course than in human subjects, and a monkey that has passed through one attack is thereby made immune.

The virus passes through a Berkefeld filter, that is, the filtered material remains infectious. It is destroyed by heating to $55^{\circ} \mathrm{C}$. for fifteen minutes, but resists drying for twenty-four hours. No development takes place on any of the usual culture-media.

Bacteriologists have found cocci and bacilli which for a time were considered the causes of the disease. 
We know now that these were accidental contaminations. Weigert also described "bodies" included in epithelial cells, which have since been variously interpreted as degenerative forms of tissue cells, or as protozoa causing the disease.

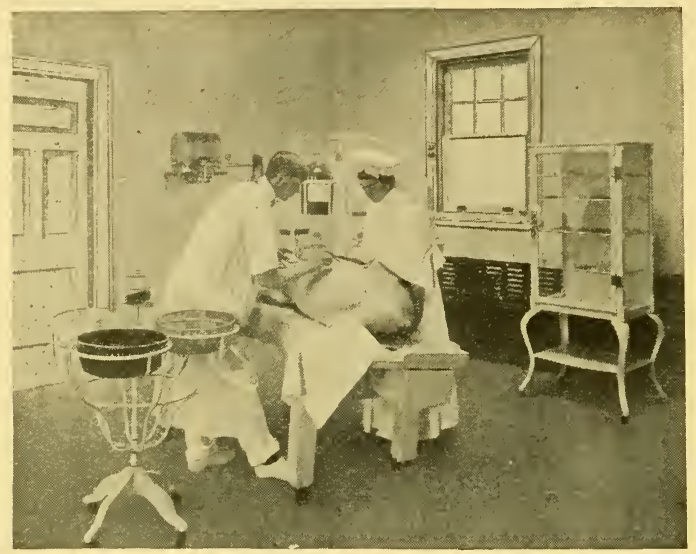

Fig. 39.-Operating-room. Collecting vaccine from a calf. The calves which are used in the preparation of the virus are first washed, the long hair is clipped, and the skin is cleaned with bichlorid solution, then in an alkaline bath, and finally all traces of the antiseptics are removed by thorough rinsing in sterile water, after which the surface to be operated upon is shaved. The animals are then conveyed to the operating-room, where they are vaccinated with tested virus under conditions similar to those existing in the operating-rooms of modern hospitals, after which they are transferred to the propagating stable and kept as clean as is possible. In about six days the virus is removed and prepared for use under rigid aseptic precautions. (Courtesy of H. K. Mulford Company, Phila.)

Cow-pox is presumably identical with small-pox, being modified because it develops in a different host. When calves are inoculated with small-pox virus they develop lesions very similar to cow-pox. In monkeys 
inoculation with cow-pox virus protects against smallpox, and vice versa, and the same protective action holds in man. This has been proved for more than a century-i.e., since Jenner, in 1796, introduced vaccination. In every country where vaccination has been made compulsory there has been a sudden and constant lowering of the number of small-pox cases, and those which do occur are of a milder nature than formerly.

The best method of vaccinating is as follows:

Carefully clean the outer surface of the arm with soap and water, followed by alcohol. Do not paint the slin with iodin. Two

or three drops of vaccine virus are now placed on the dry skin, an inch apart. With a sharp, sterile needle two or three parallel linear cuts or scratches an inch long are made, each scratch beginning in a drop of vaccine virus. With the flat of theneedle the virus is then $\mathrm{rubbed}$

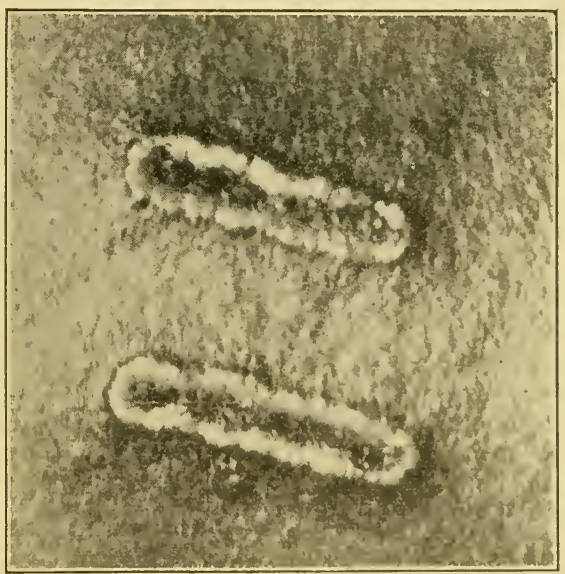

Fig. 40.-Linear vaccination. The eruption on the eleventh day. (From Rosenau, "Preventive Medicine and Hygicne.") gently into the scratches. The vaccinated area is allowed to dry. No dressing should be applied, experience having shown that the various shields often do more harm than good, for they retain heat and moisture. The illustration shows a linear vaccination made as here described. 


\section{CIIAP'TER XXIV}

\section{FILTERABLE VIRUSES}

In describing bacteria it was stated that they varied in size from $\frac{1}{50,000}$ to $\frac{1}{1000}$ inch; the average pathogenic bacterium is about $\frac{1}{10,000}$ inch long. It is obvious that

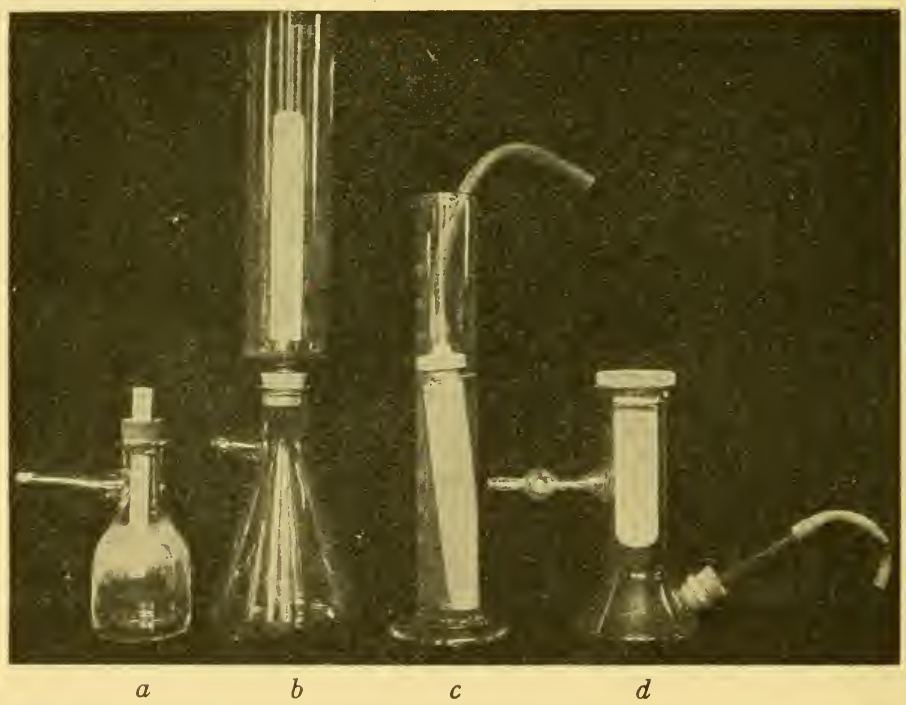

Fig. 41.-Different types of bacteriologic filters: $a$, Kitasato; $b$, Berkefeld; $c$, Chamberland; $d$, Reichel (McFarland).

such tiny organisms readily pass through ordinary paper filters and through absorbent cotton filters. It is possible, however, to construct filters which entirely hold 126 
back even such tiny particles as bacteria. Such filters are usually made of an unglazed, burnt clay. A number of different makes are on the market-Berkefeld, Pasteur, Chamberland, Pukall, etc. In all of these it is necessary to either draw the fluid through by suction or force it through by pressure. Figure 41 shows the construction of this type of filter.

Experiments conducted with filters of this type led to the astonishing discovery that the virus of certain infectious diseases was able to pass through. It was impossible to see any living particles in these filtrates even with the highest powers of the microscope, and yet the virus was present, as could be shown by appropriate animal experiments. Very little is known about the nature of these filterable viruses, but we have felt it well to mention the fact that they exist. Some of the diseases known to be caused by a filterable virus are:

$\begin{array}{ll}\text { Measles. } & \text { Infuenza (?) } \\ \text { Hydrophobia (rabies). } & \text { Common colds. } \\ \text { Poliomyelitis. } & \text { Trench fever. } \\ \text { Yellow fever. } & \text { Foot-and-mouth disease of cattle. } \\ \text { Dengue. } & \text { Rinderpest of cattle. } \\ \text { Mumps. } & \text { Hog cholera. }\end{array}$

So far as hydrophobia is concerned, it appears that some of the finer grained porcelain filters hold back the virus. Certain characteristic bodies found in the brain cells of rabid animals are diagnostic of the disease. They are spoken of as "Negri bodies," and are held by some observers to be the causative organisms, $i$. $e_{\text {. }}$, the virus. 


\section{CHAPTER XXV}

\section{MALARIA}

Malaria is an infectious disease, the cause of which is not a bacterium, but an animal micro-organism, a protozoön (plural protozoa). Its old name, "plasmodium malariæ," has been replaced by the term "hemameba malariæ." This parasite was discovered in 1880 by Laveran, a French army surgeon, and in the course of work with the malarial parasite which followed upon Laveran's discovery, Manson, Ross, Grassi, and others found that the hemameba has two distinct life-cycles, a sexual one, which takes place in mosquitos, and a non-sexual cycle, occurring in the blood of human patients. The young forms of hemameba, both male and female, live in the Anopheles, a species of mosquito which breeds and lives largely in stagnant pools and marshes. In the stomach wall of this mosquito fertilization occurs, and the development of the young forms proceeds until, at the end of ten to fourteen days, they are set free into the digestive tract of the mosquito and pass, through the bite of the insect, into the bloodstream of a human being. Here they penetrate the red corpuscles, where they remain until they are fully matured, and divide into a number of round or oval segments, which are shed into the blood-stream. The same cycle can be repeated indefinitely in man, the stage of fever marking the setting free of amebulæ. $1: 8$ 
Although it is possible, experimentally, to produce malaria by inoculating a person with blood from a patient suffering from the disease, yet, in practice, malaria can never be transmitted without the aid of the particular mosquitos mentioned. In other words, without mosquitos there can be no spread of malaria.

There are three recognized types of the hemamebathe quartan, the tertian, and the estivo-autumnal parasite. The two former cause a relatively benign infection, while the estivo-autumnal parasite causes malignant malaria. (Plate II.)

The organism of the quartan malaria develops in the blood in seventy-two hours; hence, there is a febrile stage every third day. Under the microscope, in a fresh smear, the organism is a tiny refractive body, slightly motile, and contains coarse, blackish-brown pigment. It segments into six to twelve round amebulæ.

The tertian parasite is less glistening, but more actively motile than the quartan; its cycle in the human host is completed in forty-eight hours, and it then divides into fifteen to twenty oval bodies. The pigment of the tertian parasite is yellowish brown and quite fine.

Estivo-autumnal parasites are small and show more active ameboid motion than the other two; they contain very little pigment, which is dark and quite fine. The red blood-corpuscles which contain the parasite are apt to shrink and assume a brassy color. This type completes its cycle chiefly in the blood of the internal organs (e. g., the spleen), and it may be difficult to locate it at all in the circulation. Its sexual forms are erescentic in shape. All three types are best stained with methyleneblue. The Romanowsky method uses a compound ob- 
tained by bringing together methylene-blue and watersoluble eosin; the resulting powder is soluble only in alcohol; it stains the parasites blue, red blood-cells a deep pink, and white blood-cells pale pink with blue nucleus.

Apparently there exists a slight natural immunity to malaria; occasionally a few residents in malarial districts escape infection. Also a partial immunity is acquired by some individuals who have passed through one or more infections. Thus the negroes on the west coast of Africa are less severely attacked than Europeans who go to live there, and Koch has attributed this to their having acquired a partial immunity during childhood.

The malarial parasites are actively destroyed by quinin, arsenic, and certain other substances. In the campaign in this climate against malaria it is well to direct attention also to suppressing the mosquito nuisance, and, hand in hand with that, to kill the malarial parasites in their human hosts by means of quinin.

\section{Mosquitoes}

It may be well at this point to give a brief outline of the life-history of mosquitoes, especially those concerned in the transmission of malaria and of yellow fever.

Mosquitoes reproduce themselves by means of eggs which the female lays on the surface of stagnant water. After several days the egges hatch out into what are called "wrigglers," which live in the water and can readily be seen with the naked eye. After a day or two the wriggler changes into a pupa, and from this, after a further interval, the winged insect, the mosquito, emerges. It is 
thus seen that stagnant water is necessary for mosquitoes to breed. Both wrigglers and pupæ come to the surface of the water at brief intervals in order to breathe. If a film of oil is floated on the surface of the water the wrigglers and pupæ soon die of asphyxiation.

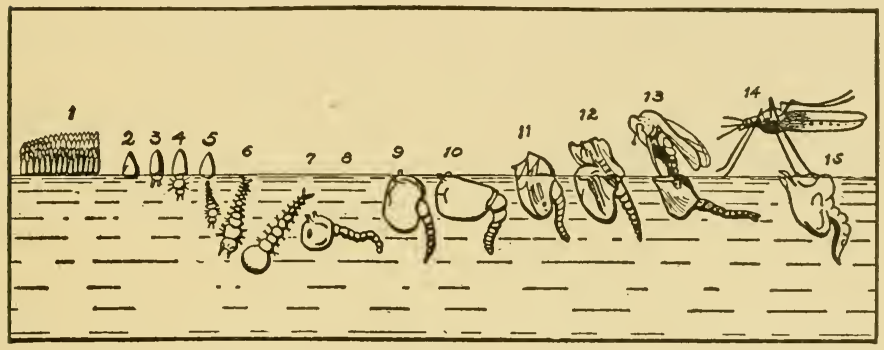

Fig. 42.-Life cycle of mosquito. Chart showing how the common house mosquito breeds: 1, The eggs, as deposited on the surface of the water; 2, separating from the mass. The larva, 3, 4, forming; 5 , emerging, about the thickness of a thread; 6 , breathing through the tail; 7 , changing to pupa. The pupa ( 8 , descending from the surface, when disturbed; 9,10 , breathing; 11, 12, changing to insect). The complete insect (13, emerging; 14, allowing its wings and body to harden and expand ready for flight, using the pupal skin, 15, as a float). The eggs and young of the malaria-carrying mosquitoes go through a similar process of development.

The mosquitoes which transmit malaria belong to the family called Anopheles. The commonest variety of this is brown in color and has four dark brown markings on each wing. Anopheles mosquitoes breed in fresh-water swamps and in stagnant water in fields and woods. Their extermination therefore requires the drainage of marsh lands, the filling-in, draining or oiling of ponds, and similar measures.

In contrast to the anopheles, the mosquitoes which 
transmit yellow fever, Aëdes calopus, are domestic pests. They breed in and around dwellings, in rain barrels, cisterns, in old tin cans and bottles, in stopped-up roof drains, and the like. They do not breed in the fields, woods, and swamps, which are the farorite haunts of the malaria mosquito.

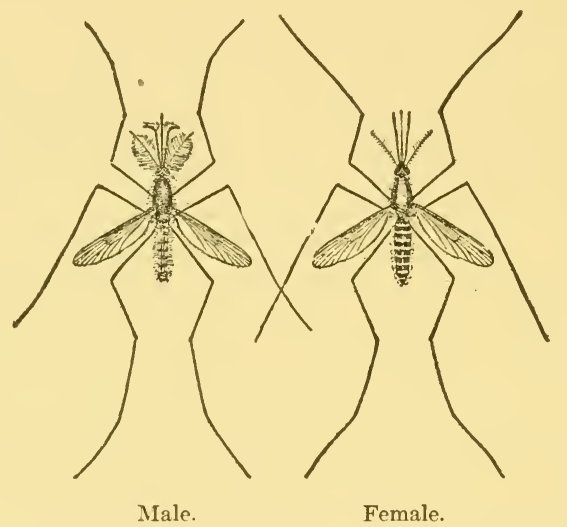

Fig. 43.-Anopheles maculipennis (Howard).

Adult female mosquitoes live a month or longer; males, but a few days. Inasmuch as only the female mosquitoes bite, it may be of interest to study the above pictures, showing the differences between the male and female insects (Fig. 43).

\section{YELLOW FEVER}

Although the specific organism of yellow fever has not yet been identified, it may be well to mention the disease here, because, like malaria, it requires a particular kind of mosquito (Stegomyia calopus) for its transmission from man to man. The disease is not conveyed by fomites. 
The bite of an infected mosquito does not become infectious until twelve days after it has bitten the first patient. There is a definite time between the bite of the mosquito and the infectivity of the patient's blood (average five days), and a definite time the blood remains infective (three days). The blood during these three days is still infective after passing through the finest-grained porcelain filters. (See page 126.)

Competent authorities incline to the belief that the organism of yellow fever is a protozoön, $i$. e., a unicellular animal micro-organism.

\section{TRYPANOSOMIASIS}

In connection with malaria and yellow fever a word may be said about trypanosomiasis or "sleeping-sickness." This dreaded African scourge is caused by a protozoön somewhat similar to that of malaria, and transmitted not by the mosquito, but by a species of biting-fly, known as the "tsetse fly." The characteristic symptoms are produced by the trypanosomes entering and growing in the cerebrospinal fluid. The disease appears to be almost invariably fatal. 


\section{CHAPTER XXVI}

\section{- BACTERIOLOGY OF MILK}

MILK, one of the most important articles of human diet, is at the same time an excellent medium for the growth and development of bacteria; hence, great importance attaches to methods pursued at the dairy. The bacteria generally found in milk have two sourcesthey may be derived from the cow's udder, or they may fall into the milk while it is being drawn, or later at any stage of handling. It is practically impossible, even under the very best conditions at the farm and with the most approved methods of distribution, to obtain a milk absolutely free from bacteria. But, fortunately, the varieties generally found in market milk are not pathogenic, and are not to be considered dangerous to the consumer unless they are allowed to multiply abundantly, when they cause souring and curdling or putrefaction, and may thus render the milk unfit for use.

Grading the Milk Supply.-Broadly speaking, we may divide market milk into three groups:

(a) Best quality, showing not over 10,000 bacteria to the cubic centimeter.

(b) Good quality, not over 500,000 bacteria per cubic centimeter.

(c) Poor quality, 5,000,000 to 50,000,000 and more bacteria per cubic centimeter.

In summer these normal milk bacteria multiply with astonishing rapidity, and soon render the milk 
unfit for food. In addition to the curdling and the souring, there are produced by some of these bacteria toxic substances which are especially badly borne by infants, and, as it is chiefly as an infant food that milk must be considered, it becomes necessary to devise means of keeping the milk sweet.

\section{Safeguarding the Milk Supply by Pasteurization.-} Much can be done at the dairy, by keeping stables and animals very clean, and by using due precautions when milking to keep out dust and dirt. Then, the warm milk must be rapidly cooled to about $40^{\circ}$ to $50^{\circ} \mathrm{F}$., bottled, and shipped in ice to the consumer. But such conditions prevail at comparatively few dairies, and naturally increase the cost of production considerably, bringing such milk beyond the reach of the great masses. When, therefore, for any reason the bacterial count of milk is high, it is best to resort to sterilizing by heat. This may mean boiling for five to ten minutes. The objections to this are: First, the coagulation of some of the proteins, which may render them less digestible, and, second, a peculiar and rather unpleasant taste and odor which are imparted to the milk. Therefore, pasteurization has largely superseded boiling. This means heating to $140^{\circ}-160^{\circ} \mathrm{F}$. for fifteen minutes or more. When done on a large scale, the milk to be pasteurized is allowed to run in a thin stream over a metal surface, which is heated by steam to the required temperature, or it may run through a coil of tubes, which are kept in hot water, bringing the temperature of all the milk up to the required degree. It is important that all the milk be thus heated, since otherwise bacteria remain alive in some of the milk, and will develop rapidly throughout the whole lot of milk. Commercial pasteurization has 
certain disadvantages as well as advantages. If properly done, with fresh milk which is then cooled rapidly, the pathogenic bacteria, such as typhoid and tubercle bacillus, are killed, as are also the lactic acid bacilli, which cause the souring of milk. What remains alive are the spore-bearing varieties. Among them are the putrefactive organisms, but these are present in small numbers only and are unable to develop at low temperature. But it is impossible to tell whether pasteurized milk was really fresh when heated, $i$. e., it may have been in a tainted condition before pasteurization. Normally, the lactic acid bacilli, by altering the reaction of the milk, keep down the growth of putrefactive organisms, but in heated milk the growth of these latter is unchecked, and, unless carefully treated, well cooled, and kept cool, pasteurized milk may have a higher bacterial count than a good quality raw milk. For this reason the pasteurization of milk supplied by the dealers should be carefully supervised by the public health authorities.

Home Pasteurization.-There is no doubt that home pasteurization of milk has been found of considerable advantage, especially for infants, and several pasteurizers have been put upon the market, the best known among them being those of Arnold and of Freeman.

A simple milk pasteurizer for home use consists of a tin pail, having a perforated cover and containing a wire basket, into which are fitted eight nursing bottles. The water in the pail is heated to boiling, the wire crate is then lowered until the bottles nearly touch the water. The milk is steamed in the open bottles for ten minutes, then the bottles are corked and steaming is continued 
another fifteen minutes. After that the milk is kept on ice until used.

Freeman's pasteurizer consists of a pail with a tightfitting cover and a removable rack, holding a number of

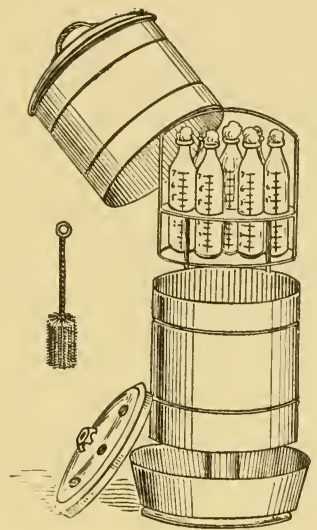

Fig. 44.-Arnold's apparatus for sterilizing milk (Ashton).

cylindric metal cups, which receive the milk bottles. The pail is filled with water to a groove about halfway

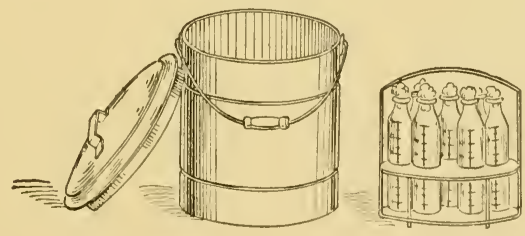

Fig. 45.-Apparatus for pasteurizing milk (Ashton).

from the top and the water is brought to the boilingpoint. The milk bottles are then placed into the metal cups and are in these surrounded by water, which 
serves as a conductor of heat. The filled rack is immersed into the boiling water in the pail, the pail is removed from the stove, and the cover replaced. Within ten minutes the temperature of both water and milk reaches $160^{\circ} \mathrm{F}$. and remains at that level for about twenty minutes. Then the bottles are removed and rapidly cooled in the water-bath, or, better, the hot water in the pasteurizer is replaced by cold, which is run in by means of a rubber tube attached to the kitchen faucet. The milk is then stored on ice.

Milk as a Carrier of Disease.-Besides the above bacteria, which are inevitable inhabitants of all market milk, and which vary in the different grades of milk in number only, other and much more serious contaminations may occasionally be found. Of those derived from the cow the most frequent are streptococci from a suppurative mastitis, and the tubercle bacilli from udder tuberculosis or tuberculous lesions elsewhere. It has been demonstrated that while the tubercle bacillus found in cows is not of the same variety as that which produces pulmonary tuberculosis in adults, it is nevertheless able to set up even fatal tuberculous processes in small children and infants.

Typhoid fever is not infrequently spread by means of milk; the bacillus is introduced into the milk directly, through uncleanly habits of the milkers, among whom there may be a so-called "carrier," that is, an apparently perfectly healthy individual who harbors in his intestines virulent typhoid bacilli, or, indirectly, by contaminated water which has been used to wash utensils, etc.

Asiatic cholera, dysentery, and similar diseases may be spread in the same manner, but are probably only infrequently disseminated in this way. Epidemics of 
scarlet fever and diphtheria, however, have been directly traced to contaminated milk.

It is important to keep flies from milk. A fly can readily infect milk through the filth which it carries on its legs.

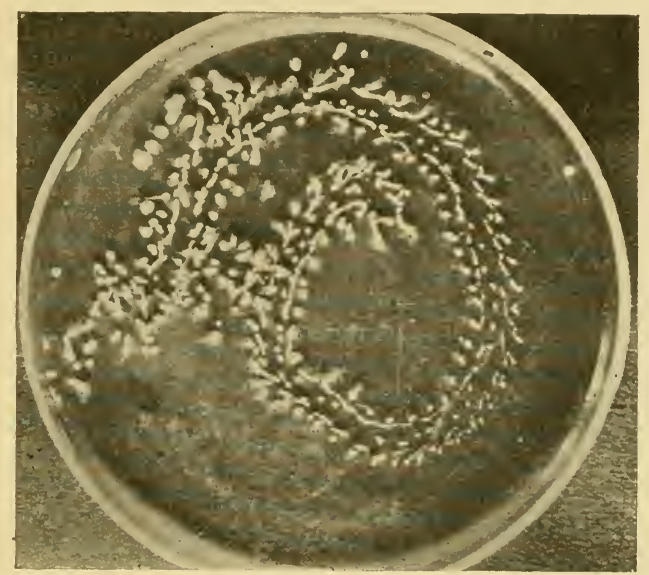

Fig. 46. - Colonies of bacteria transplanted by a fly's feet (Magruder).

When properly supervised by the health authorities, pasteurization of the milk offers the best protection against all these various infections. In New York City at the present time no milk, excepting that equal to "certified" grade, may be sold unless it has been effectively pasteurized. 


\section{CHAP'TER XXVII}

\section{FERMENTED MILKS}

According to Metschnikoff, many of the degenerative changes associated with old age are due to poisons generated in the intestines by putrefactive bacteria. Moreover, his investigations lead him to believe that excessive intestinal putrefaction can be greatly lessened by introducing bacilli which produce lactic acid in the intestines. In fact, he ascribes the healthfulness and longevity of certain people of eastern Europe to their extensive use of sour milk as an article of diet.

For many years the people of eastern Europe and western Asia have looked upon sour milk as an essential part of their daily diet. The term sour milk covers all milks or parts of milk in which lactic acid fermentation is pronounced. Ordinary buttermilk sours because of the growth of lactic acid bacteria in the raw milk. Sour milk from the dealers is more usually heated milk to which some special culture of bacteria ("starter") has been added. A starter, now extensively used, is one supplied by Metschnikoff.

Many different species of bacteria are able to provoke the lactic acid fermentation, but ordinarily only a few species are responsible for the natural souring of milk. Chief among the latter are the common lactic acid bacilli and an organism spoken of as the milk streptococcus. Inoculation of sterilized milk with pure cultures of these 
two organisms and with mixtures reproduces very closely the process of natural souring.

In addition to this lactic acid fermentation, milk is sometimes caused to undergo an alcoholic fermentation. This is done by fermenting the milk with yeast or with a mixture of lactic acid bacteria and yeast. A well-

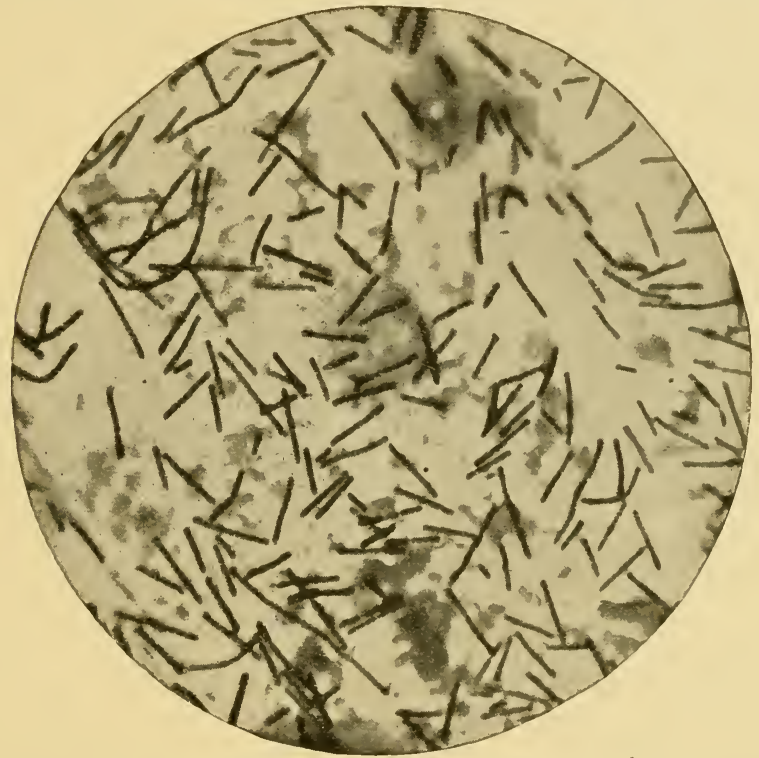

Fig. 47.-Bacillus bulgaricus of the bacillary milk; $\times 1000$ (Fairchild).

known drink, called koumiss (or kumyss), is made by the Tartars from mares' milk, a small quantity of old koumiss often being added to fresh milk as a starter. In this country koumiss is made commercially by fermenting milk with yeast and lactic acid bacilli. Such a preparation contains not only lactic acid, but also carbonic acid gas and about 1 per cent. of alcohol. 
Natzoon, yoghurt, zoolak, fermilac, etc., are made from sterilized milk by fermentation with lactic acid bacteria. These preparations contain neither alcohol nor carbonic acid gas.

Detailed directions for the preparation of various kinds of fermented milks will be found in nurses' cook books, and in the circulars supplied with the various lactic acid bacillus cultures on the market. 


\section{CHAPTER XXVIII}

\section{BACTERIAL FOOD POISONS}

Although poisoning occasionally results from mineral poisons accidentally present in food, and poisoning may also be caused by fungi, by far the largest proportion of cases of food poisoning are due to bacteria which develop on animal or vegetable foods. Among these are certain types which produce powerful toxins analogous to diphtheria or tetanus toxins. All dead organic matter offers an excellent culture-medium for the growth of bacteria, and only careful storing and thorough cooking will prevent their development and the mischief they cause.

The Bacillus enteritidis was found by Gärtner to be the cause of a severe epidemic of food poisoning, and was traced to meat from a diseased cow. This organism is apparently closely related to the common colon bacillus, a normal inhabitant of the intestinal tract, which may, however, under certain conditions become pathogenic. Like the colon bacillus, it forms a toxin which resists heating, so that ordinary boiling does not render the tainted food harmless. There is nothing in the odor or appearance of the meat to excite suspicion.

One of the most frequent and most thoroughly studied causes of epidemic outbreaks of food poisoning is the Bacillus botulinus. This was first studied by Van Ermengem in some 30 cases, all of which were due to the eating of badly cured ham. The bacillus is a sporebearing anaërobe of slight motility, producing a powerful 
toxin which acts on the nerve-cells, but which is, fortunately, easily destroyed by heat. The appearance of the food gives no warning, although there may be a slight rancid odor.

Another organism which may cause trouble is the Bacillus proteus vulgaris. This also does not alter the appearance of the food; boiling renders its toxin harmless. This explains why botulinus and proteus infections are almost entirely caused by the eating of sausages and ham, which in Northern Europe are smoked, but not cooked.

Anthrax has been known to be conveyed to man through the meat of calves or cattle suffering from the disease, as well as through gelatin made from calves' feet. As anthrax spores are very resistant to heat, ordinary boiling may not suffice to kill them.

Fish, as well as meat, can be the carrier of infection. This may be due to sewage contamination of the water (e. g., oysters spreading typhoid fever), or it may be due to the development of poisonous bacteria in smoked or canned fish.

Milk, as stated before, is an excellent culture-medium for bacteria, and may, consequently, be responsible for certain epidemics of poisoning. Apart from such diseases as typhoid, there are on record certain epidemics of "milk poisoning," notably one in Christiania in 1888, which numbered 6000 cases in three weeks. A colon-like bacillus has been isolated from some of these epidemics. What applies to milk is true also of the milk products, notably, cheese and ice-cream; poisoning by these is due to the presence of bacteria which belong to the colon group. 
From the foregoing it becomes evident that careful inspection of all food stuffs is necessary, together with such storing and preparation as will keep them in wholesome condition. Where proper storage facilities exist (i. e., large cold-storage plants), in which edibles are kept at a constantly low temperature, meat, fish, eggs, fruit, etc., can be kept in good condition for months. In the absence of such facilities, perishable foods must be freshly consumed. In warm weather it is not safe to keep fish for more than twenty-four hours. In the home foods must be kept in the refrigerator. While bacterial growth at refrigerator temperature is very slow, it is not entirely inhibited, and for this reason the ice-chest must be kept very clean. It is especially important that food spilled on the shelves be immediately removed; the ice-box should be washed from time to time with a solution of soda in hot water and quickly cooled again; at all times it should be kept well filled with ice. The fluctuations of temperature due to insufficient ice supply are especially harmful.

From what has been said elsewhere of the habits of the house-fly, it follows that no food must be allowed to stand around in uncovered vessels. Food which is at all suspicious as to color or odor should be discarded, and all foods which are not perfectly fresh-including canned fruits and vegetables-should be thoroughly cooked before eating.

When bacterial decomposition has taken place in canned food the tops of the cans may present a convex surface, making what is known as a "blown" can or a "swelled head." The contents of a "blown" can should, therefore, never be used for food. 


\section{CHAPTER XXIX}

\section{BACTERIOLOGY OF WATER}

AlL waters probably contain a greater or lesser number of bacteria, although those of the pathogenic variety" are found only wherp there is direct contamination from human sources. The naked-eye appearance of any sample of water is rarely indicative of its safety; some very clear and sparkling water may be contaminated with typhoid bacilli and constitute a serious menace, while a turbid water may owe its lack of clearness and a possible disagreeable taste and odor to the presence of minute water plants and algæ that are absolutely harmless.

Pollution to be Guarded Against.-Rural communities depend almost entirely on springs and wells for their water supply, and great care is necessary to so locate cesspools, privies, drains, stable sinks, etc., that their discharge or overflow may not contaminate the drinkingwater. Shallow wells, which are nearer the surface and receive the local wash after a rainstorm, are naturally richer in bacteria than deep wells, and in farming regions, in pasture lands, may contain large numbers of intestinal bacteria.

For cities the supply of safe and pure water has become a very important and serious problem. Where mountain springs are abundant, within reasonable distance, the water may be allowed to collect in reservoirs and be conducted to the city, often a distance of many 
miles. Such water is apt to be excellent, provided proper care is taken to prevent pollution at the reservoirs, but for most large towns and cities such a supply is unavailable, and they must often take their supply from lakes or rivers. In these cases the danger from pollution is very great, especially if the country around the body of water is thickly settled, and town after town empties its sewers into the same. The water of some rivers is practically dilute sewage, and polluting material is added so fast that the natural means of purification are entirely unavailing.

Natural Purification of Water.-The most important of the natural agents of purification are sedimentation, oxidation, and the disinfecting action of sunlight. By sedimentation the large foreign bodies suspended in the water carry with them to the bottom many bacteria, and other bacteria are killed through the life-activities of certain water plants. Sunlight does not act to any great depth, but probably kills many bacteria in the water at the surface. Freezing mechanically frees water from a certain percentage of impurities, including bacteria, by squeezing them out, but low temperatures do not kill all germs; hence the danger of using ice from polluted lakes and streams.

Water-borne Diseases.-The two most important water-borne diseases are typhoid fever and Asiatic cholera, and the latter disease has furnished a classic example of sewage contamination of drinking-water and its consequences, as well as the most striking proof of the efficiency of filtration. The two towns of Hamburg and Altona are situated closely together, at the mouth of the river Elbe, and both draw upon that river for their water supply. 
When, in 1892, the river water became polluted with the discharges of a cholera patient, Altona, which used filtered water, had but a few cases, most of which could be traced to Hamburg; while the latter city, whose sand-filters were not yet completed, paid a toll of 8000 lives. Bacterial examination of the water at Albany, N. Y., has shown that the sand-filters in use there remove from 98 to 99 per cent. of all the bacteria in the water. In Albany, as in other cities, the introduction of filter plants has enormously reduced the number of deaths from typhoid fever.

Filtration of Water Supplies.-Briefly, these filters are huge reservoirs which hold a layer of coarse, broken stone, upon this a layer of smaller stone and gravel, then a layer of coarse sand, and at the top one of fine sand. As the dirty water percolates through these different layers it gradually deposits its gross impurities at the top, and coats the individual sand grains with a slimy covering. This "dirt cover" forms the really efficient filter, but it finally becomes too tenacious to allow any water to pass through, and must be scraped off about once a month, hence it is necessary always to have at least two filtering beds. The water must not flow through the filters faster than 4 to $4 \frac{1}{2}$ inches per hour, as otherwise infectious material may be carried through. Waters which are very dirty require sedimentation to rid them of the grossest impurities before filtering. When, at the same time, the color is muddy, it is often advisable to add a chemical, usually alum, which acts much as egg-white in clearing fluids, and then to remove the jelly-like aluminum hydrate plus impurities through a relatively thin sand-filter.

Domestic Filters.- Household filtration ought to be only 
a temporary makeshift. There are some very good types of domestic filters, but they are costly, and require very intelligent and conscientious handling to give good results. Many of the cheap ones are worse than useless because they cannot be cleaned at all, and thus soon become veritable culture-media for bacteria. 'This is true of sand, charcoal, and sponge filters, which, after the first few days, are merely "strainers," keeping back gross impurities, but allowing bacteria to grow in them and pass out into the "filtered" water in greatly increased numbers. Good types of domestic filters are the Pasteur and the Berkefeld filters. Both consist of a cylinder of porous porcelain called a "candle," fitted within a larger metal cylinder. The metal cylinder is attached to the faucet, the water enters it and cannot leave it except through the porcelain candle, which retains all bacteria. But there is danger of the bacteria "growing through" the candle; hence it becomes necessary to boil and scrub the candle every few days, and then dry it in the oven to kill all germs. After that the filter is again efficient. There must be a tight connection between the two cylinders, as otherwise unfiltered water may mix with the filtered.

Purification by Chlorination.-Many cities, New York, for example, now disinfect their water supplies by means of chlorin. At first chlorinated lime was used, but now compressed chlorin gas (liquid chlorin) is preferred. This is obtainable in steel cylinders similar to those used for liquid carbon dioxid. In disinfecting water supplies $\frac{5}{10}$ part of chlorin is added to $1,000,000$ parts of water. While the water is not made sterile, the number of bacteria is greatly reduced, especially the number of bacilli 
of the colon-typhoid type. This method, therefore, affords a simple means of protecting communities against waterborne typhoid fever and other water-borne diseases.

A modification of the chlorine method has been introduced by Dakin for the emergency purification of water. It consists in the addition to the water of a tablet of halazone, a chloramine compound related to dichloramine-T. (See page 42.)

Purification by Distillation.-Another method of purifying water is to distil it, $i$. $e$., to convert it into steam and condense the steam in a vessel kept cold. Freshly distilled water is absolutely pure, since not only all living organisms are destroyed, but any chemicals in solution are kept back. Such water is quite expensive and not particularly palatable. Its continued use as a drinkingwater is thought by some to be harmful, owing to the absence of any salts and the likelihood to abstract salt from the tissues.

Purification by Boiling.-Probably the simplest, easiest, and, at the same time, a very safe process of household purification of water is to boil it for ten minutes. The objectionable "flat" taste can be removed, for drinkingwater, by pouring from the vessel at a considerable height, or by shaking it in an open vessel to aërate it. Of course, water which has been boiled to sterilize it for surgical purposes must be kept in a properly cotton-plugged vessel to prevent air contamination.

Bacteriologic Examination of Water.-Regular bacteriologic examinations of the water supply of a town are made in order to keep informed on the purity of the water and to enable one to locate contamination at once. If tap-water is to be tested, it is necessary 
to allow it to run for some time, so as to flush the pipes and taps. If an examination is desired of lake or river water, samples are taken in sterile ressels which are shipped to the laboratory in ice. A definite amount of water ( 1 c.c. or less) is then added to a tubeful of melted agar, at $40^{\circ} \mathrm{C}$., the mixture is poured in a Petri dish and allowed to stand at $22^{\circ} \mathrm{C}$. for forty-eight hours. Then the number of colonies is counted. Since the bacterial examination of water yields only approximate results, the American Public Health Association has set up certain standards that insure uniform methods and allow the results to be compared.

If there is any reason to suspect sewage contamination, special tests are made to isolate the Bacillus coli. The water is added to lactose broth in a fermentation tube and is incubated at $37^{\circ} \mathrm{C}$. for three days. The production of gas in the closed arm of the tube points to the presence of Bacillus coli. When litmus is added to lactose-agar, and the suspected sample of water is plated out, the colon bacillus will produce acid which causes its colonies to be surrounded by a red halo, while the rest of the culture-medium is blue. A few colon bacilli may accidentally occur in water, which is safe, but their presence in large numbers spells danger. It is difficult to isolate the cholera vibrio and especially the typhoid bacillus from contaminated drinking-water, hence the presence of colon bacilli is taken as showing sewage contamination, and the number of these organisms as the index of danger. 


\section{CHAPTER XXX}

\section{ANIMAL PARASITES AND VERMIN}

Although in no sense related to bacteria, we venture to include a few words concerning some of the commoner animal parasites of man, because, in most instances, the methods of guarding against such infections is similar to those employed in guarding against bacterial infection.

Tapeworms.-These have a double cycle of life, existing in man as the commor tapeworm familiar to all, and in the flesh of cattle or hogs in the form of tiny "bladder worms." The common tapeworm of North America is found in the meat of cattle, and, while it is readily killed by cooking the meat, is liable to infect persons who eat raw meat.

Sometimes it happens that man accidentally takes into his stomach the ripe ova (eggs) of a tapeworm. When this happens he is liable to become the intermediate host, the part usually played by the pig or by cattle. A disease known as "echinococcus disease" is caused by man accidentally swallowing the ripe ova of a tapeworm ordinarily infecting dogs.

Trichina.-This is a parasite found in the flesh of hogs and transmissible to man. From the intestinal canal of man these tiny worms pass into the muscles, where they lodge and give rise to considerable pain and weakness. Trichiniasis, as the disease is called, is uncommon in 
this country, where but little pork is eaten raw. Infection is usually due to eating raw (merely smoked) ham.

Hookworm.-A disease common in Porto Rico and in the Southern States is due to infection with hookworm. This parasite appears to live only in man, and infection usually takes place through the skin, especially in those walking. barefooted. The first symptoms are those due to the penetration of the skin by the young worm, and constitute what is known as "ground itch." Subsequently the parasites enter the intestines and give rise to very characteristic symptoms, chief among which are anemia and laziness. The worm is sometimes spoken of as the "lazy worm."

Filaria.-The disease known as "filariasis" and "elephantiasis" is due to infection with a tiny worm which invades the blood and lymph passages. This infection is transmitted by a species of mosquito.

So far as the nurse is concerned, the description of the mode of infection, as just presented, should suffice to indicate the mode of prevention.

Pediculosis.-Infestation with lice, called pediculosis or lousiness, is important because lice are known to spread disease (trphus fever, trench fever, and probably other infections). The body louse is said to have about 5000 offspring in the course of two months. The eggs, called "nits," are slightly elongated, and fastened to the hair of the host or clothing. They hatch out in three or four day's and are sexually mature in about eighteen days. Lice are parasitic, blood-sucking insects, and three species are known to infest man. (For methods of combating lousiness see under "Disinfestation," page 169.) 


\section{CHAPTER XXXI \\ THE PRACTICE OF DISINFECTION}

Boiling Water.-The simplest method of disinfection, and one which can be used in the most primitive establishments as well as in the best equipped hospital, is boiling. No bacteria can withstand the action of boiling water if continued for a sufficient length of time. Most pathogenic bacteria are killed by boiling
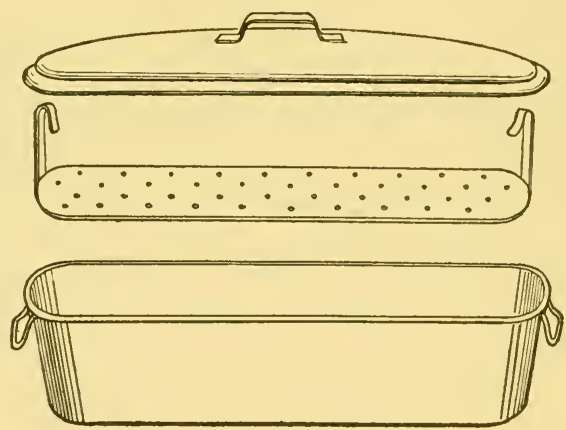

Fig. 48.-White enameled steel office sterilizer with handles and a perforated tray (Ashton).

at the end of ten minutes, while spore-bearers, like the anthrax bacillus, may require a half-hour or even longer. Any vessel which can be covered and placed over a fire answers for a sterilizer, though, of course, there are many types on the market constructed to suit various purposes. Usually they consist of a covered pan, fitted 
with a perforated tray or wire basket, supplied with handles, to enable one to lift the sterilized instruments, etc., out of the boiling water. The addition of 2 per cent. of ordinary washing soda to the water increases its disinfecting action, and at the same time prevents in a measure the rusting of metal instruments.

This method of sterilization is particularly well suited for soiled linens, for dishes, trays, pans, etc., that have come in contact with infectious material, for glass and metal instruments, such as catheters, irrigation tubes, forceps, etc. It is not so well suited for the sterilization of knives and scissors, since it spoils their keen cutting edge. For this reason some surgeons prefer to have these instruments kept in pure carbolic acid and transferred to sterile water before the operation. Catheters are to advantage boiled in water to which have been added 2 teaspoonfuls of liquid vaselin. This forms a thin, even coating of a sterile lubricant over the entire surface. Soiled linen should not at once be put into boiling water, since this fixes any stains; it may be put to soak for a few hours in cold water containing a pound of green soap in 25 gallons, and then may be heated in this to $70^{\circ}$ or $80^{\circ} \mathrm{C}$. These suds are then allowed to run off and are replaced by fresh, in which the linen is boiled fifteen to twenty minutes.

Steam.-A second method of using moist heat is in the form of live steam in a steam sterilizer, of which the Arnold sterilizer, already described, is a good example. This type of sterilizer is extensively used in bacteriologic laboratories for the sterilization of culture-media, and in hospitals for sterilizing dressings, rubber gloves, etc. Heating to $212^{\circ} \mathrm{F}$. $\left(100^{\circ} \mathrm{C}\right.$.) for an hour is enough to 
destroy all disease germs. Some culture-media, when heated to that degree for so long a time, undergo undesirable chemic changes; such media are subjected to what is known as fractional sterilization. They are heated in the Arnold sterilizer for twenty minutes on three consecutive days; the first heating destroys most,

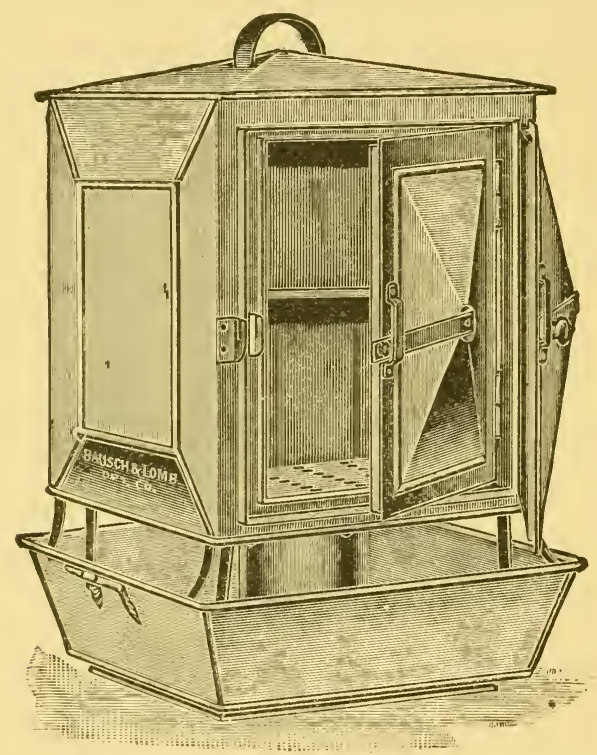

Fig. 49.-Arnold's steam sterilizer (Boston Board of Health form).

if not all, of the vegetating bacteria, and in the interval between the first and second heating the spores possibly present will develop into vegetative bacteria, in which state they are easily killed by the sccond heating. The process is repeated on the third day, in order to insure the death of all organisms which may have escaped the first two heatings. 
Steam Under Pressure.- When water is heated in an open ressel or one loosely covered-that is, at atmospheric pressure-the temperature cannot go above

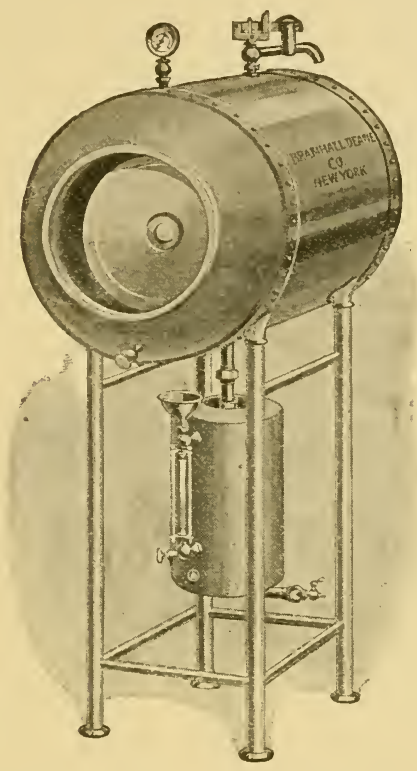

Fig. 50.-Autoclave sterilizer. Except in form, the autoclave differs but slightly from the fuli-jacketed sterilizer (Fig. 22, page 47 )。 It is made of heavy copper with solid east brass self-sealing door; the safety-valve is set to relieve at 15 pounds, and the jacket extends entirely around the chamber. The pressure, however, cannot be retained in the jacket while the door is open. Surgical dressings when withdrawn from the autoclave are dry. The latent heat of the steam at the high pressure will evaporate any moisture from the steam instantly upon exposure to the atmosphere.

$212^{\circ} \mathrm{F} .\left(100^{\circ} \mathrm{C}\right.$.), but when heated in a tightly closed container both the temperature and pressure increase, so that a temperature of $130^{\circ} \mathrm{C}$. and more, according to the amount of pressure employed, may be reached. 
Under these conditions the steam generated not only kills bacteria more readily than steam generated at atmospheric pressure, but also has a much greater power to penetrate to the interior of bulky objects, such as mattresses, bundles of dressings, or clothing. Steam under pressure is, therefore, a more valuable disinfectant. A good example of high-pressure steam sterilizer is shown in Fig. 50.

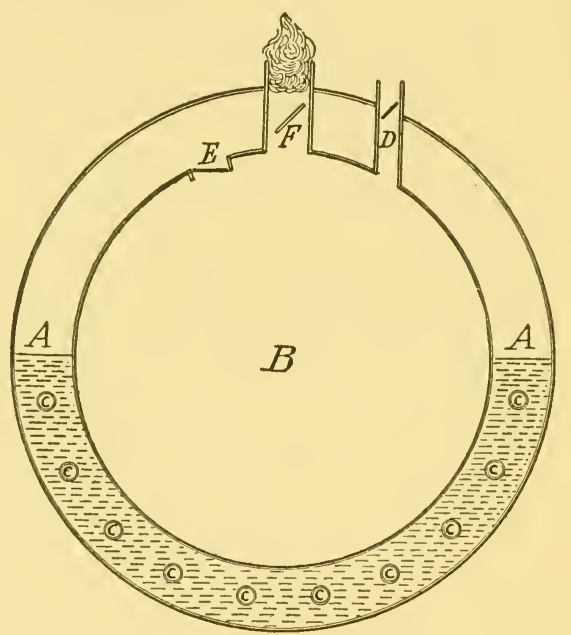

Fig. 51.-Diagram showing construction of a pressure steam sterilizer.

Another excellent type of pressure steam sterilizer consists of an outer and an inner jacket made of sheet metal. The space between these two, $A$, is half-filled with water, which is heated either from below by a gas burner or by means of steam circulating in coils $(C)$ within. As the water grows hotter, the air in the disinfecting chamber, $B$, becomes rarefied, and may be 
further exhausted by means of an exhaust valve $(D)$. When a partial vacuum has been created (5 inches, as registered by the gauge) the exhaust valve is shut off, and through another valve $(E)$ steam from the steam chamber is admitted. As this steam finds a partial vacuum it eagerly penetrates any pervious material placed in the sterilizing chamber. Dressings and all material to be sterilized are put into the apparatus as soon as the heating is started, and are, therefore, gradually warmed; consequently, when steam is admitted, it does not condense and does not wet the dressings. When the dressings, etc., have been in contact with the steam (the temperature of which varies according to the pressure under which it is produced) for twenty to thirty minutes the exhaust valve is again operated, for the purpose of sucking the excess of steam out of the material and leaving it very nearly dry.

When the door of the apparatus is to be opened, the vacuum must first be destroyed by admitting air into the steam chamber through another valve $(F)$, which is plugged with cotton.

The large municipal or private steam disinfecting plants act on the same principle, and differ only in size and details of construction.

This method of disinfection can be used for all ordinary cotton and woolen garments, bedding, rugs, mail from infected ports, etc., but it is not suited to rubber articles, furs, leather, delicate silks, or articles manufactured with gilue, such as books. Experiments conducted at the New York Quarantine Disinfecting Station with self-registering thermometers have shown that when a temperature of $110^{\circ} \mathrm{F}$. is maintained in the dis- 
infecting chamber for fifteen minutes, the same, or but a slightly lower temperature, is reached in the center of large bundles of clothes and bedding.

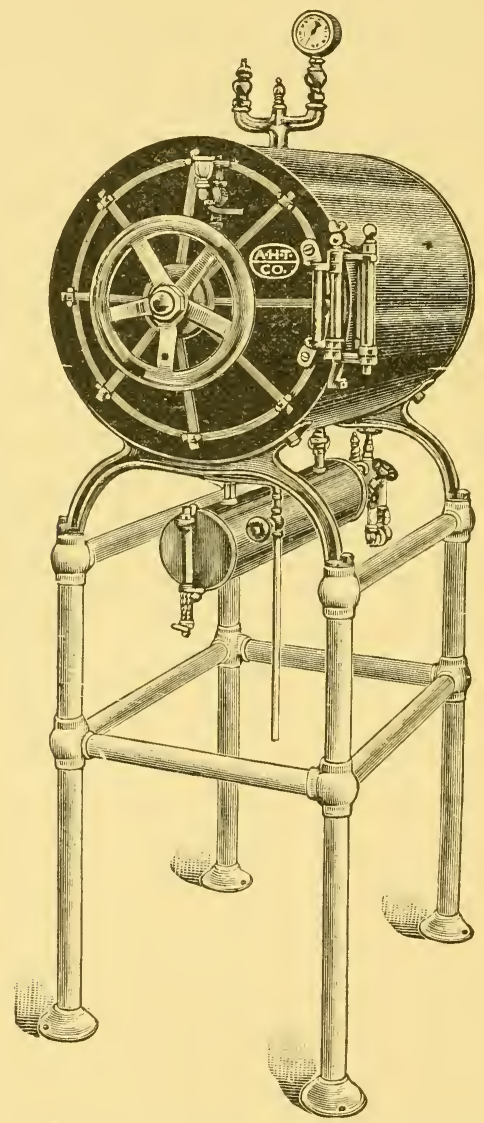

Fig. 52.-Autoclave (horizontal form).

Dry Heat.-When the rapid sterilization of small instruments, such as hypodermic needles, glass rods, 
etc., is required, these articles may be passed through the flame. This is the regular method of sterilizing the platinum wire used to transfer bacteria. But, except in an emergency, this method should not be used for surgical instruments, as it destroys the temper of steel and ruins the cutting edge of knives.

Glassware, such as catheters, pipets, test-tubes, etc., is sterilized in a hot-air oven. This is a box made of sheet metal with double walls, between which the hot air circulates. It is heated by gas burners from below, and a temperature of $150^{\circ} \mathrm{C}$. for one hour is required to properly sterilize the glass- or metal-ware, for which alone it should be used. The oven of an ordinary kitchen range answers very well for a substitute. (See Fig. 19, p. 44.)

Chemicals.-There are a few objects which cannot be sterilized by any of the foregoing methods. Mention has already been made of the fact that boiling dulls the edge of knives, which are, therefore, kept in pure carbolic. Clinical thermometers are also kept in a carbolic solution. One of the most difficult materials to render and to keep sterile is catgut, and several ways have been devised for its sterilization. Catgut may be sterilized by dry heat, being first heated to $70^{\circ} \mathrm{C}$. for two hours, to drive off the moisture. When this has been accomplished the catgut may be exposed to a temperature of $150^{\circ} \mathrm{C}$. without becoming brittle. To keep it sterile it is stored in tubes plugged with cotton. When there is any doubt about its sterility it may be placed for eight days in a 3 per cent. solution of iodin in acetone, then into acetone for four days, to remove the excess of iodin, and, finally, into a mixture of acetone 
85 parts, columbia spirits 10 parts, glycerin 5 parts. In this mixture it is kept until used.

Preparation of Patient for Operation.-Until comparatively recently it was the practice to prepare the patient for an operation by a full bath on the preceding night, to shave the site of the operation, and carefully cleanse it with hot water and green soap. It was then rinsed with alcohol and ether and with a 1:1000 solution of bichlorid of mercury. Then a gauze compress was applied which had been soaked in a 25 per cent. solution of green soap in water; this was covered with rubber tissue, and left in place from three to twelve hours. The washing with alcohol, ether, and bichlorid was then repeated and the skin covered with a bichlorid bandage. Just before the operation it was again scrubbed with soap and washed with alcohol and ether and bichlorid. This method was fairly efficient to sterilize the patient's skin, but it was cumbersome and very uncomfortable to the patient. Moreover, it was found that an absolute disinfection of the living skin could not be hoped for by any amount of scrubbing, since the deep skin glands continued to harbor bacteria. Some surgeons then covered the skin with an aseptic, gum-like substance, with the intention of holding the inevitable skin bacteria in place. These substances were apt to crack or tear and were not extensively used. Alcohol has a hardening effect on the skin, and tends to "fix" the bacteria there; it is used either alone or as a strong tincture of green soap as the sole disinfectant by some operators. This action is transient, and may be increased by adding to the alcohol such substances as tannin, ether, or nitric acid. A method which has found much favor both here 
and abroad is the disinfection by iodin. The patient receives a full bath on the evening preceding the operation; any hairy portions of the skin are shaved, but no dressing whatever is used; just before anesthetizing the site of the operation is painted with a solution of iodin in 50 per cent. alcohol and is covered with sterile towels. The painting is repeated just before the operation. The action of the iodin is the same as that of alcohol, but is more pronounced and lasting. Its greatest disadvantage is the occasional development of an iodin dermatitis; this is most likely to occur when the solution used is too strong (it should not be more than 5 per cent.); second, when the solution is old and contains decomposition products of iodin; third, when the skin is unusually tender, as in children; or, fourth, when the skin has been previously washed with antiseptic solutions or even plain water. In emergency cases no previous washing is resorted to, but the skin is cleaned with a 1 per cent. solution of iodin in benzene two to five minutes before the iodin is applied.

Disinfection of the hands is closely allied with the preparation of the patient, and, to a certain extent, the same methods can be used for both. A ten minutes' scrubbing with a bristle brush, using hot water and a tincture of green soap, and giving special attention to the skin folds at the base of the nails and the space under the nails, is followed by rinsing in alcohol, ether, and bichlorid solution. Hands may thus be superficially sterilized, but when they are immersed in hot solutions, which induces sweating, countless bacteria will be driven from the sweat and scbaceous glands to the sterilized surface. This has been repeatedly proved by 
experiments, and surgeons have had recourse to a mild process of tanning; that is, immersing the hands in a hardening solution, such as 60 per cent. alcohol or tincture of iodin. Both of these substances, when continuously used, are injurious to the skin, and the great majority of operators prefer to wear gloves during operations and require the same of the assistants. When rubber gloves are worn the soaking of the hands in bichlorid solution before putting on the gloves may calise a severe dermatitis. Rubber gloves are more frequently used than those of lisle, their chief advantages being that they are not porous, do not appreciably impair the tactile sense, and in certain cases, as in exploring a cavity, their slippery condition is a material aid. Against these are to be weighed their greater initial cost and their slight durability. Rubber gloves can be sterilized in the same sterilizer in which instruments are boiled, but they should be wrapped in gauze to prevent their coming into contact with metal; or, they may be kept for an hour in the Arnold steam sterilizer.

\section{Disinfection to Prevent the Spread of Contagious Dis-} eases.-It is usually far more important to prevent the spread of contagion during the patient's illness than it is to fumigate the apartment and its contents after convalescence. The sick room should be kept free of all unnecessary furniture, and particularly of rugs and hangings. In place of sweeping and dusting, the furniture, as well as the floor and any woodwork, should be wiped with an oiled rag or with a cloth moistened with 1:2000 bichlorid solution. No steaming, spraying, or fumigation of any efficiency can be carried out in an 
apartment which is occupied. ${ }^{1}$ Hence, during the illness, aside from thorough ventilation, and the precautions already described, the important thing is to destroy or render harmless any discharges or dressings, etc., from the patient. Anything of no value, as dressings, should be burnt immediately; likewise nasal discharges or sputum collected in rags or paper receptacles.

Stools of patients suffering from typhoid fever, cholera, or other intestinal diseases must be received in covered vessels, and at once mixed with a disinfectant fluid; neither carbolic nor bichlorid is well suited to the purpose, since both are relatively inert in the presence of much albuminous matter. When chlorid of lime or milk of lime are used, a good mixture must be effected by thorough stirring. At least 1 quart of the standard solution of chlorid of lime ( 4 ounces to 1 gallon of water) should be used for each dejection. At the recent International Congress of Hygiene and Demography, Prausnitz advocated Kaiser's method of disinfecting stools by means of the heat generated by pouring water over quicklime which had previously been mixed with the stool.

Linen and cotton clothing is best boiled, and a method has already been indicated for its disinfection by this process. It may also be soaked in a 1:1000 solution of bichlorid of mercury or a 1:50 solution of carbolic acid; woolen clothing, which would be injured by boiling, may be similarly disinfected, or by means of formaldehyd. All bundles of infected clothing removed from

${ }^{1}$ In very chronic infectious diseases, like pulmonary tuberculosis, it is, however, advisable to thoroughly clean and disinfect the patient's apartment from time to time. 
the sick room must be wrapped in a sheet, either sterilized or wrung from an antiseptic solution, to prevent spreading contagion on the way.

The patient's eating utensils must not be used by anyone else unless they have first been thoroughly boiled. This is especially true in cases of diphtheria or tuberculosis, but ought to be applied in all infectious diseases. All left-over food is to be burned.

After convalescence is established the patient should receive at least one full bath and have a complete change of clothing before he is allowed to mingle with others. Bichlorid of mercury may or may not be added to the bath.

Among the various agents used to fumigate apartments after an infectious disease sulphur dioxid has been extensively used in the past, but its action is not dependable, and it has been almost entirely superseded by formaldehyd. - Sulphur fumigation is, however, still most useful in killing vermin, such as rats and mice, fleas, lice, etc. Before fumigation the apartment may be cleaned, all gross infectious material-e.g., dried sputum, etc.is soaked in 5 per cent. solution of bichlorid of mercury, scraped off, and burnt. All dust is soaked with the same solution, the floors and all the wood work are carefully washed with it; also the walls, if this is practicable. Then soap and hot water are liberally applied, and the apartment is thoroughly ventilated. If this process is carefully and faithfully carried out it may be possible to dispense with formalin disinfection; the latter is, however, an additional safeguard. Before starting fumigation, all cracks and crevices, keyholes, and other small openings are tightly sealed with gummed paper. 
There are various methods of generating formaldehyd gas, and a number of lamps have been constructed for the purpose. Of late good results have been reported by mixing the solid commercial formalin or paraform with potassium permanganate, using 6 ounces of each for 1000 cubic feet of air space.

A special apparatus has been constructed for this, but it is possible to carry it out by using a deep enameled pail. The formalin or paraform must be thoroughly broken up before the permanganate and water are added, otherwise much will remain unaltered and will not be converted into gas. The fumes are kept in the room for twelve hours, and when the process of disinfection is completed they may be displaced by ammonia. Formaldehyd does not injure wool or silk, gilt, copper, or leather.

Formaldehyd is a very efficient surface disinfectant, but under ordinary circumstances it does not penetrate to any depths. The "Japanese method secures much greater penetration. In this the formaldehyd gas is diffused, by means of a rather complex apparatus, throughout steel chambers which have previously been heated to $65^{\circ} \mathrm{C}$. Clothing, rugs, etc., are exposed to these formaldehyd vapors for fifteen minutes with satisfactory results-i.e., bacteria in the interior of the bundles were destroyed.

So far as the need of fumigation i: concerned, the reader is referred to page 57.)

The use of chlorin in the disinfection of water supplies has already been described. (See pages 39 and 149.) 


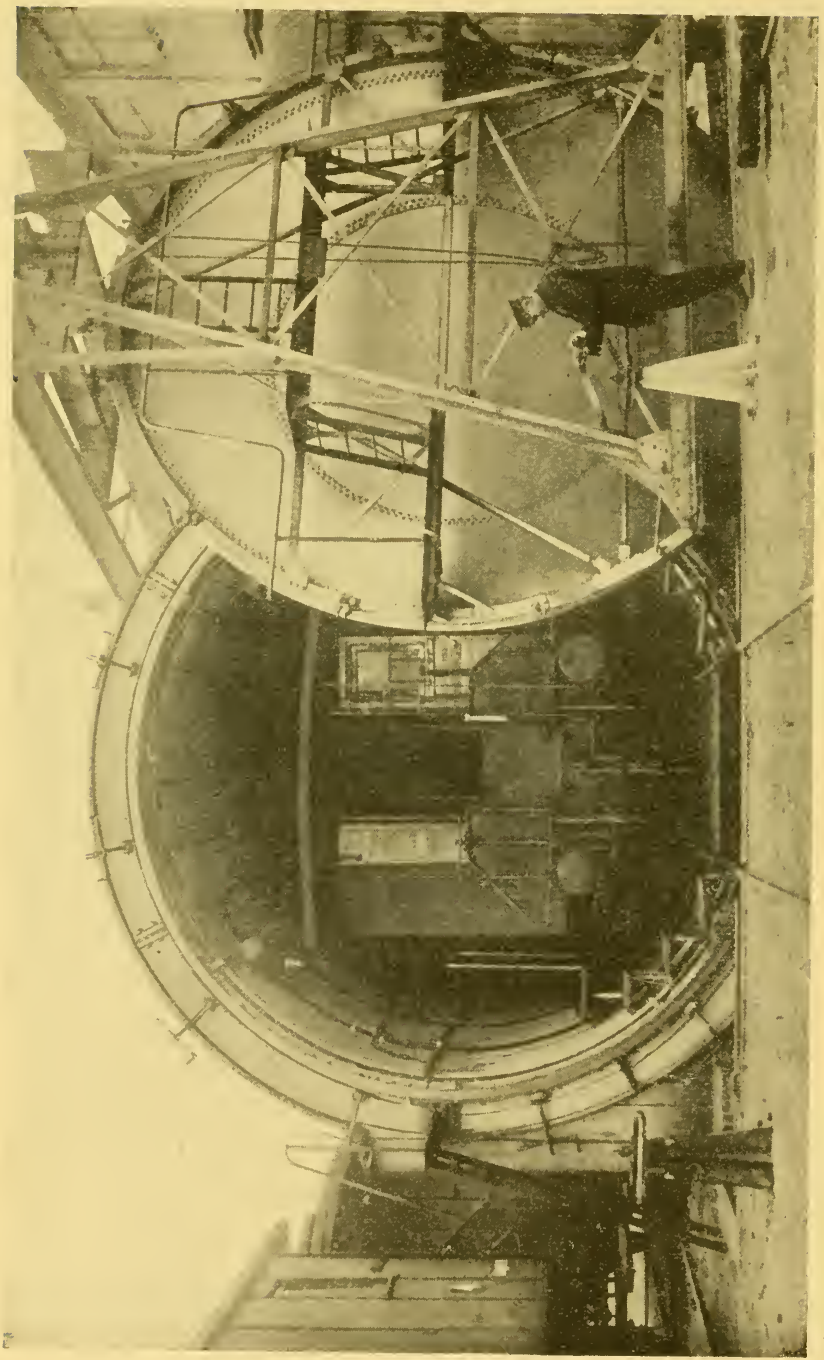

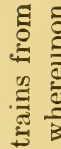

च

ㄱ. 웅

过

¿

$\frac{7}{20}$

के

흥

유

$5 \div$

○ 2

$\leftrightarrows$ ¿

छ $\cong \frac{0}{0}$

$c=$

$>0$

직

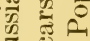

כ)

르 $\Rightarrow$

$\Xi \sum$

을

क. 융

$\frac{2}{5}=$

웡 욤

प्र

¿

ㄴ.

$-00$

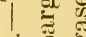
$\rightarrow ت$ o

घิ

证. 焉

胥 


\section{DISINFESTATION}

The important part played by lice in the transmission of disease has been demonstrated anew by the recent war, and delousing, or "disinfestation" as it is called, has accordingly had considerable attention. In practice it has been found that one of the most reliable means of destroying lice in clothing is by the application of dry heat or steam. Immersion of the garments in gasoline is also highly effective and may often be more convenient. Where there is a danger of fire, tetrachlorethane may be used, as this is not inflammable.

To keep lice away the application to the body of a grease containing naphthalene, coumarn, heliotropin, or certain other odorous substances has been recommended. The effect of this wears off as the grease is absorbed by the underclothing; nevertheless the treatment is of service.

So far as head lice are concerned, the application of crude petroleum at night, the head being then bound in a towel, followed by a thorough washing and combing in the morning, will usually suffice to effect disinfestation. In the picture on the opposite page is shown the application of poisonous gases to railway coach disinfestation. 


\section{CHAP'TER XXXII}

\section{COLLECTION OF MATERIAL FOR BACTERIOLOGIC EXAMINATION}

Oftentimes the material sent to the laboratory for bacteriologic examination has been so improperly collected or handled that its examination is entirely useless. Much of the trouble ran be avoided by a little attention to details.

In most cases bacteriologic specimens should be collected in sterile containers. An exception may be made in the case of sputum to be examined microscopically for tubercle bacilli. When cultures are to be made the specimens should be hurried to the laboratory without delay. In all cases where a culture is made at the bedside or operating table, a smear preparation should be made from the same material and sent to the laboratory with the culture. Oftentimes such a smear gives invaluable information not obtainable by the culture alone. All specimens should be accompanied by a memorandum showing the character and source of the material, the name of the patient, date and hour of collection, and a definite statement as to what information is wanted from the bacteriologist. It is important not to add disinfectants to specimens from which cultures are desired.

Sputum.-Care should be taken that the specimen of sputum has actually becn coughed up. Some patients 
will hawk up mucus coming from the nose, others will spit out saliva, still others will be at a loss what to do. Sputum should never be sent to the laboratory merely in a gauze handkerchief or on a piece of paper, but only in a small, wide-mouthed bottle securely corked, or in specially prepared water-proofed wood boxes. In infants and children sputum can be obtained by means of a small piece of gauze, held with a stick or thumb forceps in the child's throat. This induces a reflex cough, with the expulsion of some of the desired sputum on the gauze.

Special care should be taken in the collection of sputum from pneumonia patients for the purpose of having the type of pneumococcus determined. Such sputum should be collerted in a clean, sterile bottle, without disinfectant, and the specimen should at once be sent by special messenger to the bacteriological laboratory.

Throat Smears. - When the throat is covered with membrane the physician often desires cultures to determine the nature of the infection. These are made as follows: Prepare a small sterile cotton swab, place the patient in a good light, and then gently wipe off some of the exudate. Make sure that no antiseptic has been applied to the throat within the previous two hours. If culture-tubes are available, wipe the swab holding the exudate over the surface of the culture, being careful not to break the surface. For accurate diagnosis it is advisable also to spread some of the exudate on the swab on a glass slide and send this along with the culture.

Water.-Water for bacteriologic examination should be collected in sterile 1-ounce bottles, and kept cool during transportation to the laboratory. In collecting 
water from a faucet care should be taken to secure a typic specimen by allowing the water to run for some time before collecting. In the case of springs, wells, reservoirs, etc., one should not dip water from the surface, for such a specimen would probably contain an undue proportion of bacteria from the dust of the air.

Milk. - When milk is to be examined, one must be sure to secure a representative sample by thoroughly mixing milk and cream. The latter always contains a very large number of bacteria.

Autopsies.-Specimens of organs are secured free from outside contamination by first searing the surface of the organ with a hot iron, and then cutting a piece of tissue from beneath the seared surface. Similarly, in securing specimens of heart's blood the surface of the heart is first seared with a hot iron, and then, with a sterile hollow needle, blood is drawn from within the heart cavity by thrusting the needle through the seared surface. The piece of tissue or blood should be placed in a sterile bottle or test-tube plugged with cotton and at once carried to the laboratory.

Urine.-The nurse will be familiar with the collection of specimens of urine for the ordinary chemical and microscopic examination. In certain instances, however, it is desired to make cultures, and then great care must be taken to collect the specimens, by means of a sterile catheter, in a sterile bottle.

Feces.-Bacteriologic examinations of feces are frequently undertaken in order to discover the presence of typhoid bacilli. Such specimens should be placed in a clean wide-mouthed bottle and tightly corked. The bottle should never be more than half-full. The specimen 
should be fresh, and should be sent to the laboratory without delay. In summer the specimen should be kept cool with ice. Under no circumstances should a disinfectant be added.

Spinal Fluid.-Inasmuch as the bacteriological examination of spinal fluid by means of cultures is so often of decisive importance, care should be taken to collect this fluid only in clean, sterile bottles or test-tubes, and forward these at once to the laboratory. A disinfectant should not be added. 


\section{CHAPTER XXXII}

\section{OTHER IMPORTANT PATHOGENIC MICRO-ORGANISMS}

Is addition to the micro-organisms already described, the following are important ones pathogenic for man:

Colon Bacillus.-A rather plump, Gram-negative bacillus, normally occupying the intestines of man and animals, and capable of producing infection in man.

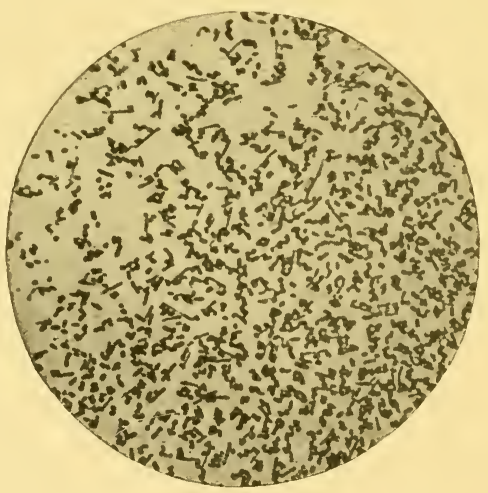

Fig. 54.-Colon bacillus; twenty-four-hour agar culture; $\times 650$ (Heim).

Occasionally this organism produces infection in man, the commonest form being pyelitis (inflammation of the funnel-shaped urinary tube connecting the kidney with the ureter) and cystitis.

The presence of colon bacilli is used in sanitary water examinations as an indication of fecal pollution. Pro- 
phylaxis is similar to that discussed under Typhoid Bacillus.

Pneumobacillus of Friedländer.-A short bacillus, often occurring in pairs or chains of four, capsulated, and Gram-negative. Found in certain cases of pneumonia and pleurisy. Prophylaxis is similar to that discussed under the Pneumococcus.

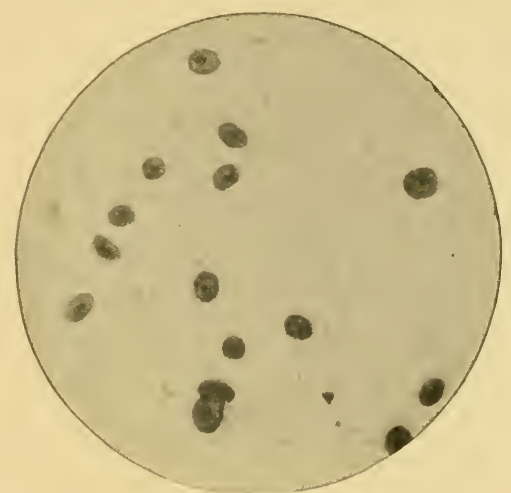

Fig. 55.-Friedländer's pneumobacillus. Welch's capsule stain; $\times 1100$ (Jordan).

Paratyphoid Bacilli.-Similar to tỵphoid bacilli and colon bacilli, and producing infections in man resembling typhoid fever or, at times, symptoms of epidemic meatpoisoning. Prophylaxis is discussed under Typhoid Bacillus and under Bacterial Food Poisoning.

Influenza Bacillus (Pfeiffer's Bacillus).-A very small, moderately thick bacillus, growing only on media containing blood (hence spoken of as a "hemophilie" bacillus), and occurring chiefly in inflammations of the respiratory passages.

The opinion is gaining ground that influenza is caused 
by some virus, perhaps ultramicroscopic (filterable), as yet unidentified, and that the so-called influenza bacillus (Pfeiffer's bacillus) is really a secondary invader. It would seem probable that the original infection makes secondary invasion by other germs, especially influenza bacilli, pneumococci, and streptococci, much more easy. In this connection it may be stated that a French investigator, Nicolle, claims to have demonstrated the filterable nature of the influenza virus.

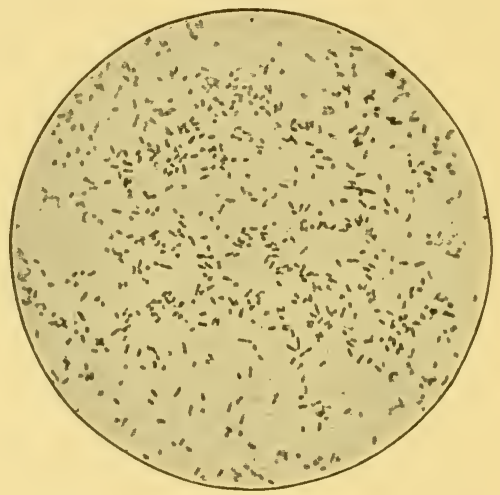

Fig. 56. - Peieffer's bacillus; $\times 1000$ (Král).

Now and then the influenza bacillus produces a typical meningitis. This is very fatal. A bacillus similar to the influenza bacillus appears to be associated with whoopingcough. Prophylaxis in influenza is similar to that discussed under Pneumococcus.

Micrococcus of Malta Fever.-A very small, rounded or slightly oval micro-organism, Gram-negative, and growing rather feebly on artificial media. The organism appears to be present in the feces of goats in Malta, and probably contaminates the milk. In man a typhoid- 
like fever is produced. Prophylaxis is similar to that discussed under Typhoid Bacillus.

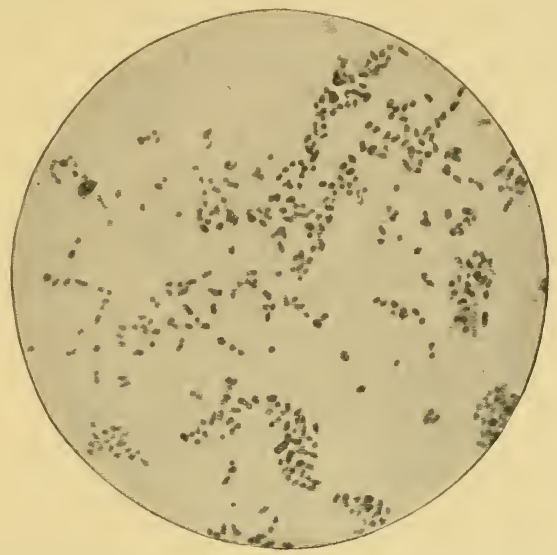

Fig. 57.-Micrococcus of Malta fever. Carbol fuchsin; $\times 1200$ (Jordan).

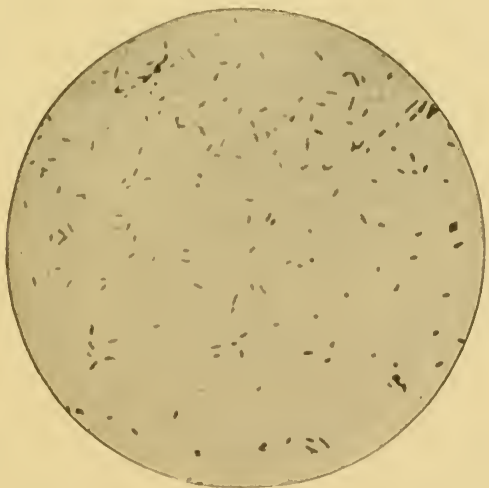

Fig. 58.-Bacillus pyocyaneus. Pure culture on agar. Fuchsin stain (Kolle and Wassermann).

Bacillus Pyocyaneus.-A slender, aërobic, motile bacillus, widely distributed in nature and occasionally pro- 
ducing infections in man. These are characterized by the production of a blue or blue-green pus, whence the name, pyocyaneus, signifying blue pus. Prophylaxis is similar to that described under Streptococcus and Staphylococcus.

Glanders Bacillus.-A small bacillus with rounded ends, Gram-negative, non-motile. Common in horses, where it produces the disease known as glanders or farcy, and easily communicated to man, where it produces an in-

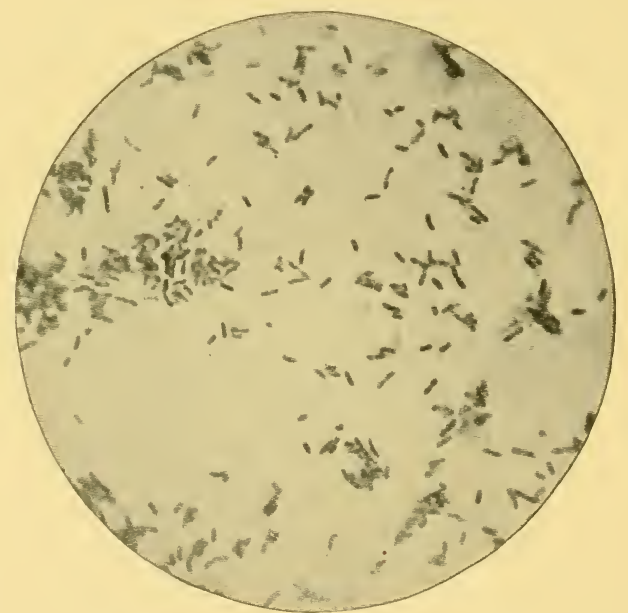

Fig. 59-Bacillus mallei (glanders). Pure culture from glucoseagar. Carbol fuchsin; $\times 1200$ (Jordan).

fection which is fatal in 60 per cent. of the cases. The infective material exists in the secretions of the horses' nose, in the pus of glanders nodules, and frequently in the blood. Prophylaxis is indicated by what has just been said. Glandered horses should be promptly destroyed. 
In diagnosing the infection in horses serum examinations are of service. The serum is tested by means of complement fixation and agglutination reactions. The animals can also be tested by means of "mallein" (made from glanders bacilli), the injection of mallein being followed by a typical febrile reaction.

Bubonic Plague Bacillus.-Short, thick rods with rounded ends, Gram-negative, aërobic, and non-motile.

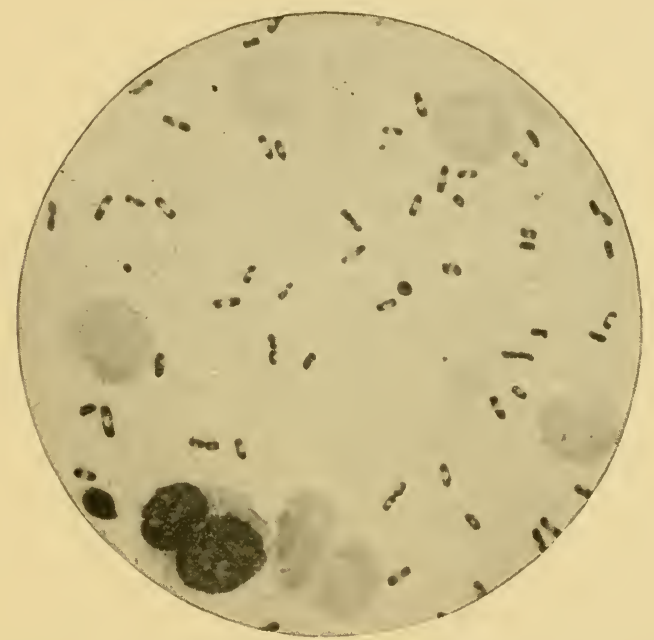

Fig. 60.-Bacillus pestis (bubonic plague) in smear from rat's liver, showing bipolar staining; $\times 720$ (Wherry).

In man the infection occurs in two forms: the bubonic, involving the lymph-glands; the pneumonic, involving the lungs. The disease is spread directly from man to man, especially in the pneumonic form, and also from rats, ground squirrels, and other rodents to man. In the latter case infection is usually intermediate through 
fleas infesting these rodents. Prophylaxis: Discovery and destruction of all infected rodents, and in the pneumonic form extreme care to guard against infection through coughing, sneezing, etc., and infection from the sputum.

Anthrax Bacillus.-Mostly in the form of slender, nonmotile rods, Gram-positive, and forming spores possessing great resistance to destructive agents. Anthrax is primarily a disease of cattle and sheep, but humans,

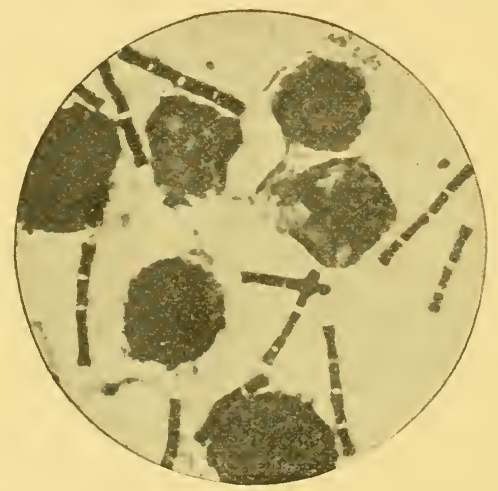

Fig 61.-Bacillus of anthrax in spleen pulp. Fuchsin stain; $\times 2000$; C. Fränkel prep. (Kolle and Wassermann).

especially those who handle hides or whose occupation brings them into contact with animals, are occasionally infected, usually in the form of "malignant pustule." Among wool-sorters a very fatal pulmonic type of infection is observed. Some recent cases observed among soldiers were traced to the use of shaving brushes made from bristles which had not been sterilized. Most of the bristles came from China. Prophylaxis: The disease in cattle and sheep is combated by means of immunizing 
injections of anthrax vaccine. Care should be taken to properly dispose of the carcass of any animal dead of anthrax.

Malignant Edema Bacillus.-A fairly long, thick rod with square ends, Gram-negative, and forming spores. It is a strict anaërobe. The infections in man are usually the result of infecting wounds with garden earth. Pro-

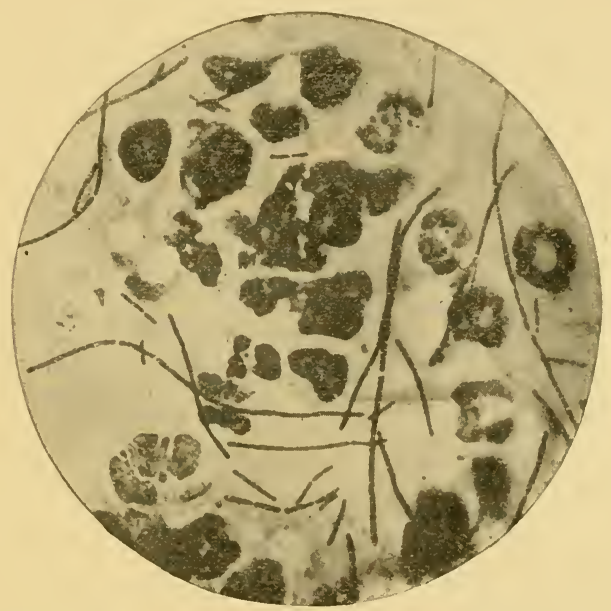

Fig. 62-Bacillus of malignant edema. Tissue juice of guineapig after injection with a broth culture. Smear preparation, stained with fuchsin. $\times 1000$ (Fränkel and Pfeiffer).

phylaxis: The careful cleansing of all wounds, especially those thought to be infected with earth.

Bacillus Perfringens.-This organism, also known as the bacillus of gas gangrene, Welch's bacillus, or the Bacillus aërogenes capsulatus, is found in the intestinal canal of man and animals and in soil and dust. When introduced into wounds, as, for example, in the recent 
war, by the contamination of wounds with soil or infected dust, it causes a serious infection characterized by the formation of gas in the tissues.

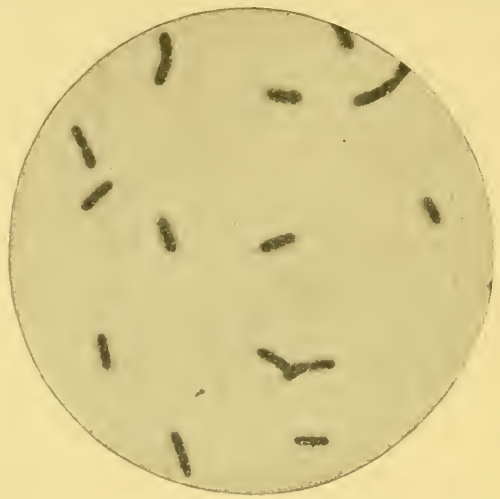

Fig. 63.-Bacillus perfringens, showing capsule; $\times 1100$ (Hicks).

The bacillus is a large rod, Gram-positive, and under certain conditions produces spores. It produces a toxin against which, recently, an antitoxin has been developed. This has been utilized to some extent during the war.

Leprosy Bacillus.-Small, acid-fast rods, resembling tubercle bacilli, found in large numbers, especially in the cutaneous lesions. It is not yet established just how the disease is communicated.

Trench Fever.-An infection which caused an enormous amount of illness among the troops in France, and at first mistaken for influenza, for rheumatic fever, and for other febrile infections, is now known to be a distinct disease, and called "trench fever." It is caused by a filterable virus (see Chapter XXIV) which is present in the blood of the patients. Occasionally the virus is found also in the patient's urine and sputum. 


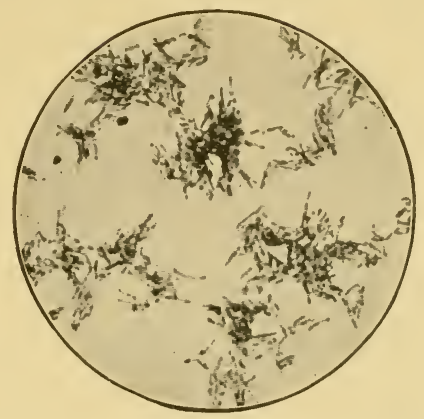

Fig. 64.-Pure culture of bacillus of leprosy, showing the characteristic morphology and arrangement of the bacilli (Duval).

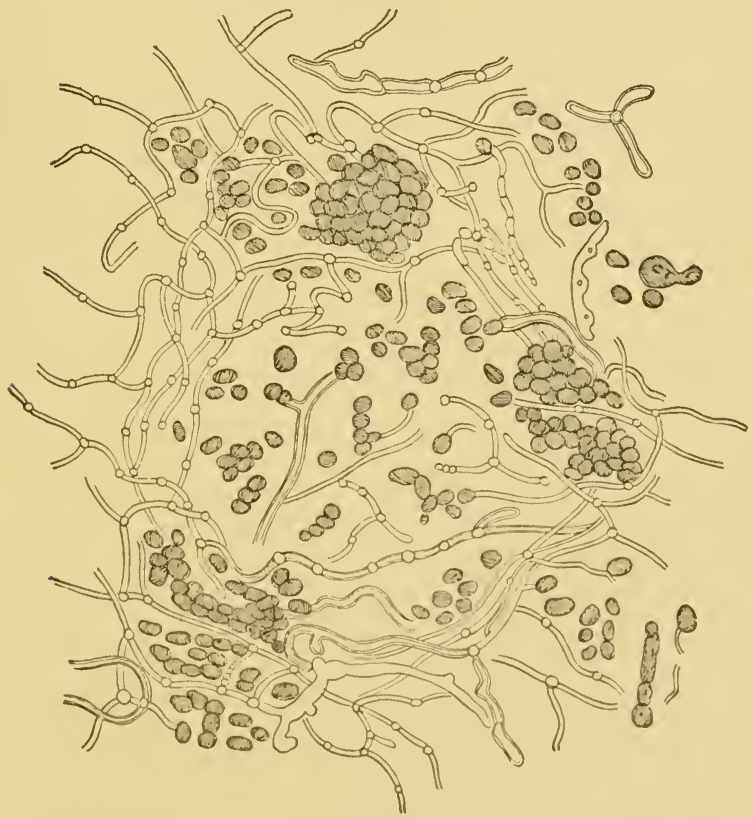

Fig. 65.-Microsporon furfur, fungus of pityriasis versicolor; $\times 700$ (Kaposi). 
The disease is commonly transmitted by the bite of the common louse; sometimes by scratching into the skin the excreta from infected lice. Prevention of the disease is chiefly by the prevention of lousiness.

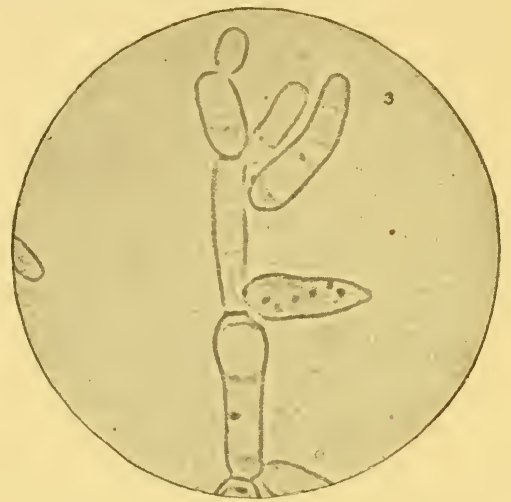

Fig. 66.-Oïdium (Kolle and Wassermann).

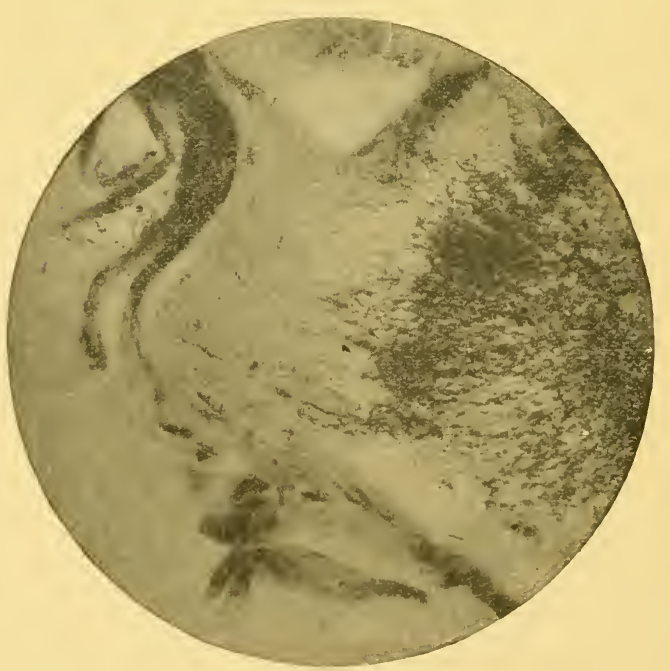

Fig. 67.-Achorion schönleinii, section showing the hyphæ (Fränkel and Pfeiffer). 
Microsporon Furfur. - This is a mold producing in man the skin disease known as "pityriasis." It is observed chiefly in persons living under conditions of uncleanliness or among those who combine these conditions with a tendency to profuse perspiration.

Oidium Albicans.-This is a mold producing in children the disease of the mouth known as "sool" or "thrush."

Achorion Schönleinii.-This is a mold producing the discase known as "favus," is an affertion of the scalp, which rums an extremely chronic course.

Trichophyton Tonsurans.This is a nold producing the disease in man known as "ring-worm."

Poliomyelitis.-The infecting microörganism of this disease has not yet been isolated, but is known to exist in the nasal sccretion and blood of infected individuals. It must be very small, for it passes through the pores of a

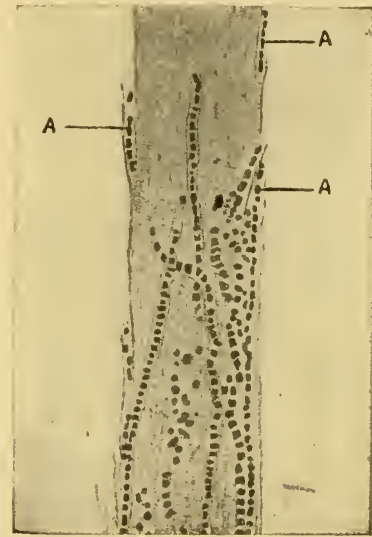

Fig. 68.--Invasion of a human hair by trichophyton: A, Points at which the parasitic fungi coming from the epidermis are elevating the cuticle of the hair and entering into its substance; $\times 200$ (Sabouraud).

Berkefeld filter. The disease is said to be transmitted through the bite of stable flies, but probably mainly through infected nasal discharges. 



\section{INDEX}

Abscess, 52

stitch, 112

Achorion sehönleinii, 1S5

Acid, effect of, on stained bacteria, 26

formed by bacteria, 35

Aeid-fast, definition of, 26, 77

Aëdes calopus mosquitoes, 5s, 132

Aërobie bacteria, definition of, 20

Agglutination of typhoid bacilli, 71

Agglutinin, nature of, 70

Alcohol, effect of, on leukocytes, 67

Anaërobic bacteria, definition of, 20

Anaphylaxis, nature of, 75

Animal parasites, 152

Anopheles in malaria, 58, 128 mosquitoes, 131

Anthrax, bacillus of, 180 inmunity of dogs to, 64 through food, 144

Antibodies as defence against bacteria, 67

Antimeningoeoccus serum, 115

Antiseptic surgery, Lister's, 12

Antiseptics, effeet of, on bacteria, 36

Antistreptococeus serum, 110

Antitoxin of diphtheria, 99 of tetanus, 103

Antitoxins, nature and rôle of, 67
Arnold steam sterilizer, 45 sterilizer for milk, 136

Autoclave, 46, 157

Autopsies, collection of material from, 172

Bacillus aërogenes capsulatus, 181 botulinus, 143 coli, 174 definition of, 15 enteritidis, 143 mallei, 178 of anthrax, 180 of blue pus, 177 of diphtheria, 95 of dysentery, 86 of gas gangrene, 181 of glanders, 178 of influenza, 175 of lactie acid, 140 of leprosy, 182 of malignant edema, 181 of paratyphoid fover, 175 of plague, 179 of pneumonia, 175 of scarlet fever, 12: of tetanus, 101 of tuberculosis, 91 of typhoid fever, 81 perfringens, 181

pestis, 179

Pfeiffer's, 175 
Bacillus, proteus vulgaris, 144 pyocyaneus, 177

Welch's, 181

Bacteria, rharacter of, 14 cultivation of, 27 definition of, 13, 14 effect of disinfectants and antisepties on, 36 of heat and cold on, 36 important pathogenic species, 49

in food poisoning, 143

in milk, 134

incubation of, 29

methods of studying, 22

motility, 17

relation of, to destructive in-

fluences, 36

to disease, 48

spore formation, 17

staining of, 25

Bacterial vaceines, 77,78

Bactericidal serum, 69

Bacteriology, definition of, 13 historic, 11

Bacteriolysins, nature and rôle of, 68

Behring, discovery of diphtheria antitoxin, 97

Bichlorid of mercury, effect of, on bacteria, 37

Blood, defensive rôle of bloorlserum, 66

parasite of malaria in, 128

Blood-stains, test for, 7.5

Blown cans, 145

Boiling water for disinfection, Cytolysin, nature of, 69 154

Boils, treatment, with bacterial vaccines, 79,113

Bronchopneumonia, 106

Budding, definition of, 13
C/.Lmette test for tuberculous infection, 94

Cancer, relation of bacteria to, 49

Carbolic acid, effect of, on bacteria, 38

Carriers in the transmission of disease, 56

Cellulitis, 52

Chanere in syphilis, 119

Chicken-pox, quarantine in, 63

Chickens, immunity to tetanus, 64

Chloramine- $\mathrm{T}$ as disinfectant, 41

Chlorid of lime, effect of, on bacteria, 39

Chlorin in disinfection of water, 39,149

Cholera, bacteriology of, 88

carried by water, 147

quarantine in, 63

spirillum, 88

treatment of, 79

Coceus, definition of, 15

Cold, effect of, on bacteria, 36 on leukocytes, 67

Colon bacillus, 174

in food poisoning, 144

in sanitary water examinations, 151

Colostrum, rôle of, in transmission of immunity, 65

Complement, rôle of, 70

Cow-pox, 124

Creolin, effect of, on bacteria, 38

Culex in relation to malaria, $5 \mathrm{~s}$

Cultures, method of making, 27

DAKIN's solution, 41

Davaine, anthrax discoveries, 11

Delousing, 169

Dengue, virus of, 127 
Dichloramine- $\mathrm{T}$ in dressing in- Exanthemata, bacteriology of, fected wounds, 41

Diphtheria antitoxin, 99 bacillus, 95

bacteriology of, 95

quarantine in, 61

Schick test, 100

serum treatment, 78

throat smears in, 97, 171 toxin, 98

Diplococci, definition of, 16

Diplocoecus of gonorrhea, 117 of meningitis, 114

of pneumonia, 104

Disease, relation of bacteria to, 48

transmission of infectious, 55

Disinfectants, effect of, on bacteria, 36 testing of, 42

Disinfection in contagious diseases, 164

of drinking-water, halazone for, 42,150 practice of, 134

Disinfestation, 169

Drinking-water, halazone in disinfection of, 42,150

Dry heat for destroying lice, 169 for sterilization, 43

Drying, effect of, on bacteria, 36 Dysentery, amebic, 86

bacillus of, $\$ 6$

bacteriology of, 86

Limpyema, 53 122

Fanduener on transmission of immunity, 65

Favus, 185

Feces, collection of, 172

Fermentation tube, 34

Fermented milk, bacteriology of, 140

Fermilac, bacteriology of, 142

Filaria, 153

Filterable viruses, 126

Filters, bacterial, 126 domestic, $14 \mathrm{~S}$

Fire for sterilization, 43

Fishing for pure cultures, 34

Fixing of microscopic smears, 25

Flagella in motile bacteria, 17

Flies as carrier's of infection, 58 , 139 in relation to poliomyelitis, 185 to typhoid fever, $\$ 2$

Fomites as carriers of disease, 55

Food poisoning, bacterial, 143

Foot-and-mouth disease, virus of, 127

Formaldehyd, effect of, on bacteria, 40

for fumigation, 167

Fracastor's conception of nature of infectious diseases, 11

Freeman's pasteurizer for milk, 136

Friedländer's bacillus of pneumonia, 175

Epidemic eerebrospina! meningi- Fumigation after infectious distis, 114

quarantine in, 62

serum and vaceines in, 78

Estivo-autumnal malaria, parasite of, 129

terminal, 57

to kill vermin, 168

with sulphur, 40

Fungi, definition of, 13 
Gartner's bacillus in food poi- Incubator for bacteria, 29 soning, 143

Gas, formation of, by bacteria, 35 gangrene, bacillus of, 181

Gasoline for destroying lice, 169

Gastric juice, rôle of, in combating bacteria, 66

German measles, 123

quarantine in, 63

Glanders, bacillus of, 178

Goats, immunity to tuberculosis, 64

Gonococcus, 117

Gonorrhea, bacteriology of, 117 vaccine treatment of, 118

Gram's stain, 26

Grease for destroying lice, 169

Halazone for disinfection of drinking-water, 42,150

Heat, destructive effect of, on bacteria, 36

dry, for destroying lice, 169

in cultivation of bacteria, 31

sterilization by, 43

to fix bacteria, 26

Hemameba malariæ, 128

Hip disease, 92

Hog cholera, virus of, 127

Hookworm, 153

Horses for antitoxin, 98

Hot air, sterilizing with, 43

Hydrocephalus, 92

Hydrogen peroxid, effect of, on bacteria, 40

Hydrophobia, virus of, 127

Inмunity, definition of, 64 kinds of, 64 maternal transmission of, 65

Immunizing against diphtheria, 100

Infantile paralysis, 185 . See also Poliomyelitis.

Infected wounds, Dakin's solution for, 41

dichloramine- $\mathrm{T}$ in dressing, 41

Infectious disease, definition of, 12 fumigation after, 57 quarantine against, 60

Infestation with lice, 153

methods of combating, 169

Infiltration, purulent, 52

Inflammation, 50

Influenza bacillus, 175

serum and vaccines in, 79

virus of, 127

Insects as carriers of infectious diseases, 57

Iodin as disinfectant, 40

JeNNER, introduction of vaccination, 125

КосH, early work in bacteriology, 12

Kumyss, bacteriology of, 141

LACTATION in relation to transmission of immunity, 65

Lactic acid bacilli in milk, 140

Laveran, discoverer of malaria parasite, 128

Lazy-worm, 153

Leeuwenhoek, discoverer of bacteria, 11

Leprosy, bacillus of, 182

Leukocytes, defensive rôle of, 66

Lice in transmission of disease, 169

infestation with, 153

methods of combating, 169 
Lice, transmission of trench fever Microbe, definition of, 13

$$
\text { by, } 58,184
$$

Life cycle of mosquito, 131

Light, influence of, on bacteria, 19

Lime, chlorid of, as disinfectant, 39, 149

freshly slaked, as disinfectant, 39

Linear vaccination, 125

Lipo-vaccines, 78, 85

Liquid air, effect of, on bacteria, 36

Lister, antiseptic surgery, 12

Litmus to study acid formation, 35

Lobar pneumonia, 106

Lockjaw, 101. See also Tetanus.

Lousiness, 153 methods of combating, 169

Lysol, effect of, on bacteria, 39

MaLARIa, parasites of, 128 transmission of, 5S, 12S, 131

Malignant edema, bacillus of, 181 pustule, 180

Mallein in diagnosis of glanders, 179

Mallory, observations in scarlet fever, 122

Malta fever, micrococcus of, 176

Matzoon, bacteriology of, 142

Measles, quarantine in, 61 virus of, 123

Meningitis, bacteriology of, 114 quarantine in, 62 treatment with serum, 115

Meningococcus, 114

Mercuric chlorid, effect of, on bacteria, 37

Metschnikoff fermented milks, Novy jars for anaërobic bacteria, 140
Micrococcus of Malta fever, 176

Microscope, bacteriologic, 22

Microsporon furfur, 1Sj

Milk as carrier of discase, 138 bacteriology of, 134 collection of, for examination, 172 fermented, bacteriology of, 140 grading, 134

in transmission of typhoid fever, $\$ 2,138$ pasteurization of, 135, 136 streptococci in, 138 tubercle bacilli in, 91, 138

Molds pathogenic for man, 185

Mordants in staining, 25

Moro's test for tuberculous infection, 94

Moser's antistreptococcus serum, 110

Mosquitoes, 130

Aëdes calopus, 132 anopheles, 131 in malaria, 128, 131 in yellow fever, 132 life cycle of, 131 reproduction of, 130

Motility of bacteria, 17

Mucous membrane, protection afforded against bacteria by, 66 patches in syphilis, 119

Mumps, quarantine in, 63 virus of, 127

Negri bodies in hydrophobia, 127 Nicoll treatment of tetanus, 103 Nicolle on nature of influenza virus, 176 20 
Ö̈DIUM albicans, 185

Oil-immersion objective, 23

Opsonic index, 74

Opsonin, nature of, 73

Oxygen, influence of, on growth of bacteria, 20

Oysters in typhoid fever, 82

Paratyphoid bacillus, 175

Park, diphtheria immunity, 100

Parotitis, quarantine in, 63

Pasteurization, definition of, 36 of milk, 135, 136

Pasteur's early work in bacteriology, 12

treatment of rabies, 79

Pathogenic bacteria, definition of, 18

Patients, disinfection of, prior to operation, 162

Pediculosis, 153

methods of combating, 169

Pellagra not a germ disease, 50

Perfringens bacillus, 181

Peroxid of hydrogen, effect of, on bacteria, 40

Pertussis, 176

quarantine in, 63

vaccines in, 79

Pest, bacillus of, 179

Petri dishes for cultures, 32

Petroleum, crude, in destroying lice, 169

Peyer's patches, 52

Pfeiffer's bacillus, 175

Phenol, effect of, on bacteria, 38

Pityriasis, 185

Plague, bacillus of, 179

vaccines in, 79

Plasmodium malarix, 128

Plates for growing bacteria, 32

Pleurisy, dry, 53
Pneumobacillus, Friedländer's, 175

Pneumococcus, 104

varieties of, 105

Pneumonia, bacteriology of, 106 lobar, 106

patients, collection of sputum from, 171

serum and vaccine treatment, 79

Poliomyelitis, 185

mode of transmission, 185

quarantine in, 62

virus of, 127

Pott's disease, 92

Precipitins, nature of, 74

Pressure, steam, in sterilizing, 46

Protozoa, definition of, 13

in certain diseases, 128

Purulent infiltration, 52

Pyocyaneus, bacillus of, 177

Quarantine in control of infectious diseases, 60

Quartan malaria, parasite of, 129

Quicklime, effect of, on bacteria, 39

Quinin in malaria, 130

Rabies, treatment of, 79

virus of, 127

Rags as vehicles of infection, 56

Rashes after serum injections, 75

Rats, destruction of, by sulphur fumigation, 40

in spread of plague, 179

Rheumatism, bacteriology of, 50

Rinderpest, virus of, 127

Rose spots in typhoid fever, 81 
SCARLET fever and antistrepto- Stools, disinfection of, 3s, 39 coccus serum, 110

Streptococci in milk, 138

quarantine in, 61

virus of, 122

Schich reaction, 100

Serum therapy, 76

Skin as protection against bacteria, 66

Sleeping sickness, 133

Small-pox, 124

quarantine in, 62

Smear preparations, importance of, 170

Streptococcus, definition of, 15

hemolyzing, 109

infections, serum or vaccines in, 79

pyogenes, 108

Sulphur for fumigation, 40, 166

Sunlight, influence of, on bacteria, 19

Swelled head, 145

Syphilis, bacteriology of, 119

Wassermann test in, 121

Snuffles in syphilis, 120

Soap as disinfectant, 41

Soor, 185

Sour milk, bacteriology of, 140

TAPEWORMS, 152

Temperature, influence of, on growth of bacteria, 19

Spinal fluid, collection of, for bac- Terminal fumigation, 57

teriologic examination, 173

Spirilla, definition of, 15

Spirillum of cholera, 88

Spores, character of, 16

Sputum, collection of, for examination, 105,170

from pneumonia patients, 171

Squirrels in spread of plague, 179

Staining of bacteria, 25

Tetanus antitoxin, 103

bacillus, 101

bacteriology of, 101

serum treatment, 78

toxin, 102

Tetrachlorethane for destroying lice, 169

Tetrads, definition of, 16

Throat smears, collection of, for examination, 97,171

Staphylococcus, definition of, 15 Thrush, 185 pyogenes, 111

Steam, effect of, on bacteria, 44 for destroying lice, 169

for disinfection, 46

for sterilization, 44, 157

Stegomyia in relation to yellow fever, 132

Sterilization by heat, 43

by stcam, 46, 157

of instruments, etc., 155

with chenicals, 161

Stitch abscess, 112

Stools, collection of, 172

Toxin of diphtheria, 98

Transmission of infectious diseases, 55

Trench fever, 127,182

transmission by lice, 58,184

virus of, 127,1 , 2

Treponema pallida in syphilis, 119

Trichina, 152

Trichophyton tonsurans, 18.5

Tricresol, effect of, on bacteria, 39

Triple vaccine, 85

Trypanosomiasis, 133 
Tsetse fly in transmission of W WASERMANN test for syphilis, sleeping sickness, 58, 133

Tubercle bacillus, 91

Tuberculin, diagnostic use of, 93 nature of, 93

Tuberculosis, bacteriology of, 91 disinfection in, 165

immunity of goats to, 64 serum and vaccine treatment, 79

tests for, 93,94

Typhoid fever, bacteriology of, 81

quarantine in, 61

use of vaccination against, 78,85

stools, disinfection of, 83,84

Typhus fever, quarantine in, 62

Ultramicroscope in diagnosis of syphilis, 119

121

Water, bacteriologic examination of, 146,150

collection of, for examination,

171

disinfection of, 39, 149

drinking-, halazone in disin-

fection of, 42,150

filtration of, 148

in transmission of cholera, 88 , 147

of typhoid fever, 87,147

purification of, by boiling, 150

by chlorination, 149

by distillation, 150

natural, 147

Water-borne diseases, 147

Welch's bacillus, 181

Whooping-cough, 176

Urine, collection of sterile speci- quarantine in, 63

mens, 172

VACCINATION against small-pox, 125

linear, 125

method of, 125

Vaccine, collecting, from calf, 124 therapy, 76

triple, 85

Vaccines, bacterial, 77, 78

in treatment of boils, 113

of gonococcus infections, 113 lipo-, 78, 85

Vaccina, 124

Varicella, quarantine in, 63

Variola, 124

quarantine in, 62

Vermin, 152

sulphur fumigation in, 40

von Pirquet's test for tuberculous infection, 94

Widal reaction in typhoid fever, 84

nature of, 72

Wool-sorters' disease, 180

Wounds, infected, Dakin's solution in, 41

dichloramine- $\mathrm{T}$ in dressing, 41

Wright's investigations on opsonins, 73

YEAST, definition of, 13

in fermenting milk, 141

Yellow fever, quarantine in, 62

transmission of, 58, 132

virus of, 127, 132

Yoghurt, bacteriology of, 142

ZiNGHer, diphtheria immunity, 100

Zoölak, bacteriology of, 142 




$2 \frac{10}{120}=$ 
